2015

EXPLORATION OF THE MTSAT2 SATELLITE CAPABILITIES FOR

REAL TIME DETECTION AND CHARACTERIZATION OF VOLCANIC EMISSIONS

Nicholas R. Stewart

Michigan Technological University

Follow this and additional works at: https://digitalcommons.mtu.edu/etds

Part of the Geology Commons, and the Remote Sensing Commons

Copyright 2015 Nicholas R. Stewart

Recommended Citation

Stewart, Nicholas R., "EXPLORATION OF THE MTSAT2 SATELLITE CAPABILITIES FOR REAL TIME DETECTION AND CHARACTERIZATION OF VOLCANIC EMISSIONS", Master's Thesis, Michigan Technological University, 2015.

https://doi.org/10.37099/mtu.dc.etds/938

Follow this and additional works at: https://digitalcommons.mtu.edu/etds

Part of the Geology Commons, and the Remote Sensing Commons 


\title{
EXPLORATION OF THE MTSAT2 SATELLITE CAPABILITIES FOR REAL TIME DETECTION AND CHARACTERIZATION OF VOLCANIC EMISSIONS
}

\author{
By
}

Nicholas R. Stewart

\begin{abstract}
A THESIS
Submitted in partial fulfillment of the requirements for the degree of MASTER OF SCIENCE

In Geology
\end{abstract}

MICHIGAN TECHNOLOGICAL UNIVERSITY

2015

(C) 2015 Nicholas R. Stewart 
This thesis has been approved in partial fulfillment of the requirements for the Degree of MASTER OF SCIENCE in Geology.

Department of Geological and Mining Engineering and Sciences

Thesis Advisor: $\quad$ Simon A. Carn

Committee Member: Louisa J. Kramer

Committee Member: Ann L. Maclean

Department Chair: John S. Gierke 


\section{TABLE OF CONTENTS}

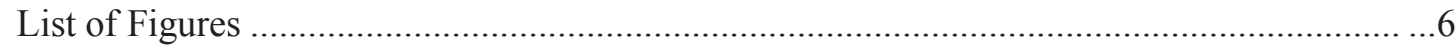

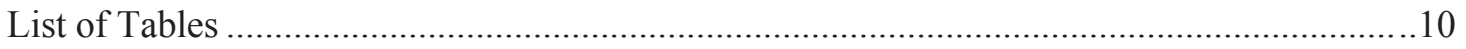

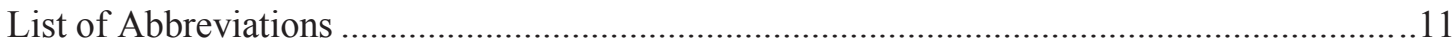

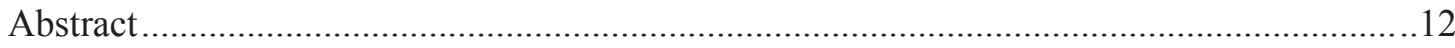

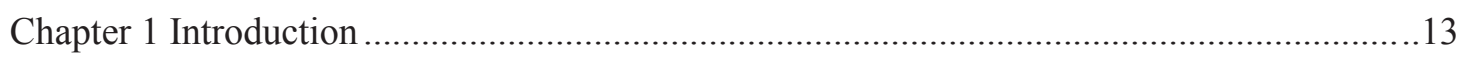

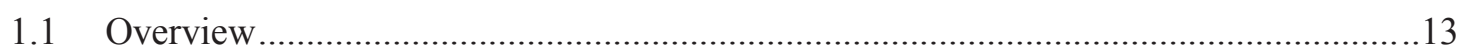

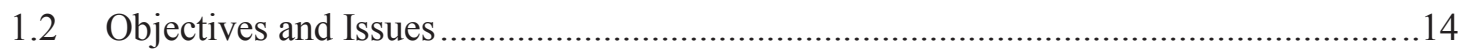

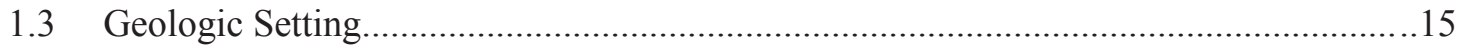

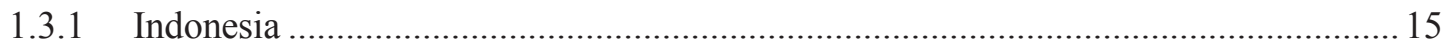

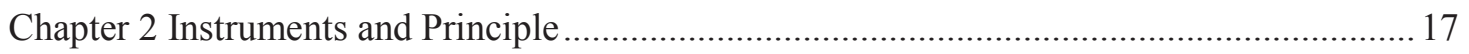

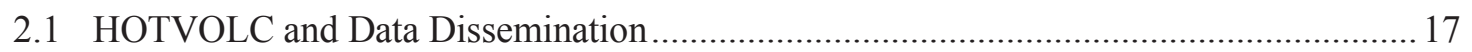

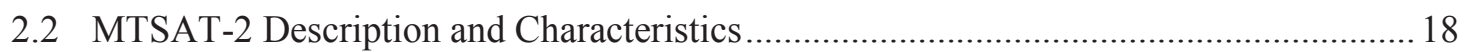

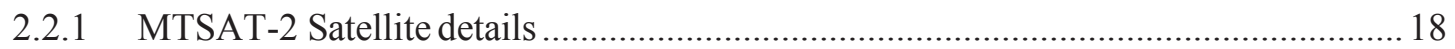

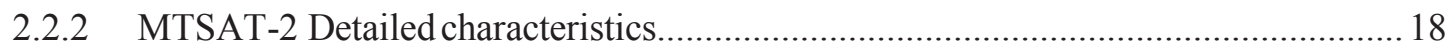

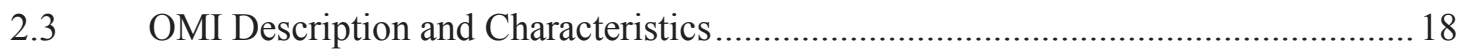

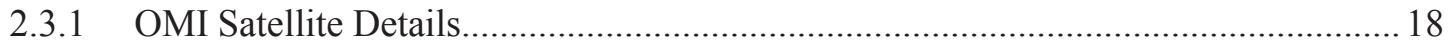

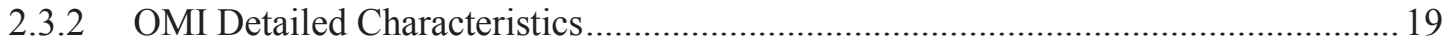

$2.4 \quad$ Fundamental principles of thermal "hot spot" detection ............................................20

2.4.1 Principles of Infrared Remote Sensing for Single-Channel Radiance $(4-\mu \mathrm{m})$.............21

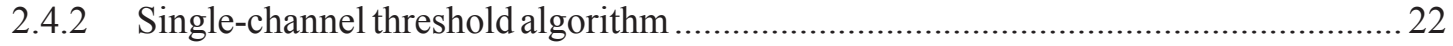

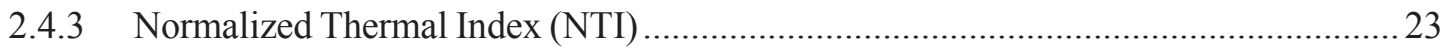

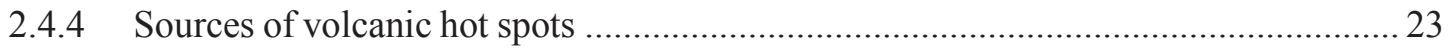

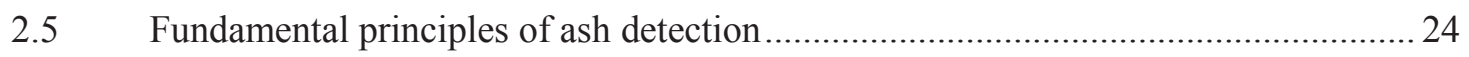

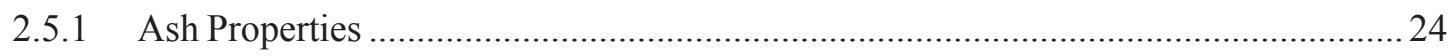

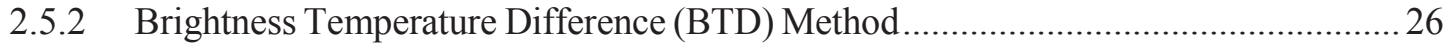

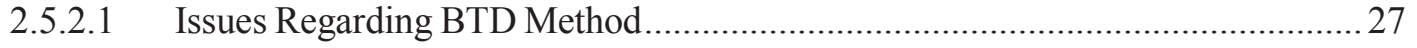

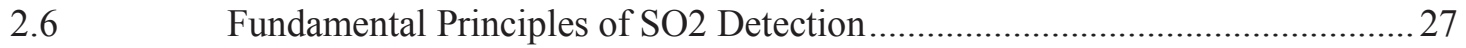

2.6.1 Principles of UV Remote Sensing of $\mathrm{SO}_{2}$ and other Trace Gases .............................2 27

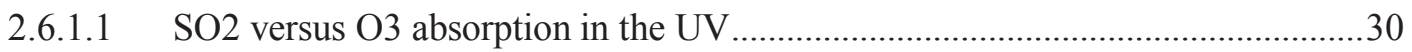




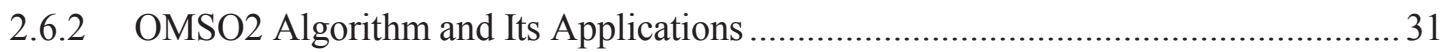

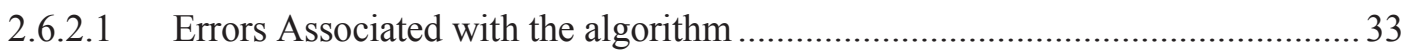

Chapter 3 Thermal Anomaly Detection Case Studies: January 2014 Sinabung Eruption.......35

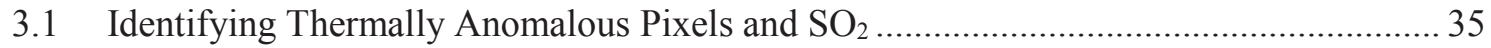

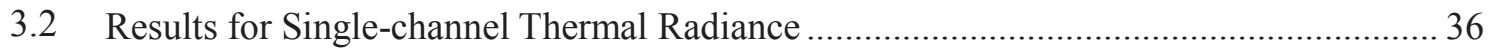

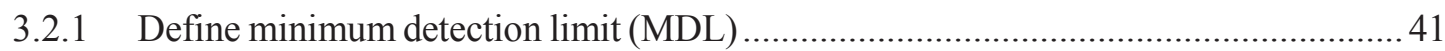

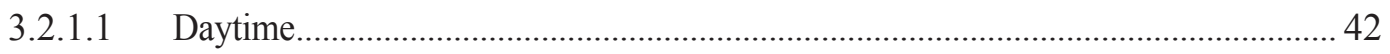

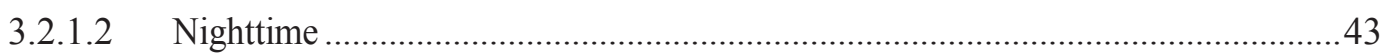

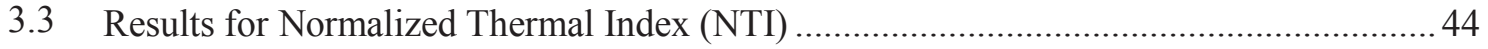

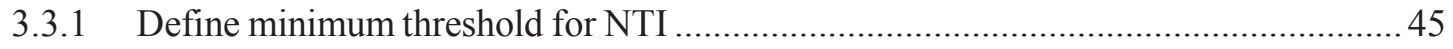

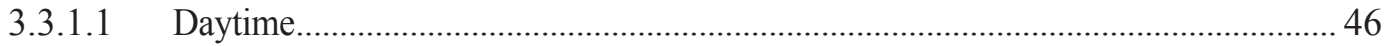

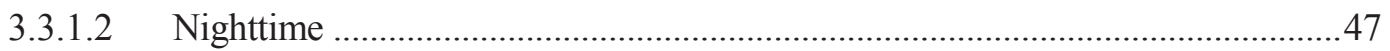

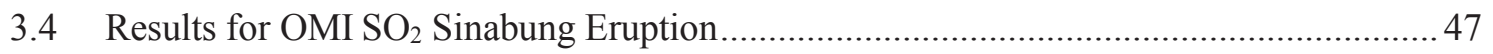

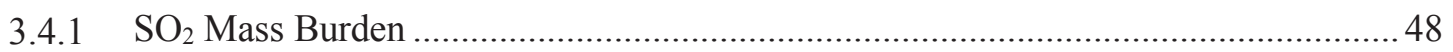

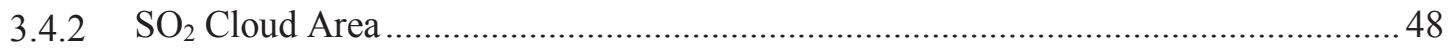

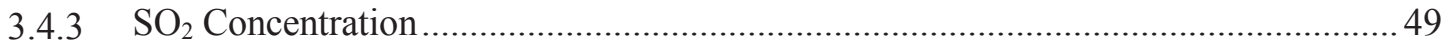

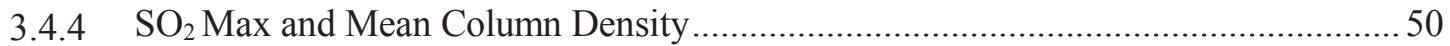

3.5 Comparison of the Single-channel Thermal Radiance with the NTI Method ....................51

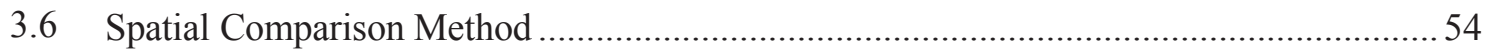

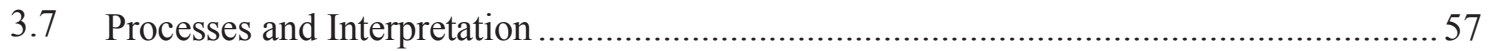

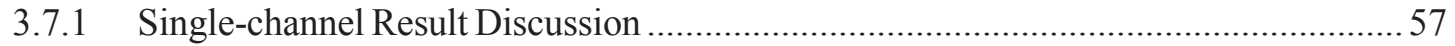

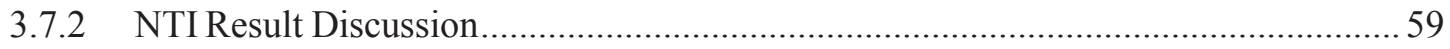

3.7.3 Comparison of $\mathrm{SO}_{2}$ and Thermal Datasets Discussion ...........................................59

Chapter 4 Volcanic Ash and $\mathrm{SO}_{2}$ Case Studies: February 2014 Kelut Eruption....................62 62

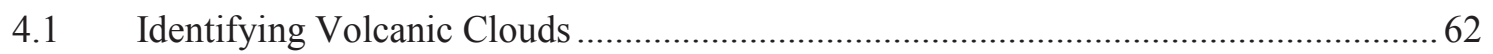

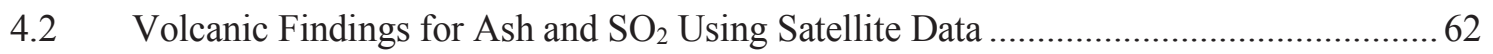

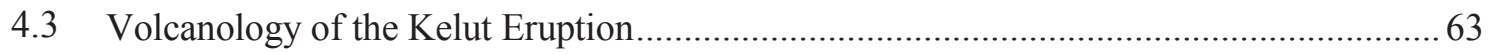

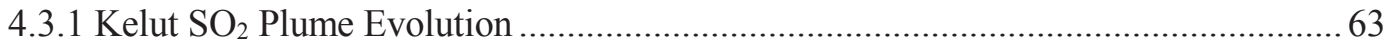

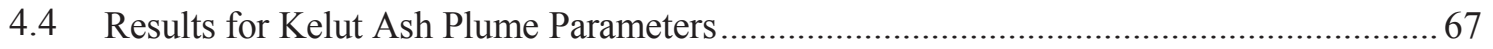

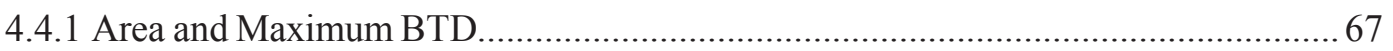

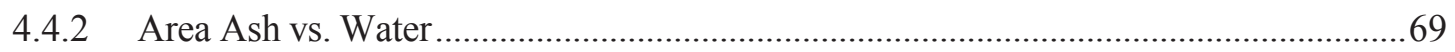

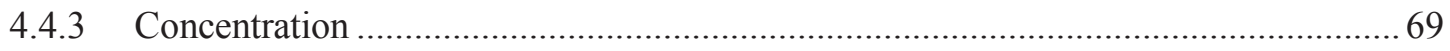




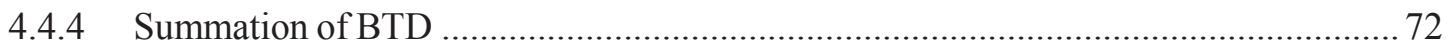

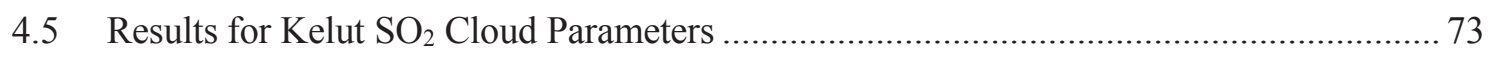

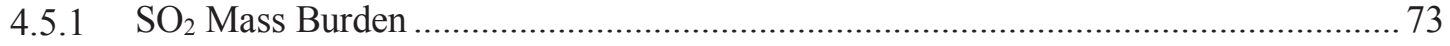

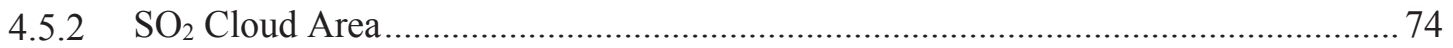

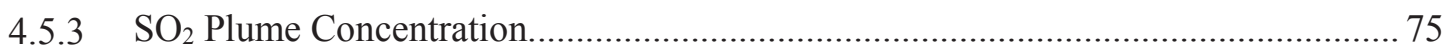

4.5.4 Max and Mean $\mathrm{SO}_{2}$ Column Densities ................................................................. 76

4.5.5 $\mathrm{SO}_{2}$ Removal and Dilution Rates (i.e. Mass and Concentration) .............................. 77

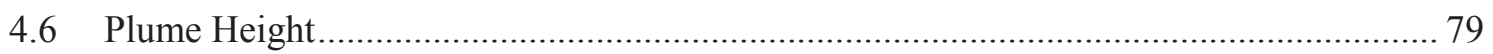

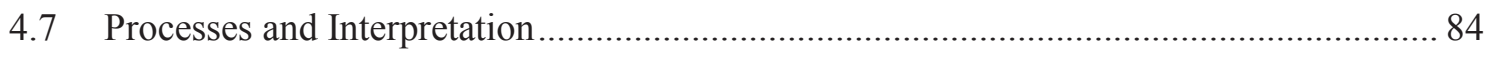

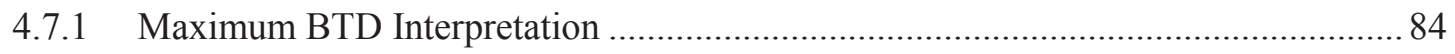

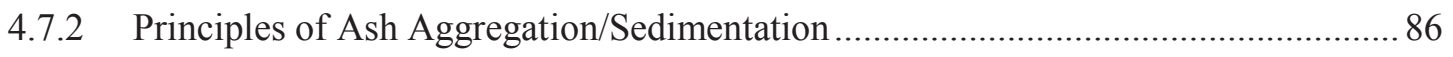

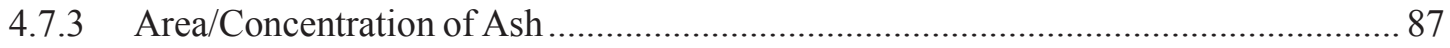

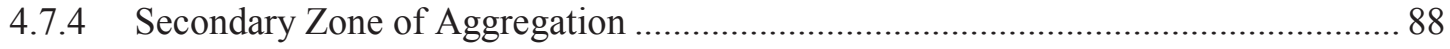

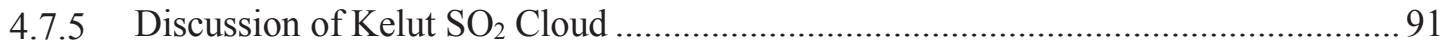

4.7.5.1 $\quad \mathrm{SO}_{2}$ Mass Discussion................................................................... 91

4.7.5.2 Discussion of $\mathrm{SO}_{2}$ Plume Area and Concentration ........................ 92

4.7.5.3 Discussion of $\mathrm{SO}_{2}$ Removal Rate ............................................... 93

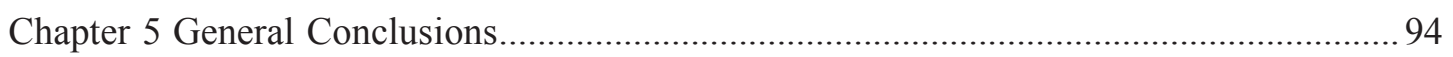

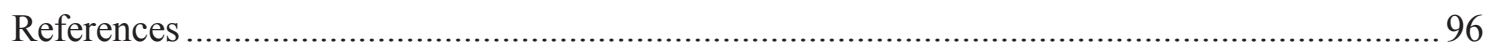

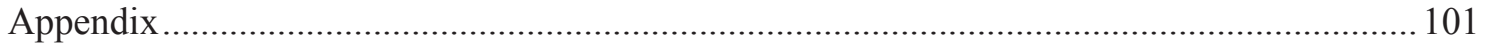




\section{LIST OF FIGURES}

Figure 1. Map of Indonesian volcanoes. Yellow stars indicate the volcanoes used in this study (Sinabung and Kelut) (Topinka, USGS 1997). Image courtesy of the U.S. Geological Survey. See Appendix.

Figure 2. HOTVOLC webpage. Interactive webpage with real-time data on volcanic eruptions. Image courtesy of HVOS-OPGC. Permission for use of this image is granted by Dr. Mathieu Gouhier, the lead operator of the HOTVOLC system. See Appendix for official permission. See Appendix.

Figure 3. A graph defining Planck's Law. The radiance of an object increases with increasing temperature and decreasing wavelength (Wein's Law). Earth emits radiation in IR around $300 \mathrm{~K}$. Peak thermal IR radiance emission around $4 \mu \mathrm{m}$. Image by Darth Kule (Own work) [Public domain], via Wikimedia Commons under GNU Free Documentation License. See Appendix.

Figure 4. Plot displaying Mie scattering applied to the scattering of radiation by ash. The plot roughly displays scattering intensity per direction. From right to left: Rayleigh, intermediate, and full Mie scattering. Ash can be detected by IR satellites in a narrow wavelength region $(11-12 \mu \mathrm{m})$ and particle size $(\sim 1-30 \mu \mathrm{m})$. Image provided by Sharayanan under GNU Free Documentation License. See Appendix .

Figure 5. List of refractive indices for different silicate particles. Notice that each particle absorbs more energy in the $10.3-11.3 \mu \mathrm{m}$ region than the $11.5-12.5 \mu \mathrm{m}$ region (Wen and Rose 1994). (C) John Wiley and Sons. Reproduced with permission. All rights reserved. See Appendix.

Figure 6. Images displaying the differing nature of the two particles using an illustration of a volcanic and meteorological clouds (Rose et al. 2003). (C) John Wiley and Sons. Reproduced with permission. All rights reserved. See Appendix. 26

Figure 7. Absorption cross-section for $\mathrm{SO}_{2}$ at wavelengths in the UV (Song et al. 2012). (C) IOP Publishing. Reproduced with permission. All rights reserved. See Appendix . .28

Figure 8. Radiance contribution functions (C) for the wavelength regions pertinent for $\mathrm{O}_{3}$ and $\mathrm{SO}_{2}$ absorption (i.e. $290-334 \mathrm{~nm}$ ) as a function of altitude. The atmosphere is assumed to be cloud and aerosol-free (Yang et al. 2010). (C) John Wiley and Sons. Reproduced with permission. All rights reserved. See Appendix.

Figure 9. A comparison of ozone absorption coefficients with sulfur dioxide absorption coefficients in the longer-UV wavelengths (i.e. $300-320 \mathrm{~nm}$ ). $\mathrm{SO}_{2}$ absorbs higher than $\mathrm{O}_{3}$ in the $310 \mathrm{~nm}$ range, making this wavelength channel best-suited for $\mathrm{SO}_{2}$ detection by OMI (McPeters and D.F. 1984). (C) John Wiley and Sons. Reproduced with permission. All rights reserved. See Appendix

Figure 10. Image processed in MATLAB displaying hot-spot detection at Sinabung volcano. Red triangle corresponds to geolocated position of Sinabung.

Figure 11. Mount Sinabung volcano spews ash during an eruption, January 11, 2014. The figure is a MATLAB processed image of Sinabung thermal anomaly $\left(01 / 11 / 2011 \_0100\right.$ UTC). Morning Image. Moderate emitted radiance..

Figure 12. OMIplot processed $\mathrm{SO}_{2}$ image corresponding to the same explosion that produced the above thermal anomaly on January $11^{\text {th }}$. The overpass time for OMI was several hours ( $\sim 5-6$ hours) after the MTSAT-2 record of the initial thermal anomaly allowing for the sulfur dioxide cloud to disperse as shown in this image. 37

Figure 13. Mount Sinabung volcano spews hot, January 13, 2014. The figure is a MATLAB processed image of Sinabung thermal anomaly (01/13/2011_2000 UTC). Nighttime image. 
Low emitted radiance.

Figure 14. OMIplot processed $\mathrm{SO}_{2}$ image corresponding to the same explosion that produced the above thermal anomaly on January $13^{\text {th }}$. The overpass time for OMI was several hours ( $\sim 12-13$ hours) prior to the MTSAT-2 record of the above thermal anomaly. The intensity of this explosion can be deduced by comparing the two images ............................38 Figure 15. The Mount Sinabung eruption, January 16, 2014. The figure is a MATLAB processed image of Sinabung thermal anomaly (01/16/2011_0300 UTC). Daytime Image. High emitted radiance

Figure 16. OMIplot processed $\mathrm{SO}_{2}$ image corresponding to the same explosion that produced the above thermal anomaly on January $16^{\text {th }}$. The overpass time for OMI was several hours ( $\sim 2-3$ hours) after to the MTSAT-2 record of the above thermal anomaly allowing for the cloud to migrate and disperse. The row anomaly is inhibiting imaging of the source and main body of the $\mathrm{SO}_{2}$ cloud; however, the intensity of this explosion can be deduced by comparing the magnitude of the column densities and the edge of the row anomaly with the thermal imagery.

Figure 17. Time series plot for data using only single-channel thermal radiance for the eruption of Sinabung. A dotted line is used to define the base minimum detection limit (MDL) discovered using the MTSAT-2 data. As can be clearly seen, this MDL comes with many false alarms (blue dots above dotted line). A definitive trend for daytime versus nighttime monitoring is evident with the increasing and subsequent decreasing thermal radiance.

Figure 18. Thermal anomaly detection time series for daytime only. All nighttime (1500-0100 UTC) is zeroed. Each higher MDL corresponds to a lower false alarm rate, but there are a greater amount of true anomalies missed

Figure 19. Thermal anomaly detection time series for nighttime only. All daytime (02001400 UTC) is zeroed. Each higher MDL corresponds to a lower false alarm rate, but there are a greater amount of true anomalies missed .

Figure 20. Time series plot for data processed using NTI algorithm for the eruption of Sinabung. The units of the NTI are dimensionless and of a negative value. NTI is merely a "flagging" method to use as a way to confirm or deny a hot spot. The closer the NTI value gets to 0 , the more intense the signal is. The same general trends (daytime/nighttime) are prevalent here in this time series as compared with the Figure $19 .$.

Figure 21. Histogram showing the frequency of output values for individual pixels when analyzing thermal anomalies utilizing the NTI algorithm. The lowest MDLs for day ($0.92)$ and night $(-0.925)$ are plotted, which incorporate every true anomaly.............................46 Figure 22. Thermal anomaly detection time series for daytime only. All nighttime (15000100 UTC) values are zeroed. Each higher MDL corresponds to a lower false alarm rate, but there are a greater amount of true anomalies missed

Figure 23. Thermal anomaly detection time series for nighttime only using NTI. All daytime (0200-1400 UTC) is zeroed.

Figure 24. Daily $\mathrm{SO}_{2}$ masses generated from the Sinabung eruption during January $11-20$, 2014. Data generated using OMIplot.

Figure 25. Areas of the $\mathrm{SO}_{2}$ clouds produced daily during the period of increased activity for Sinabung. Data acquired using OMIplot.

Figure 26. $\mathrm{SO}_{2}$ concentrations for individual explosions at Sinabung during January 2014.

Data obtained using OMIplot.

Figure 27. Column densities of $\mathrm{SO}_{2}$ for the Sinabung eruption in January 2014; Data processed using OMIplot 
Figure 28. Comparison of Single-Channel and NTI methods for accurately detecting volcanic thermal anomalies.

Figure 29. Visual inspection of the Single-Channel and NTI methods in identifying thermal anomalies displays no marked difference.

Figure 30. Sketch describing the spatial comparison method used as a second parameter to minimize false alarms. The $(\mathrm{X})$ is the location of the volcanic vent. The DL is the pixel outside of the volcanic region with the largest radiance value. It will always be the pixel used for comparison with the volcanic region

Figure 31. (A) True anomaly verified through spatial comparison method. There are 2 pixels corresponding to a thermal anomaly in this image. The 2 pixels in the center of the image are all greater than every individual pixel surrounding them. (B) A false detection verified using the spatial comparison method. At least one or more of the original nine pixels near the "triangle" (Sinabung location) emitted radiance higher than the minimum threshold. The spatial comparison method is able to verify the false alarm...................................56 Figure 32. First $\mathrm{OMI} \mathrm{SO}_{2}$ column density image of the Kelut plume on February 14, 2014. OMIPLOT software was used to generate this image. The overpass time of the Aura platform was between 0500 and 0818 UTC..

Figure 33. Second OMI image of the Kelut $\mathrm{SO}_{2}$ eruption plume recorded on February 15, 2014. The overpass time used to acquire this image is from 0537 to 0902 UTC.

Figure 34. Third $\mathrm{OMI} \mathrm{SO}_{2}$ image recorded between 0439 and 0946 on February 16, 2014.65

Figure 35. $\mathrm{OMI} \mathrm{SO}_{s}$ image of the Kelut plume on February 25, 2014 (12 days after the eruption) acquired between 0122 and 1604 UTC.

Figure 36. (A) The evolution of the area with time for the February 2014 Kelut ash cloud. Notice the steep incline in the area followed by a subsequent plateau between 2300 UTC on

Feb. 13 and 0600 UTC on the $14^{\text {th }}$. (B) Graph representing the maximum BTD value for an individual pixel in the Kelut ash plume. Each value corresponds to a single image taken every hour from the start of the eruption. Presented in absolute value.

Figure 37. Area of ash versus the area of water/ice evolving progressively with time in the Kelut volcanic cloud.

Figure 38. Graph of ash BTD $/ \mathrm{km}^{2}$ versus water $/ \mathrm{ice} \mathrm{BTD} / \mathrm{km}^{2}$

Figure 39. Three consecutive images $(0200,0300,0400$ UTC) showing the reflected radiance values in the $4-\mu \mathrm{m}$ wavelength region for the migrating Kelut ash cloud. All three radiance scales are equivalent $(E 10+5)$. The only difference in the images are the times that they were recorded. MATLAB processed MTSAT-2 images...

Figure 40. The evolution of the sum of (-) BTD values with time for the Kelut eruptive cloud. The numbers displayed are absolute values. The maximum sum of BTD during this Kelut eruption occurred between the maximum area and concentration of ash at 0200 UTC. Just as stated in Section 4.4.3 regarding the Mie scattering expression, the diameter of the ash particles greatly affect the magnitude of the BTD values. Therefore, the sum of BTD values can be regarded as the maximum diameter of the ash constituents ..........73 Figure 41. The evolution of the sulfur dioxide in the Kelut eruptive plume from January 1427, 2014. Data processed using OMIplot.

Figure 42. The sulfur dioxide plume area time-series for the February 13, 2014 eruption of Kelut. Data processed using OMIplot. .75

Figure 43. Time series of the evolution of the sulfur dioxide concentrations in the Kelut eruption plume. Data processed using OMIplot. . .76

Figure 44. Time series of the maximum and mean column densities for $\mathrm{SO}_{2}$ in the Kelut 
eruption. Data processed using OMIplot.

Figure 45. Time series of the daily removal rates for the $\mathrm{SO}_{2}$ mass in the Kelut eruptive plume. Data processed with OMIplot.

Figure 46. Time series of the daily dilution rates for the $\mathrm{SO}_{2}$ concentrations in the Kelut plume. Data processed using OMIplot.

Figure 47. Profile of the evolution of the ash plume height from the Kelut eruption determined using the CTT method. Error bars of $0.5 \mathrm{~km}$ are associated with the $11 \mu \mathrm{m}$ brightness temperature. The error bars are calculated based on (Hamada and Nishi 2010) utilizing brightness temperatures of the pixels. Any brightness temp. below $\sim 240 \mathrm{~K}$ has an error of about $0.5 \mathrm{~km}$. All pixels used in this study had brightness temperatures of around $200 \mathrm{~K}$.

Figure 48. Atmospheric profile of the conditions indicative of the tropical region near Kelut volcano recorded on February 14, 2014 at 0000 UTC. X-axis is temperature in ${ }^{\circ} \mathrm{C}$. Y-axis is altitude in meters. Image obtained from University of Wyoming, Department of Atmospheric Science.

Figure 49. HYSPLIT Trajectory Model obtained from NOAA for the Kelut ash plume on February 13, 2014. The use of these results obtained from the online version of HYSPLIT requires the citations of [(Draxler and Rolph 2015); (Rolph 2015)].

Figure 50. CALIPSO LiDAR image of Kelut ash plume taken from NASA's CALIOP instrument at 18:11 UTC on February 13, 2014. "Red circle" indicates location of ash plume. While the major cloud attenuation occurred $\sim 18 \mathrm{~km}$, portions of the cloud can be seen ejected to $\sim 26$ $\mathrm{km}$. Image courtesy of NASA (NASA 2014). See Appendix for reuse permission from NASA.

Figure 51. An MTSAT-2 image of the Kelut eruption taken at 1800 UTC. The red circle encompasses the warm cluster of pixels near the vent whose brightness temperatures correspond to a height of $26 \mathrm{~km}$

Figure 52. MATLAB processed image of early stage in cloud migration. Ash particles masked by ice/ash aggregate formation.

Figure 53. MTSAT-2 processed image from 0000 UTC of the Kelut ash cloud tracking. The magnitudes of the BTD values are very high, as the cloud detaches from the vent. . .85

Figure 54. Conceptual model depicting the processes involved for the secondary zone of aggregation proposed for the Kelut eruption cloud on February 14, 2014. Several remote sensing techniques were used to provide the conclusion. Model adapted from (Durant, Rose, et al. 2009). 90

Figure 55. Image displaying the "trail" of $\mathrm{SO}_{2}$ produced by the Kelut eruption and migrating according to wind patterns. 


\section{LIST OF TABLES}

Table 1. MTSAT-2 instrument details. Flown onboard Himawari-7 satellite. Data provided by Observing Systems Capability Analysis and Review Tool (World Meteorological Organization (OSCAR) 2011-2015)

Table 2. MTSAT-2 wavelength bands. Provided by Observing Systems Capability Analysis and Review Tool (World Meteorological Organization (OSCAR) 2011-2015) .18

Table 3. OMI and Aura description. OMI flown onboard NASA's Aura platform. Provided by Observing Systems Capability Analysis and Review Tool (World Meteorological

Organization (OSCAR) 2011-2015)

Table 4. OMI wavelength bands. Provided by Observing Systems Capability Analysis and Review Tool (World Meteorological Organization (OSCAR) 2011-2015).

Table 5. Results for amount of images and pixels included in the data using single-channel thermal radiance for the Sinabung eruption.

Table 6. Table showing the major results obtained from the MTSAT-2 data of the Sinabung eruption. Notice that each "average" is separated into daytime and nighttime values due to the trends observed in Figure 17.

Table 7. Table displaying the results for differing minimum detection limits (MDLs) for the daytime only.....

Table 8. Table displaying the results for differing minimum detection limits (MDLs) for the nighttime only

Table 9. Results for amount of images and pixels included in the data using the NTI

algorithm.

Table 10. Table showing the major results obtained from the MTSAT-2 data processed using NTI. Notice that each "average" is separated into daytime and nighttime values due to the trends observed in Figure 19.

Table 11. Table displaying the results for differing minimum detection limits (MDLs) for the daytime only using NTI.

Table 12. Table displaying the results for differing minimum detection limits (MDLs) for the nighttime only using NTI.

Table 13. Results using the spatial comparison method as a second parameter to the fixed threshold methods

Table 14. Table explaining some of the eruption statistics from the February 13, 2014 Kelut eruption in Indonesia. 


\section{LIST OF ABBREVIATIONS}

$\begin{array}{ll}\text { BTD: } & \text { Brightness Temperature Difference } \\ \text { BUV: } & \text { Backscattered Ultraviolet Radiation } \\ \text { CCD: } & \text { Charge-coupled Device } \\ \text { CTT: } & \text { Cloud-Top Temperature } \\ \text { CVGHM: } & \text { Centre of Volcanology and Geological Hazard Mitigation } \\ \text { DOAS: } & \text { Differential Optical Absorption Spectroscopy } \\ \text { DU: } & \text { Dobson Units } \\ \text { HRIR: } & \text { High-Resolution Infrared Radiometer } \\ \text { HYSPLIT: } & \text { Hybrid Single-Particle Lagrangian Integrated Trajectory } \\ \text { IDL: } & \text { Interactive Data Language } \\ \text { LF: } & \text { Linear-Fit Algorithm } \\ \text { MDL: } & \text { Minimum Detection Limit } \\ \text { MIR: } & \text { Mid-Infrared } \\ \text { MSG: } & \text { Meteosat Second Generation } \\ \text { MTSAT-2: } & \text { Multifunctional Transport Satellite 2 } \\ \text { NTI: } & \text { Normalized Thermal Index } \\ \text { OMI: } & \text { Ozone Monitoring Instrument } \\ \text { OMSO2: } & \text { OMI SO } 2 \text { Data } \\ \text { PBL: } & \text { Planetary Boundary Layer } \\ \text { SEVIRI: } & \text { Spinning Enhanced Visible and InfraRed Imager } \\ \text { SWIR: } & \text { Shortwave Infrared } \\ \text { TIR: } & \text { Thermal Infrared } \\ \text { TM: } & \text { Landsat Thematic Mapper } \\ \text { TOA: } & \text { Top of the Atmosphere } \\ \text { UV: } & \text { Ultraviolet } \\ \text { VAAC: } & \text { Volcanic Ash Advisory Center } \\ \text { VSI: } & \text { Volcanological Survey of Indonesia } \\ & \end{array}$




\begin{abstract}
Keywords: MTSAT-2, OMI, Thermal Remote Sensing, Normalized Thermal Index (NTI), Brightness Temperature Difference(BTD)
\end{abstract}

In this report, we attempt to define the capabilities of the infrared satellite remote sensor, Multifunctional Transport Satellite-2 (MTSAT-2) (i.e. a geosynchronous instrument), in characterizing volcanic eruptive behavior in the highly active region of Indonesia. Sulfur dioxide data from NASA's Ozone Monitoring Instrument (OMI) (i.e. a polar orbiting instrument) are presented here for validation of the processes interpreted using the thermal infrared datasets. Data provided from two case studies are analyzed specifically for eruptive products producing large thermal anomalies (i.e. lava flows, lava domes, etc.), volcanic ash and $\mathrm{SO}_{2}$ clouds; three distinctly characteristic and abundant volcanic emissions. Two primary methods used for detection of heat signatures are used and compared in this report including, single-channel thermal radiance $(4-\mu \mathrm{m})$ and the normalized thermal index (NTI) algorithm. For automated purposes, fixed thresholds must be determined for these methods. A base minimum detection limit (MDL) for single-channel thermal radiance of $2.30 \mathrm{E}+05 \mathrm{Wm}^{-}$ ${ }^{2} \mathrm{sr}^{-1} \mathrm{~m}^{-1}$ and -0.925 for NTI generate false alarm rates of $35.78 \%$ and $34.16 \%$, respectively. A spatial comparison method, developed here specifically for use in Indonesia and used as a second parameter for detection, is implemented to address the high false alarm rate. For the single-channel thermal radiance method, the utilization of the spatial comparison method eliminated $100 \%$ of the false alarms while maintaining every true anomaly. The NTI algorithm showed similar results with only 2 false alarms remaining. No definitive difference is observed between the two thermal detection methods for automated use; however, the single-channel thermal radiance method coupled with the $\mathrm{SO}_{2}$ mass abundance data can be used to interpret volcanic processes including the identification of lava dome activity at Sinabung as well as the mechanism for the dome emplacement (i.e. endogenous or exogenous). Only one technique, the brightness temperature difference (BTD) method, is used for the detection of ash. Trends of ash area, water/ice area, and their respective concentrations yield interpretations of increased ice formation, aggregation, and sedimentation processes that only a high-temporal resolution instrument like the MTSAT-2 can analyze. A conceptual model of a secondary zone of aggregation occurring in the migrating Kelut ash cloud, which decreases the distal fine-ash component and hazards to flight paths, is presented in this report. Unfortunately, $\mathrm{SO}_{2}$ data was unable to definitively reinforce the concept of a secondary zone of aggregation due to the lack of a sufficient temporal resolution. However, a detailed study of the Kelut $\mathrm{SO}_{2}$ cloud is used to determine that there was no climatic impacts generated from this eruption due to the atmospheric residence times and e-folding rate of $\sim 14$ days for the $\mathrm{SO}_{2}$. This report applies the complementary assets offered by utilizing a high-temporal and a high-spatial resolution satellite, and it demonstrates that these two instruments can provide unparalleled observations of dynamic volcanic processes. 


\subsection{Overview}

The benefits offered by satellite volcanology in assisting the study of volcanic activity can be traced to its origins in 1965. Satellite data from the Nimbus I High Resolution Infrared Radiometer (HRIR) indicated higher thermal emissions from Kilauea volcano than from Mauna Loa, its inactive neighbor (Gawarecki et al. 1965). However, it was not until the implementation of the Landsat Thematic Mapper (TM) that thermal remote sensing became an accepted method used in volcanology. Subsequent research has advanced the capabilities of thermal remote sensing from mere detection of a heat signature to intricate thermal analysis of active lava flows, lava domes, lava lakes, and fumaroles (Harris et al. 1999).

Geostationary coupled with polar orbiting satellites are perfectly suited for monitoring an active volcanic region (Pyle et al. 2013). Geostationary instruments orbit the earth around $36,000 \mathrm{~km}$ and remain fixed at the equator, so they image the same swath width continuously. The image capacity is about $40 \%$ of the entire earth for geostationary satellites (Gouhier et al. 2012). Although the distant orbital location of a geosynchronous satellite provides a low-spatial resolution $(\sim 3-4 \mathrm{~km})$, the stationary position allows for rapid imaging of the same location (up to 1 image/ 5 minutes). The high-temporal resolution of geostationary satellites offers unparalleled opportunities to study rapidly evolving volcanic processes. The spatial resolution forfeited by the geostationary satellites can be enhanced by polar orbiting satellites, which orbit much closer to the Earth's surface (i.e. $1000 \mathrm{~km}$ ). High-spatial resolution $(<1 \mathrm{~km}$ pixel-size) imagery can yield useful data regarding detailed information of the product of study, but the low-temporal resolution ( $>2$ day revisit time) inhibits a satellite from monitoring sparse isolated events or studying dynamic processes. The use of geostationary and polar orbiting instruments offer unprecedented coverage to study active volcanism, especially in regions marked by insufficient ground-based monitoring. 


\subsection{Objectives and Issues}

The ultimate goal that this research aspires to attain is automated volcanic eruption notification uploaded directly onto a web-based system entitled HOTVOLC (operated by the Laboratoire Magmas et Volcans at the Universite Blaise Pascal). However, the current research of this project is concentrated on:

- Processing and analyzing thermal infrared data from the geostationary Multifunctional Transport Satellite-2 (MTSAT-2) for the implementation of operational procedures, mainly the detection of eruptive activity in Indonesia

- Calibration/Validation of MTSAT-2 data for reliable detection of volcanic activity

- Processing and analyzing sulfur dioxide $\left(\mathrm{SO}_{2}\right)$ data acquired from the hyperspectral Ozone Monitoring Instrument (OMI)

- Compare thermal infrared data with $\mathrm{SO}_{2}$ data to create sophisticated interpretations of volcanic processes

- Reinforce the advantageous capabilities of a geostationary satellite despite the low spatial resolution and discuss how data is complimentary to high spatial resolution data

- Define capabilities of MTSAT-2 in creating a volcanic heat index by utilizing 2 popular techniques for hot spot detection: Single Thermal Radiance $(4-\mu \mathrm{m}$ wavelength) and Normalized Thermal Index

- Compare and develop best methods for automating thermal detections while maximizing real detections and limiting false alarms

- Major issues associated with global monitoring of hot spots is defining a universal detection limit; however, the scope of this project is only one tropical region (Indonesia), so the problems associated with alternating detection limits are essentially diminished

- Utilize OMIplot software and the Linear Fit (LF) algorithm to estimate various $\mathrm{SO}_{2}$ parameters to validate the thermal data and create more sophisticated interpretations 
- Define a proper monitoring campaign for volcanic ash clouds mainly using the Brightness Temperature Difference (BTD) method

- Emphasize near-real time techniques capable for use by the MTSAT2 data to analyze recently erupted volcanic clouds

- Do a detailed study of a plinian volcanic $\mathrm{SO}_{2}$ cloud and compare it with the corresponding ash cloud

The main volcanic eruptive features analyzed in this work are high thermal activity, ash clouds, and sulfur dioxide plumes given the ability of the MTSAT-2 to detect emitted radiance in the infrared and OMI's ability to detect radiance in the ultraviolet.

\subsection{Geologic Setting}

\subsubsection{Indonesia}

The archipelago of Indonesia consists of about 13,000 islands. As a country, Indonesia houses the most volcanoes that are active in the world (about 127), and nearly $4 / 5$ of these volcanoes have erupted since 1900 . More than $75 \%$ of Indonesian residents live within $100 \mathrm{~km}$ of one of these active volcanoes, the highest number of people of any of the world's volcanic regions. In 1920, The Indonesian government implemented the Volcanological Survey of Indonesia (VSI), now known as the Centre of Volcanology and Geological Hazard Mitigation (CVGHM), to continually monitor Indonesia's most active volcanoes. It currently operates a network of 76 volcano observatories continuously monitoring 66 volcanoes (Simkin and Siebert 1997). 


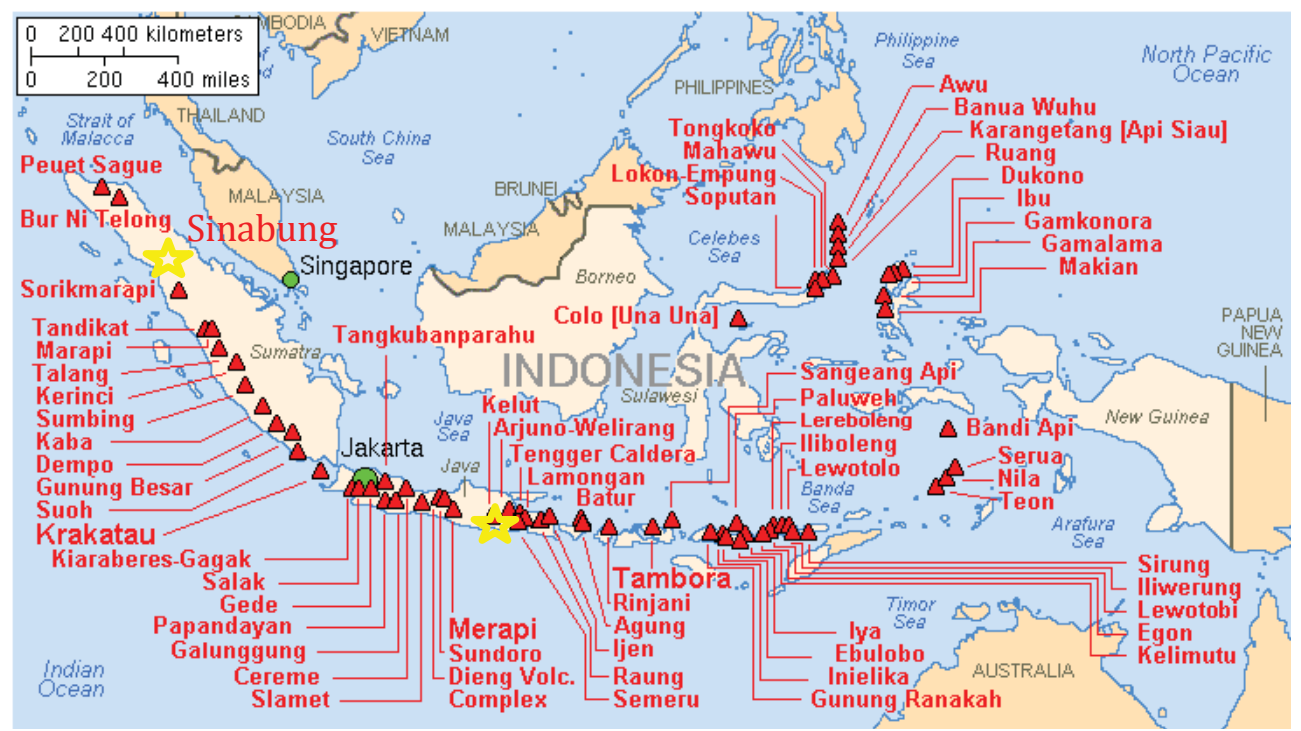

Figure 1. Map of Indonesian volcanoes. Yellow stars indicate the volcanoes used in this study (Sinabung and Kelut) (Topinka, USGS 1997). Image courtesy of the U.S. Geological Survey. See Appendix.

Indonesia is subjected to some of the world's most frequent volcanic hazards. It is home to the most historically active volcanoes (i.e. 1250 eruptions), which is only exceeded by Japan's 1469. Indonesia leads the world in the number of residents living within 30 and $100 \mathrm{~km}$ of a Holocene volcano. The combination of a densely packed population in a volcano-rich country has led Indonesia to suffer the highest number of eruption-producing fatalities (114 eruptions) and damage to infrastructure (195 eruptions) (Simkin and Siebert 1997). These statistics emphasize the need for a remotely sensed instrument (MTSAT-2 and OMI) to continually monitor the volcanoes in this region on a near-real time basis, since alternate ground-based monitoring equipment can be scarce at many locations. 


\subsection{HOTVOLC and Data Dissemination}

The final product that the current research aspires to implement is the automated retrieval and uploading of volcanic products processed by the MTSAT2 data onto HOTVOLC. HOTVOLC is a web-based system developed to achieve near-real time detection of volcanic products through the execution of automated algorithms. HOTVOLC is hosted by the Laboratoire Magmas et Volcans (LMV) a section of the Observatoire de Physique du Globe de Clermont-Ferrand (OPGC) - and is based at the Université Blaise Pascal (Clermont-Ferrand, France) (Labazuy et al. 2012). The primary mission of HOTVOLC is to distribute data in near-real time to the scientific community. This task is made possible through data acquisition received by OPGC since 2009 from high temporal resolution geostationary satellites (i.e. MSG/MTSAT/etc.). Algorithms developed at LMV allow immediate processing of data and dissemination of 3 sub-quantitative parameters (i.e. ash clouds, lava indices, and $\mathrm{SO}_{2}$ ) in the form of maps and standardized time series (Labazuy et al. 2012). Through licensing agreements, HOTVOLC has also been acquiring and storing data from other prominent polar orbiting (i.e. CALIOP, Terra MODIS, etc.) and geostationary satellites (GOES East, GOES West, etc.) in order to provide global coverage and increase confidence in the data.

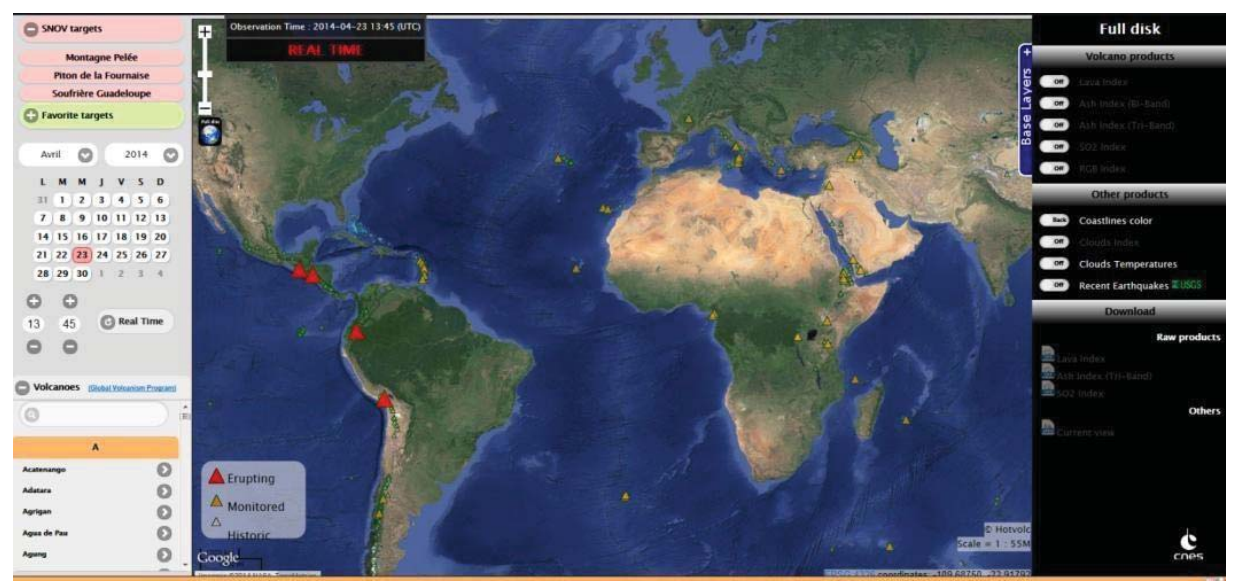

Figure 2. HOTVOLC webpage. Interactive webpage with real-time data on volcanic eruptions. Image courtesy of HVOS-OPGC. Permission for use of this image is granted by Dr. Mathieu Gouhier, the lead operator of the HOTVOLC system. See Appendix for official permission. See Appendix. 


\subsection{MTSAT-2 Description and Characteristics}

\subsubsection{MTSAT-2 Satellite details}

Table 1. MTSAT-2 instrument details. Flown onboard Himawari-7 satellite. Data provided by Observing Systems Capability Analysis and Review Tool (World Meteorological Organization (OSCAR) 2011-2015).

\begin{tabular}{|c|c|c|c|}
\hline Full name & \multicolumn{3}{|c|}{ Multi-Function Transport Satellite-2 Imager (MTSAT-2) } \\
\hline Longitude & \multicolumn{3}{|l|}{$145^{\circ} \mathrm{E}$} \\
\hline Orbit & Geostationary orbit & Altitude & $35786 \mathrm{~km}$ \\
\hline $\begin{array}{l}\text { Type of } \\
\text { Instrument }\end{array}$ & \multicolumn{3}{|c|}{ 01. Moderate-resolution optical imager } \\
\hline Purpose & \multicolumn{3}{|c|}{$\begin{array}{l}\text { Multi-purpose imagery and wind derivation by tracking } \\
\text { clouds and water vapor features }\end{array}$} \\
\hline Wavelength Bands & \multicolumn{3}{|c|}{ 5-channels [see detailed characteristics below] } \\
\hline Scanning & \multicolumn{3}{|c|}{ Mechanical, 3-axis stabilized satellite, E-W continuous, S-N } \\
\hline Resolution & \multicolumn{3}{|c|}{$4.0 \mathrm{~km}$ for IR channels; $1.0 \mathrm{~km}$ for the VIS channel } \\
\hline Coverage / Cycle & \multicolumn{3}{|c|}{ Full disk each 1 hour. Half disk each $30 \mathrm{~min}$. } \\
\hline
\end{tabular}

\subsubsection{MTSAT-2 Detailed characteristics}

Table 2. MTSAT-2 wavelength bands. Provided by Observing Systems Capability Analysis and Review Tool (World Meteorological Organization (OSCAR) 2011-2015).

\begin{tabular}{|lll|} 
Central wavelength & $\begin{array}{l}\text { Spectral } \\
\text { interval }\end{array}$ & SNR or NEAT @ specified input \\
\hline $\mathbf{0 . 6 7 5} \boldsymbol{\mu m}$ & $0.55-0.80 \mu \mathrm{m}$ & $6.5 @ 2.5 \%$ albedo \\
\hline $\mathbf{3 . 7 5} \boldsymbol{\mu m}$ & $3.50-4.00 \mu \mathrm{m}$ & $0.09 \mathrm{~K} @ 300 \mathrm{~K}$ \\
\hline $\mathbf{6 . 7 5} \boldsymbol{\mu m}$ & $6.50-7.00 \mu \mathrm{m}$ & $0.12 \mathrm{~K} @ 300 \mathrm{~K}$ \\
\hline $\mathbf{1 0 . 8} \boldsymbol{\mu m}$ & $10.3-11.3 \mu \mathrm{m}$ & $0.11 \mathrm{~K} @ 300 \mathrm{~K}$ \\
\hline $\mathbf{1 2 . 0} \boldsymbol{\mu m}$ & $11.5-12.5 \mu \mathrm{m}$ & $0.20 \mathrm{~K} @ 300 \mathrm{~K}$ \\
\hline
\end{tabular}

\subsection{OMI Description and Characteristics}

\subsubsection{OMI Satellite Details}


Table 3. OMI and Aura description. OMI flown onboard NASA's Aura platform. Provided by Observing Systems Capability Analysis and Review Tool (World Meteorological Organization (OSCAR) 2011-2015).

\begin{tabular}{|c|c|c|c|}
\hline Full Name & \multicolumn{3}{|c|}{ Ozone Monitoring Instrument (OMI) } \\
\hline Orbit & $\begin{array}{l}\text { Polar, Sun- } \\
\text { synchronous }\end{array}$ & Altitude & $705 \mathrm{~km}$ \\
\hline Ascending Node & 13:42 local time & Viewing Angle & $114^{\circ}$ \\
\hline $\begin{array}{l}\text { Type of } \\
\text { Instrument }\end{array}$ & \multicolumn{3}{|c|}{ Cross-nadir scanning SW sounder } \\
\hline Purpose & \multicolumn{3}{|c|}{$\begin{array}{l}\text { Ozone profile and total-column or gross profile of other } \\
\text { species. Tracked species: } \mathrm{BrO}, \mathrm{NO}_{2}, \mathrm{O}_{3}, \mathrm{OClO}, \mathrm{SO}_{2} \text {, and } \\
\text { aerosol }\end{array}$} \\
\hline Short Description & \multicolumn{3}{|c|}{ UV/VIS grating imaging spectrometer } \\
\hline Wavelength Bands & \multicolumn{3}{|c|}{$\begin{array}{l}\text { 3-bands, } 1560 \text { channels total [see detailed characteristics } \\
\text { below] }\end{array}$} \\
\hline $\begin{array}{l}\text { Scanning } \\
\text { Technique }\end{array}$ & \multicolumn{3}{|c|}{$\begin{array}{l}\text { Pushbroom scanner, cross-track swath } 2600 \mathrm{~km} \text {; Zoom mode } \\
\text { available with swath } 725 \mathrm{~km}\end{array}$} \\
\hline Resolution & \multicolumn{3}{|c|}{$\begin{array}{l}13 \times 24 \mathrm{~km}^{2} \text { associated with } 2600 \mathrm{~km} \text { swath; reduced to } 36 \mathrm{x} \\
48 \mathrm{~km}^{2} \text { for profiles; } 13 \times 24 \mathrm{~km}^{2} \text { in zoom mode }\end{array}$} \\
\hline Coverage / Cycle & \multicolumn{3}{|c|}{ Diurnal global coverage, in daylight } \\
\hline
\end{tabular}

\subsubsection{OMI Detailed Characteristics}

Table 4. OMI wavelength bands. Provided by Observing Systems Capability Analysis and Review Tool (World Meteorological Organization (OSCAR) 2011-2015).

\begin{tabular}{|c|c|c|c|}
\hline Wavelength Band & $\begin{array}{l}\text { Spectral } \\
\text { Range }\end{array}$ & $\begin{array}{c}\text { No. of } \\
\text { Channels }\end{array}$ & Spectral Resolution \\
\hline UV-1 & $270-314 \mathrm{~nm}$ & 390 & $0.42 \mathrm{~nm}$ \\
\hline UV-2 & $306-380 \mathrm{~nm}$ & 390 & $0.45 \mathrm{~nm}$ \\
\hline VIS-1 & $350-500 \mathrm{~nm}$ & 780 & $0.63 \mathrm{~nm}$ \\
\hline
\end{tabular}

The OMI has contributed hyperspectral analyses with contiguous daily global coverage at a spatial resolution exceeding any of its predecessors. OMI possesses twodimensional charge-coupled device (CCD) detectors. The CCDs enable the retrieval of the backscattered radiation both spectrally and spatially. These characteristics facilitate 
unparalleled sensitivity to trace atmospheric constituents including $\mathrm{SO}_{2}$.

\subsection{Fundamental principles of thermal "hot spot" detection}

The physical basis of thermal remote sensing of active volcanoes is the Planck Function. The Planck Function describes how spectral radiant emissions, $\mathrm{M}(\lambda, \mathrm{T})$, from a blackbody (i.e. a perfect emitter) varies with temperature $(\mathrm{T})$ and wavelength $(\lambda)$. The function is given by:

$$
\mathrm{M}(\lambda, \mathrm{T})=2 \pi h c^{2} \lambda^{-5}\left[\exp ^{\frac{h c}{\lambda k T}}-1\right]^{-1}\left(\mathrm{~W} \mathrm{~m}^{-2} \mathrm{~m}^{-1}\right)
$$

In which $h$ is Planck's constant $\left(6.6256 \times 10^{-34} \mathrm{~J} \mathrm{~s}\right), c$ is the speed of light $\left(2.9979 \times 10^{8}\right.$ $\left.\mathrm{m} \mathrm{s}^{-1}\right)$, and $k$ is the Boltzmann gas constant $\left(1.38 \times 10^{-23} \mathrm{~J} \mathrm{~K}^{-1}\right)$. The brightness temperature of an object can be calculated by using the inverse of the Planck Function and can be useful in interpreting the source of heat (Harris, 2013).

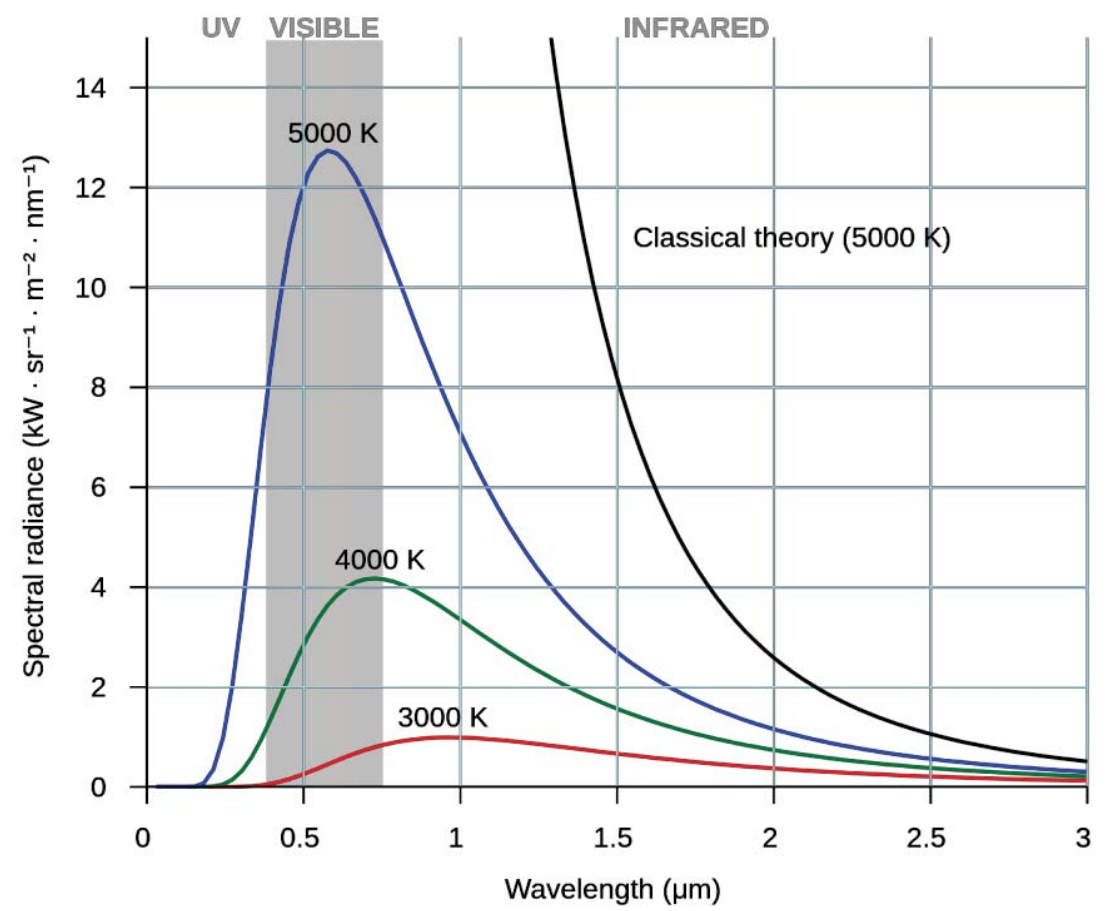

Figure 3. A graph defining Planck's Law. The radiance of an object increases with increasing temperature and decreasing wavelength (Wein's Law). Earth emits radiation in IR around 300K. Peak thermal IR radiance emission around $4 \mu \mathrm{m}$. Image by Darth Kule (Own work) [Public domain], via Wikimedia Commons under GNU Free Documentation License. See Appendix.

Based on Wein's Displacement Law, as the temperature of an object increases, the wavelength of the peak spectral radiant emissions moves to shorter wavelengths. Therefore, an infrared wavelength band of a shorter wavelength $(3.8 \mu \mathrm{m})$ should 
record higher temperatures than a wavelength band of longer wavelengths $(12 \mu \mathrm{m})$. It is important to note; however, that based on the Planck function, the dependence of radiance on temperature is nonlinear as depicted in Figure 3.

A blackbody preferentially emits radiation in a narrow bandwidth. The location of that band is variable according to its temperature. Therefore, a satellite that operates in the infrared region of the electromagnetic spectrum (i.e. MTSAT-2) can distinguish between the intensities of the radiation being emitted by objects on the earth's surface. A thermal anomaly will be an object that is higher in temperature than its immediate surroundings, and will therefore emit more radiation in a particular wavelength. The type of radiance described is Lambertian or diffuse, meaning that there is no directional character to the emission (Harris 2013). The radiance that will be analyzed throughout most of this report is from a point source that projects radiance over an area defined by a solid angle (i.e. steradian, $\mathrm{W} \mathrm{m}^{-2} \mathbf{s r}^{-1} \mathrm{~m}^{-1}$ ).

\subsubsection{Principles of Infrared Remote Sensing for Single-Channel Radiance (4-} $\mu \mathrm{m})$

Planck's function describes that Earth emits radiance particularly in the infrared region of the electromagnetic spectrum, which makes a satellite designed to image infrared data optimal for studying surface processes. Different infrared regions, and therefore satellite wavelength bands, respond differently to the presence of high temperatures. When material ascertains temperatures of magmatic levels (i.e. 200 $1100^{\circ} \mathrm{C}$ ) within a generally thermally homogeneous pixel, the spectral radiance occupying the short-wave infrared (SWIR) (i.e. 4- $\mu \mathrm{m}$ ) increases dramatically compared to the long-wave infrared (i.e. 12- $\mu \mathrm{m}$ ) part of the electromagnetic spectrum (Wright et al. 2004). Being that the MTSAT-2 possesses wavelength bands in both regions; data involving this phenomenon can be analyzed. Wright et al. 2004 demonstrated using data acquired from ASTER that radiance emitted in the 4- $\mu \mathrm{m}$ wavelength of an anomalous pixel increased by as much as $800 \%$ above the surrounding pixels; whereas, the increase for the anomalous pixel in the $12-\mu \mathrm{m}$ wavelength was a mere $5 \%$ above background levels.

SWIR data is not only capable of detecting pixel-sized heat anomalies, but 
this region of the spectrum can provide information on sub-pixel sized thermal sources. Harris et al. 1997a determined from visual inspections of AVHRR 3.7- $\mu \mathrm{m}$ data that sub-pixel sized hot spots can be detected if the heat source causes the temperature of the entire pixel to increase by $5^{\circ} \mathrm{C}$ above the background temperature. Hence, even if the pixel contains a very small portion of a thermal feature, the radiance emitted is averaged for every pixel that the satellite instrument generates. Therefore, a volcanic edifice or process including lava flows [(Oppenheimer 1991); (Flynn et al. 1994)], lava domes (Oppenheimer et al. 1993), lava lakes (Oppenheimer and Francis 1997), and fumaroles (Harris and Stevenson 1997) that generates excessive heat can still cause a multi-pixel thermal anomaly, despite its size, if it occupies a portion of multiple pixels. Despite the efficiency of infrared satellites to detect increased radiance emitted at $4-\mu \mathrm{m}$, a noticeable difference in its capabilities occurs during daytime and nighttime sequences due to solar irradiance. Daytime data offer difficulties in detecting thermal anomalies because solar reflection can mask thermal emissions at 4- $\mu \mathrm{m}$ (Wright et al. 2004).

Two methods have already demonstrated the capabilities of low-spatial satellite data for detecting heat signatures which include: the spectral comparison method (Prins and Menzel 1992) and the spatial comparison method (Flasse and Ceccato 1996). These methods were initially developed for detection of large biomass burning events or wildfires. The spectral comparison methods (i.e. NTI) involve utilizing single to multiple spectral bands for the detection of thermal anomalies; whereas, the spatial comparison method utilizes evaluation of the immediate surrounding pixels to distinguish an anomaly.

\subsubsection{Single-channel threshold algorithm}

Single-channel threshold algorithms rely completely upon a geostationary satellite's mid-infrared channel centered approximately on $3.75-\mu \mathrm{m}$. The single-channel threshold enables direct comparison of the radiation emitted in the mid-infrared from each pixel. A pixel that displays markedly higher radiation, measured in spectral radiance $\left(\mathrm{W} \mathrm{m} \mathrm{mr}^{-1} \mathrm{~m}^{-1}\right.$ ), at this wavelength will be considered anomalous. This algorithm can be extremely useful for defining the intensity of a given pixel or anomaly since the 
output of this method is spectral radiance $\left(\mathrm{W} \mathrm{m}^{-2} \mathrm{sr}^{-1} \mathrm{~m}^{-1}\right)$. The data provided by this method can then be correlated with actual volcanic processes occurring on the ground.

Issues associated with the single-channel threshold algorithm include strong reflection due to solar radiation. Since solar radiation reflects highly in the mid-infrared region of the electromagnetic spectrum, clouds or bright land can cause normal background pixels to appear anomalous (Wright et al. 2002). Solar reflection is subjected to the incident solar radiation and the albedo of a particular surface. The albedo of vegetated lands is significantly lower than barren lands. Barren lands in the form of lava fields surround many volcanic complexes, which can be the sources of numerous false thermal anomalies. Therefore, the single-channel threshold method performs noticeably better during nighttime monitoring, in highly forested areas, or in locations with cooler background temperatures (i.e. polar regions).

\subsubsection{Normalized Thermal Index (NTI)}

An algorithm developed by the Hawaii Institute of Geophysics and Planetology for implementation by the MODIS satellite instrument addresses the difficulties involved with the simple- subtraction method by normalizing the values. This algorithm, titled MODVOLC, was manufactured for use on the world's first global automated near-real time monitoring of active volcanoes. Wright et al. (2004) determined that by normalizing the difference of the $4-12-\mu \mathrm{m}$ radiance by the sum of the $4+12-\mu \mathrm{m}$ radiance, a dimensionless value can be generated that is weighted toward features that emit large amounts of radiation in the $4-\mu \mathrm{m}$ wavelength such as lava flows or other volcanic heat sources.

$$
N T I=\frac{4 \mu m-12 \mu m}{4 \mu m+12 \mu m}
$$

\subsubsection{Sources of volcanic hot spots}

Provided with extensive time series of eruptive activity, volcanic processes can be interpreted from geostationary satellite thermal radiance data. Being that lava flows are spatially extensive and they can radiate heat at large temperatures, they provide a relatively easy target for satellite detection. Despite the relatively efficient cooling 
process accompanying lava contact with ambient air, flow motion fractures the thin outer cooled crust and exposes molten cores close to eruption temperatures. As a result, lava flows emit substantial amounts of radiation compared to other volcanic processes and can be easily detected (Wright et al. 2001).

Lava dome growth is much harder to detect, since most of the molten core is surrounded by a layer of cooled rock. Wright et al. 2002 performed a high-temporal resolution analysis of a dome growth cycle at Popocatepetl. They discovered that despite the domes persistent residence in the summit crater, anomalous levels of radiance only occurred periodically. However, during destructive episodes of these lava domes, explosions that cause hot pyroclastic flows can be imaged by satellite data. They analyzed $\mathrm{SO}_{2}$ gas flux data and real-time seismic amplitudes to determine that the periods of increased thermal emissions correlated with explosions at the dome. Therefore, it may be the processes that are associated with dome growth that enable geostationary satellite detection and not the domes themselves.

\subsection{Fundamental principles of ash detection}

\subsubsection{Ash Properties}

For a volcanic eruptive product to be characterized as volcanic ash, the material can be a fragment of any nature consisting of pulverized rock, minerals, or shards of volcanic glass, but it has to be smaller than 2 millimeters in diameter (Rose and Durant 2009). Despite the size distribution of volcanic ash, the majority of the total mass erupted falls out very quickly (i.e. $<30$ minutes) leaving only a small portion to be defined as fine ash (i.e. $<20 \%$ ) (Rose et al. 1995). The ash particles in a volcanic plume, which can travel greater distances, range in size from $0.1 \mu \mathrm{m}$ to $1000 \mu \mathrm{m}$. About $50 \%$ of the composition of those ash particles is considered very fine ash, and they range in size from 1 - $30 \mu \mathrm{m}$ (Rose and Durant 2009). The most widely used method for ash retrieval in the infrared (BTD method), can only sense ash in the Mie-region of scattering, which affects the very fine ash portion $(1-30 \mu \mathrm{m})$ (A. Prata 1989), which is highly present $(>50 \%)$ in a migrating cloud. 

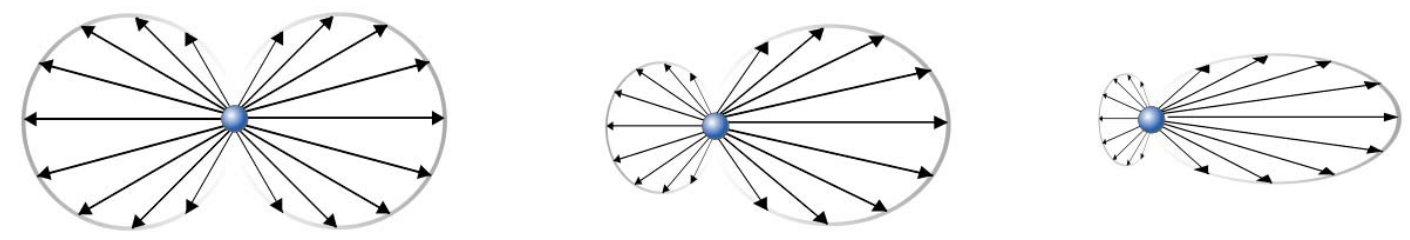

Figure 4. Plot displaying Mie scattering applied to the scattering of radiation by ash. The plot roughly displays scattering intensity per direction. From right to left: Rayleigh, intermediate, and full Mie scattering. Ash can be detected by IR satellites in a narrow wavelength region $(11-12 \mu \mathrm{m})$ and particle size $(\sim 1-30 \mu \mathrm{m})$. Image provided by Sharayanan under GNU Free Documentation License. See Appendix.

Scattering by particles similar in size to or larger than the wavelength of light being redirected is defined by the Mie region of scattering $(r / \lambda>0.1 \rightarrow$ large particles). Particles functioning in the Mie region display strong forward scattering, so most of the incident radiation is propagated toward the sensor (Shu-Guang et al. 2003). The composition of the ash particle itself determines the amount of scatter and emissivity associated with incoming electromagnetic radiation. Ash particles can range from about $50 \%$ silica for basaltic eruptions to about $74 \%$ silica content for explosive rhyolitic eruptions (Wen and Rose 1994). Silicates have high emissivities close to 1 , which mean they absorb solar radiation very efficiently. Hence, ash clouds appear dark in the atmosphere as opposed to meteorological clouds, which have emissivities close to 0 .

A parameter of great importance associated with the composition of the ash particles is the refractive index. The refractive index of an object is a dimensionless value that describes how radiation propagates through a medium. The speed at which light travels through a particular medium is compared against the refractive index of a vacuum (i.e. refractive index of 1) (Hecht 2002). Therefore, a substance with a refractive index of 1.33 (i.e. water) will cause light to travel 1.33 times slower than through a vacuum. The wavelength is also a parameter affecting the refractive index. Therefore, the radiation traveling through a particular medium can be measured using a complexvalued refractive index including a "real" and "imaginary" index. The "real" value accounts for refraction while the "imaginary" value accounts for attenuation (Wen and Rose 1994). Here is a list of complex refractive indices for silicate particles. 


\begin{tabular}{|c|c|c|c|c|c|}
\hline \multirow[b]{2}{*}{ Sample Description } & \multicolumn{2}{|c|}{ Band 4, 10.3-11.3 $\mu \mathrm{m}$} & \multicolumn{2}{|c|}{ Band 5, 11.5-12.5 $\mu \mathrm{m}$} & \multirow[b]{2}{*}{ Source } \\
\hline & Real & Imaginary & Real & Imaginary & \\
\hline (1) Andesite, $54.12 \% \mathrm{SiO}_{2}$ & 2.0534 & 0.60897 & 1.8392 & 0.13786 & Pollack et al. [1973] \\
\hline (2) Basalt, $53.25 \% \mathrm{SiO}_{2}$ & 2.1848 & 0.48812 & 1.9051 & 0.14670 & Pollack et al. [1973] \\
\hline (3) Basaltic glass, $53.45 \% \mathrm{SiO}_{2}$ & 2.1241 & 0.71211 & 2.0129 & 0.24037 & Pollack et al. [1973] \\
\hline $\begin{array}{l}\text { (4) Obsidian-little glass, Mt. } \\
\text { California, rhyolite, } 73.45 \% \\
\mathrm{SiO}_{2}\end{array}$ & 2.0085 & 0.27476 & 1.7281 & 0.18407 & Pollack et al. [1973] \\
\hline
\end{tabular}

Figure 5. List of refractive indices for different silicate particles. Notice that each particle absorbs more energy in the $10.3-11.3 \mu \mathrm{m}$ region than the $11.5-12.5 \mu \mathrm{m}$ region (Wen and Rose 1994). (C) John Wiley and Sons. Reproduced with permission. All rights reserved. See Appendix.

The silicates react to incident radiation differently in the $10.3-11.3 \mu \mathrm{m}$ region compared with the $11.5-12.5 \mu \mathrm{m}$ region. The refractive indices are higher for the 10.3 $-11.3 \mu \mathrm{m}$ region, signifying that absorption is stronger. As will be discussed in the following section and depicted in Figure 6, water and ice display the opposite behavior between these two wavelength regions.

\subsubsection{Brightness Temperature Difference (BTD) Method}

The principles of the BTD method are as follows. Given the opposing behaviors of water/ice and silicate ash particles regarding the absorption of incident light at the 11- and 12- $\mu \mathrm{m}$ regions, a simple subtraction equation can be used to decipher the two types of clouds. This is illustrated below:

- $\quad$ BTD ash: Band $4(10.8 \mu \mathrm{m})-$ Band $5(12 \mu \mathrm{m})=(-) B T D$

- BTD $_{\text {water: }}$ Band $4(10.8 \mu \mathrm{m})-$ Band $5(12 \mu \mathrm{m})=(+)$ BTD
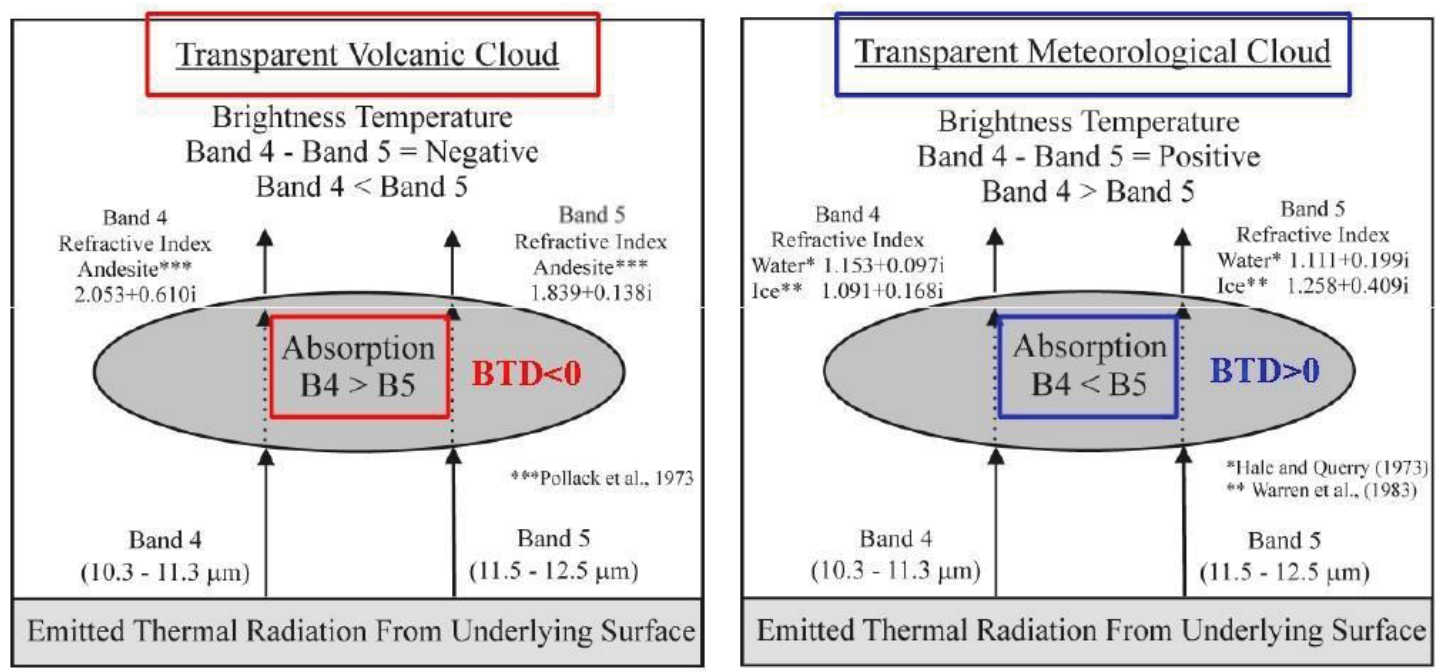

Rose et al., 2003

Figure 6. Images displaying the differing nature of the two particles using an illustration of a volcanic and 
meteorological clouds (Rose et al. 2003). (C) John Wiley and Sons. Reproduced with permission. All rights reserved. See Appendix.

- $\quad$ Issues Regarding BTD Method

Some known issues regarding the 2-band BTD method are the following:

- Water vapor can mask the presence of volcanic ash by attenuation of the IR signal resulting in underestimation

- Ash core of a mixed ice/ash aggregate $(0<\mathrm{BTD}<1)$ are usually not detected and considered pure ice particles leads to an underestimation

- Non-volcanic dust $(\mathrm{BTD}<0)$ may be erroneously interpreted as volcanic ash leading to an overestimation

Although meteorological clouds generally have positive BTD values, regions of slightly negative (-0.5 to -2.0$)$ BTD values are frequently observed when:

- Thermal inversion in the lower troposphere as well as the top of a cumulonimbus cloud entering the stratosphere can lead to overestimation

- This is common in the tropics where convection is typical

- Ground thermal relaxation at night leads to overestimation (Prata et al. 2001)

\subsection{Fundamental Principles of $\mathrm{SO}_{2}$ Detection}

\subsubsection{Principles of UV Remote Sensing of $\mathrm{SO}_{2}$ and other Trace Gases}

The measurement of $\mathrm{SO}_{2}$ molecules in the atmosphere is predicated upon the principle that $\mathrm{SO}_{2}$ absorbs ultraviolet (UV) radiation emitted by the sun, subsequently entering a vibrational excited state. The $\mathrm{SO}_{2}$ molecule successively decays to a lesser energy state thereby emitting the absorbed radiation at a longer wavelength (EPA 2004). The amount of this known wavelength can then be backscattered and recorded by the satellite sensor to obtain an $\mathrm{SO}_{2}$ column amount present in the atmosphere. 


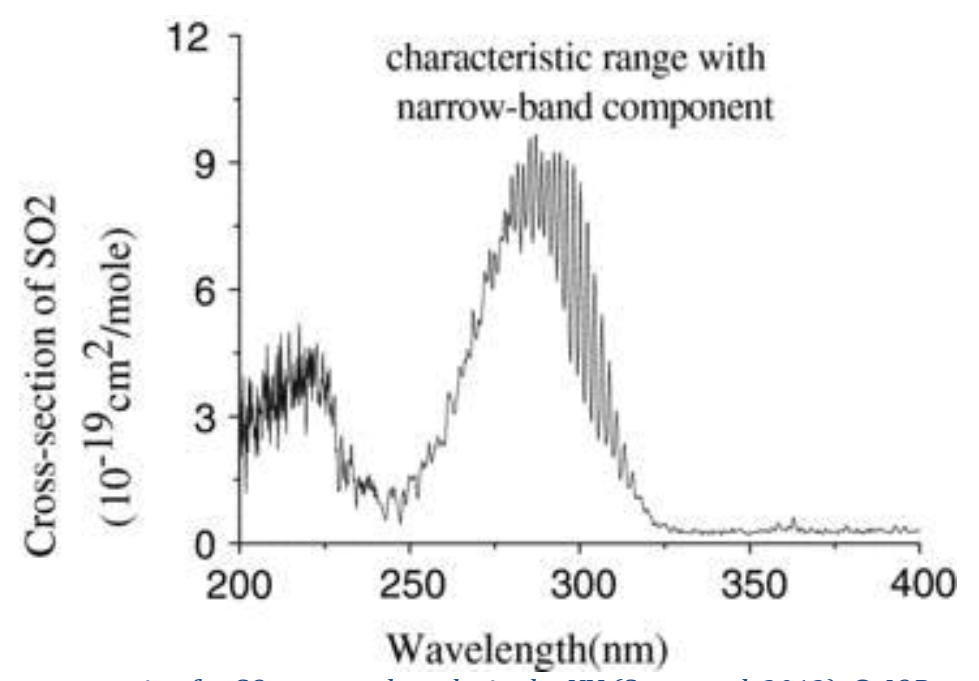

Figure 7. Absorption cross-section for $\mathrm{SO}_{2}$ at wavelengths in the UV (Song et al. 2012). (C) IOP Publishing. Reproduced with permission. All rights reserved. See Appendix.

According to Figure 7, $\mathrm{SO}_{2}$ produces many strong spectral signatures in the $270-$ $340 \mathrm{~nm}$ wavelength range of the electromagnetic spectrum. However, $\mathrm{SO}_{2}$ is not the only molecular species contributing to the strong absorption of solar radiation in the $270-340$ nm region.

Ozone $\left(\mathrm{O}_{3}\right)$ also contains strong spectral signatures in this wavelength region resulting in some potential problems in deciphering between the two species in a remotely sensed dataset. Through the multiplication of ozone absorption cross-sections with commonly observed ozone column densities in the atmosphere, a plot can be manufactured that compares the amount of radiance contribution with altitude. 


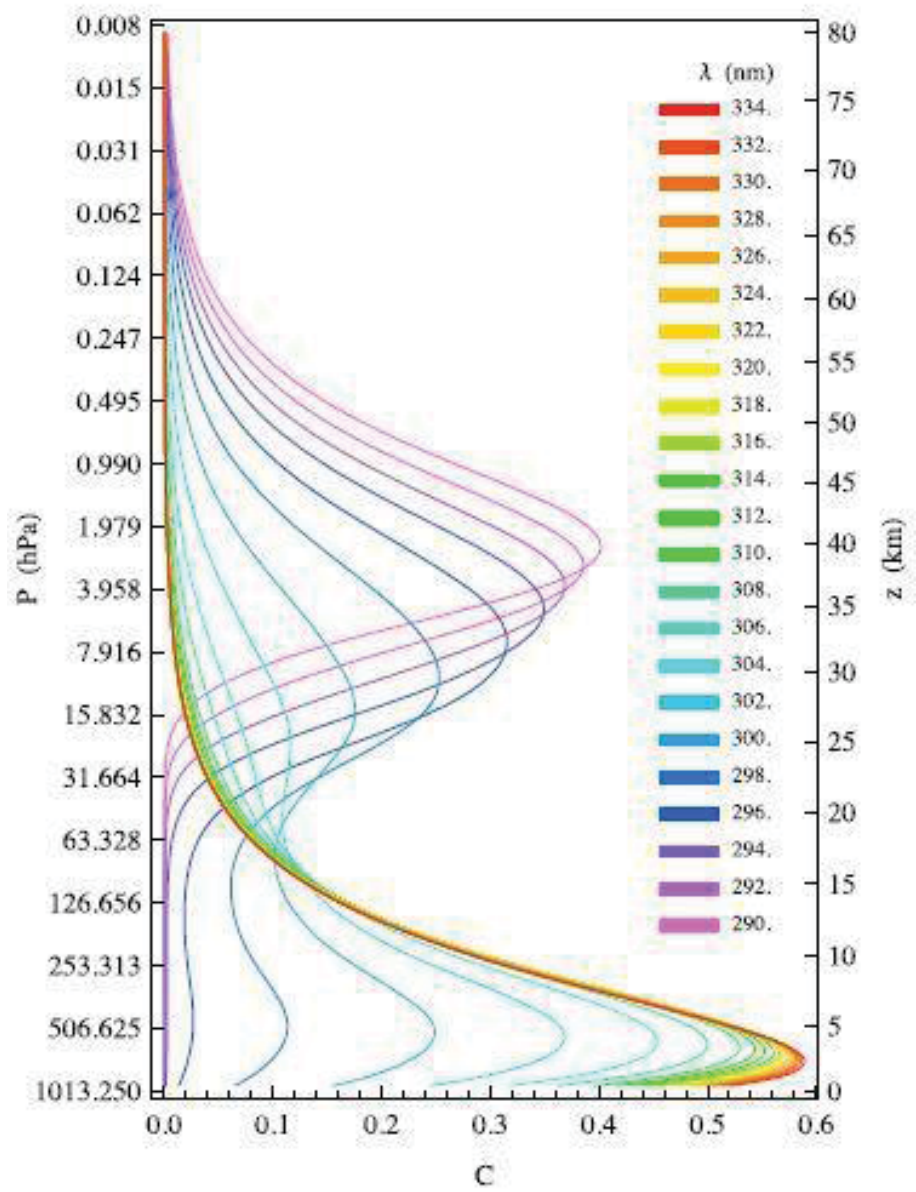

Figure 8. Radiance contribution functions (C) for the wavelength regions pertinent for $\mathrm{O}_{3}$ and $\mathrm{SO}_{2}$ absorption (i.e. $290-334 \mathrm{~nm}$ ) as a function of altitude. The atmosphere is assumed to be cloud and aerosol-free (Yang et al. 2010). (C) John Wiley and Sons. Reproduced with permission. All rights reserved. See Appendix.

The magnitude of the backscattered UV (BUV) radiation from the troposphere is subjected to atmospheric interactions consisting of scattering from molecules, clouds and aerosols, reflection from the surface, and absorption by trace gas species. Figure 8 shows the radiance contribution functions $(\mathrm{C})$ for the wavelength regions pertinent for $\mathrm{O} 3$ and

$\mathrm{SO}_{2}$ absorption (i.e. $290-334 \mathrm{~nm}$ ) as a function of altitude. The atmosphere is assumed to be cloud and aerosol-free (Yang et al. 2010). Figure 8 depicts the contributions to the measured radiance from the photons backscattered from varying atmospheric levels. The areas to the left of the peaks indicate the amount of backscattered photons at that respective level and wavelength, which is a proxy for the magnitude of the total radiance to the top of the atmosphere (TOA).

As indicated in, the radiance contribution functions peak toward the lower part of 
the atmosphere and correspond to increasing wavelengths. Since about $95 \%$ of the UV radiation is absorbed in the stratosphere by the existing ozone layer, a minimal amount of radiation traverses to the troposphere at wavelengths less than $295 \mathrm{~nm}$ (Bhartia 2002). Therefore, more photons penetrate deeper into the atmosphere as a result of weaker ozone absorption and Rayleigh scattering. Hence, radiation at longer wavelengths (i.e. $>310$ $\mathrm{nm}$ ) can traverse the majority of the troposphere before being backscattered to the UV remote sensor providing pivotal column amounts and vertical distributions for the constituent absorbers for essentially the entire atmosphere (Yang et al. 2010).

It is appropriate to mention that the wavelength region surrounding about $305 \mathrm{~nm}$ displays a broad range of radiance contributions with peaks in both the stratosphere and troposphere. Therefore, the longer wavelength channels on a UV satellite instrument are suitable for measuring total column amounts of the desired gas constituent (i.e. $\mathrm{O}_{3}$ or $\left.\mathrm{SO}_{2}\right)$; whereas, the mid-UV wavelengths $(\sim 305-310 \mathrm{~nm})$ are apt for measuring the stratospheric ozone profile (Bhartia 2002).

\subsubsection{SO2 versus 03 absorption in the UV}

The background abundance of $\mathrm{SO}_{2}$ in clean air is extremely small (i.e. $<1 \mathrm{ppb}$ (Breeding et al. 1973)), especially when compared with that of ozone (i.e. $<0.1 \%$ of $\mathrm{O}_{3}$ abundance (Bhartia 2002)). In addition to the relatively minimal concentration, background $\mathrm{SO}_{2}$ resides in the planetary boundary layer $(\mathrm{PBL})$ where due to the turbulent air flow, a mixture of light-scattering molecular species are concentrated making BUV remote sensing of a particular constituent extremely difficult. However, frequent episodic injection of $\mathrm{SO}_{2}$ to altitudes above the PBL, either from volcanic emissions or anthropogenic pollution, can produce significant vertical column densities that can be easily detected from space. 


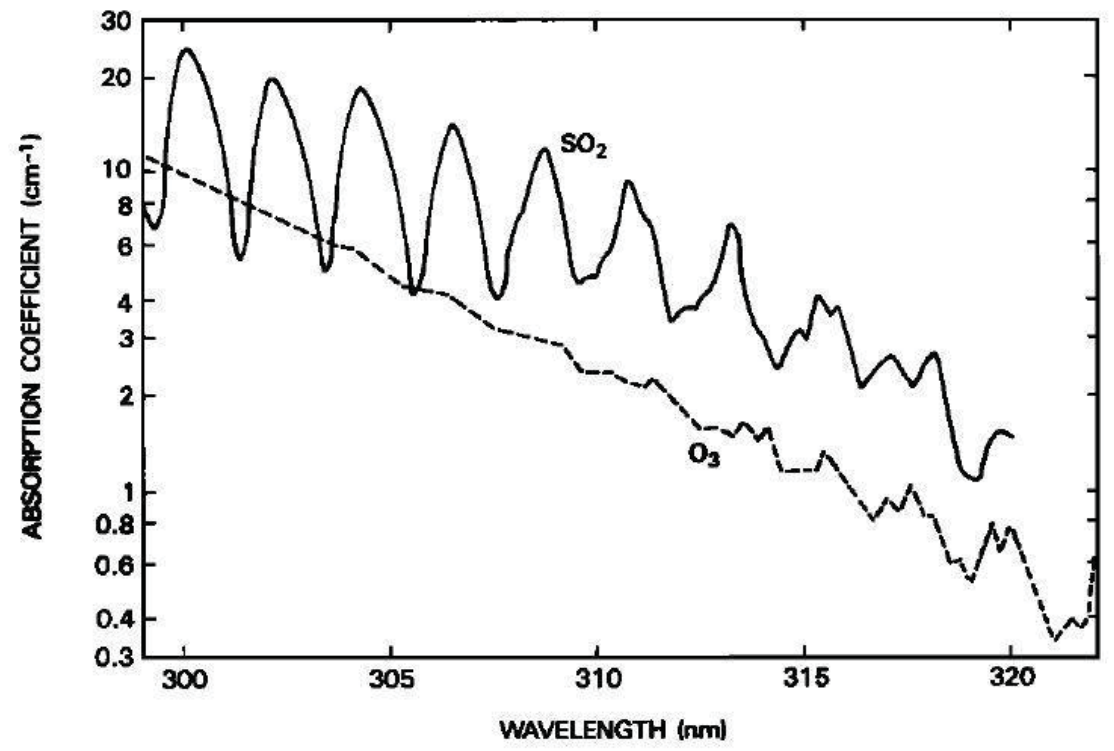

Figure 9. A comparison of ozone absorption coefficients with sulfur dioxide absorption coefficients in the longer-UV wavelengths (i.e. $300-320 \mathrm{~nm}$ ). $\mathrm{SO}_{2}$ absorbs higher than $\mathrm{O}_{3}$ in the $310 \mathrm{~nm}$ range, making this wavelength channel best-suited for $\mathrm{SO}_{2}$ detection by OMI (McPeters and D.F. 1984). (C) John Wiley and Sons. Reproduced with permission. All rights reserved. See Appendix.

Figure 9 exhibits instances where sulfur dioxide can be injected into the atmosphere from a volcanic intermediate. $\mathrm{SO}_{2}$ can be distinguished from $\mathrm{O}_{3}$ because it has strong absorption features in the wavelength range $300-310 \mathrm{~nm} . \mathrm{O}_{3}$ Huggins band structure is not significant below $315 \mathrm{~nm}$ (McPeters and D.F. 1984). Therefore, volcanic eruptions provide an ideal time to detect and interpret sulfur dioxide data in the atmosphere especially at wavelengths around $310 \mathrm{~nm}$. At wavelength bands greater than $310 \mathrm{~nm}$, the $\mathrm{SO}_{2}$ absorbs almost 2.5 times greater than $\mathrm{O}_{3}$, forcing corrections to be made for accurate estimates of $\mathrm{SO}_{2}$.

\subsubsection{OMSO2 Algorithm and Its Applications}

Throughout the history of $\mathrm{SO}_{2}$ retrieval by satellite-based remote sensing instruments, several algorithms have been applied to various datasets including the Krueger-Kerr algorithm for the TOMS $\mathrm{SO}_{2}$ data (Krueger et al. 1995), the standard Differential Optical Absorption Spectroscopy (DOAS) fitting technique for GOME and SCIAMACHY (Richter et al. 2006), and the Band Residual Difference algorithm for the OMI instrument (Krotkov et al. 2006). These various algorithms have contributed to the long time-series now available on increased atmospheric $\mathrm{SO}_{2}$ 
emissions, but they will not be discussed in detail in this report.

A retrieval algorithm for $\mathrm{SO}_{2}$ must account for the migratory aspects of a gas through the atmosphere as well as dramatically variable source emission abundances. Some parameters to consider are:

- A dynamic range of $\mathrm{SO}_{2}$ masses from $<0.1 \mathrm{Tg}$ to $>20 \mathrm{Tg}$

- Interference from ozone absorption

- Location of the PBL

- Volcanic aerosol interference

All $\mathrm{SO}_{2}$ data assimilated in this report was processed utilizing a software program implemented at Michigan Technological University entitled, OMIPlot (Carn 2011). The software employs the use of a robust algorithm for $\mathrm{SO}_{2}$ retrieval called the Linear Fit (LF) algorithm, which has been demonstrated by (Yang et al. 2007). The LF algorithm computes the radiance measurements utilizing a radiative transfer model. The radiance measurements from OMI acquired from a few discrete UVwavelengths derive $\mathrm{SO}_{2}$, ozone, and effective reflectivity simultaneously through the use of an inverse model. Thealgorithm computationally compares the BUV radiance measurements $(I m)$ with the vertical columns of ozone $(\Omega), \mathrm{SO}_{2}(\Theta)$, and surface reflectivity $(R)$ that are the desired parameters. A radiative transfer model that calculates the TOA radiances $(I)$ is used to obtain these values. Taking the $\log$ of the radiative model can be expressed as:

\section{$\log \left(I_{\mathrm{m}}\right)=\log (\Omega, \Theta, R)+N$}

Where $N$ denotes the error. The retrievals of the geophysical parameters can be adjusted until TOA radiances from the forward radiative model match the measurements at the selected wavelength bands. The retrieval algorithm can choose to select all hyperspectral measurements in a wavelength window or only a few discrete coupling bands where $\mathrm{SO}_{2}$ absorbs greatly as well as weakly to maximize the differentiation. The large number of measurements serves to reduce errors associated both systematically and randomly. Prior to completion, a series of empirical corrections addressing the residuals from the calculation of $\mathrm{SO}_{2}$ at varying wavelength-dependent 
absorption cross sections are applied. This algorithm is computationally robust and fast up to relatively moderate eruption rates making this suitable for near-real time monitoring (Yang et al. 2010).

\subsubsection{Errors Associated with the algorithm}

The algorithm is susceptible to three main errors including:

- $\quad$ Forward Model Errors

- The radiative transfer model undoubtedly contains errors being that the absorption and scattering coefficients can only be estimated. Therefore, the forward model results in errors in the computation of the radiances.

- Inverse Model Errors

- The inverse model error stems from the inversion of radiances into geophysical parameters that require the assumption of a priori information. For instance, when ozone is being measured in the atmosphere, an assumption regarding its vertical distribution must be made.

- Instrumental Errors

- Spectral Calibration: Error associated with the calibration of the spectral bands. OMI is expected to have $<1 \mathrm{~nm}$ spectral calibration error (Bhartia 2002).

- Radiometric Calibration: Error in sensitivity of the instrument to detect subtle differences in the atmosphere. OMI is expected to have radiometric calibration errors of $<1 \%$ (i.e. $<4-6$ DU error) (Bhartia 2002).

- Instrument Noise: OMI is expected to have $<2$ DU $(1 \sigma)$ instrument noise.

- Row Anomaly

- Since June 25, 2007, the cross-track positions of the CCD detectors have been affected by a row anomaly, which leads to 
a drastic decrease in the radiance signal (KNMI 2012). The row anomaly affects all wavelengths for a particular viewing angle. Depending on the scene, major sections of an $\mathrm{SO}_{2}$ plume can be opaque leading to severe underestimations in $\mathrm{SO}_{2}$ column amounts. 


\section{Chapter 3 Thermal Anomaly Detection Case Studies: January 2014 Sinabung Eruption}

\subsection{Identifying Thermally Anomalous Pixels and $\mathrm{SO}_{2}$}

Visually identifying anomalous pixels is quite simple for a trained human analyst. Each pixel corresponds to a color defined by a MATLAB script (Gouhier et al. 2012). The color scale ranges from white, which relates to the lowest value, to red, which relates to the highest value. Increasing the height on the color bar correlates to increased radiance emissions. A thermally anomalous pixel will emit a color higher on the scale than the surrounding pixels.

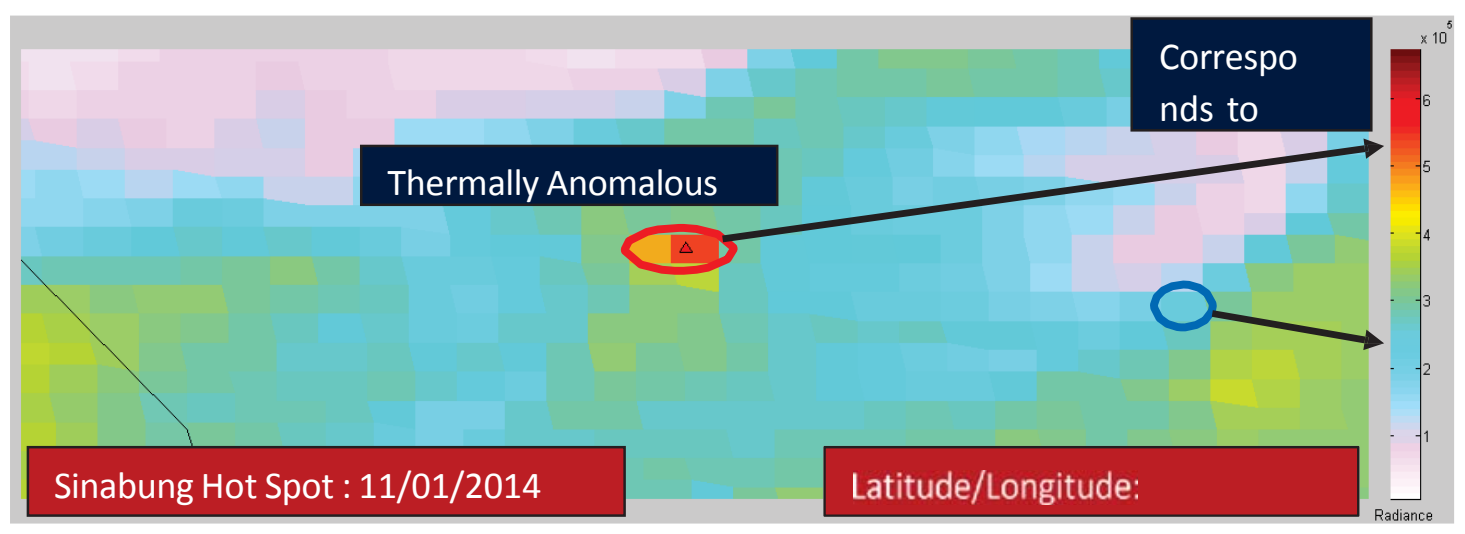

Figure 10. Image processed in MATLAB displaying hot-spot detection at Sinabung volcano. Red triangle corresponds to geolocated position of Sinabung.

The $\mathrm{OMI} \mathrm{SO}_{2}(\mathrm{OMSO})$ data is freely obtained from NASA archived satellite data on their Goddard Earth Sciences (GES) Data and Information Services Center (DISC). The OMSO2 data is acquired in Hierarchical Data Format version 5 (HDF5), which can be easily manipulated using Interactive Data Language (IDL) software. The HDF files store individual parameters as separate arrays that may be extracted singularly without querying the entire file. For OMSO2 data, the parameters include latitude, longitude, $\mathrm{SO}_{2}$ column amount, ozone column amount, reflectivity, cloud fraction, and aerosol index for each OMI pixel. The OMSO2 data is processed from a software developed for the visualization of OMI data entitled OMIplot. This software not only develops a graphical representation of the $\mathrm{SO}_{2}$ cloud overlaid onto a 2-dimensional global map, but it is also capable of calculating such post-processing parameters as $\mathrm{SO}_{2}$ cloud tonnages, areas, migrated distance from the source, and maximum and mean 
column densities (Carn 2008). There are several different options available in the OMIplot software for estimating the $\mathrm{SO}_{2}$ cloud mass corresponding to levels in the atmosphere including PBL (Planetary Boundary Layer), TRL (3 km), TRM (5 km), and STL $(15 \mathrm{~km})$, Since the height of the $\mathrm{SO}_{2}$ cloud is the most important parameter for calculating its mass (Krotkov et al. 2006), choosing the appropriate height from local observatory reports or Lagrangian trajectory modelling (i.e. HYSPLIT) is essential to obtain the best estimation.

\subsection{Results for Single-channel Thermal Radiance}

The following results are presented without being corrected for emissivity or atmospheric effects. The purpose of this project is to understand the operational capabilities of the MTSAT-2 instrument for automated detection. The MTSAT-2 instrument will be required to scan and monitor a multitude of different volcanic areas under differing atmospheric circumstances in the future. Therefore, a onetime correction of data will not be indicative of the continued monitoring conditions and will actually inhibit proper analysis of the current data.

Table 5. Results for amount of images and pixels included in the data using single-channel thermal radiance for the Sinabung eruption.

\begin{tabular}{|c|c|c|c|c|}
\hline \multicolumn{5}{|c|}{$\begin{array}{l}\text { Results for Single-channel 3.8- } \mu \mathrm{m} \text { Thermal Radiance for Sinabung } \\
\text { Eruption }\end{array}$} \\
\hline $\begin{array}{l}\text { Total \# } \\
\text { Images } \\
\text { (1img./1hour/9d } \\
\text { ays) }\end{array}$ & $\begin{array}{l}\text { Images } \\
\text { with } \\
\text { Thermal } \\
\text { Anomaly }\end{array}$ & $\begin{array}{l}\text { \# Pixels } \\
\text { Occupied by } \\
\text { Hot Spot }\end{array}$ & $\begin{array}{l}\text { Total \# of } \\
\text { Pixels } \\
\text { Evaluated }\end{array}$ & $\begin{array}{l}\text { \# Pixels } \\
\text { with } \\
\text { Thermal } \\
\text { Anomaly }\end{array}$ \\
\hline 216 images & 52 images & $\begin{array}{l}\text { 9-pixel } \\
\text { Network }\end{array}$ & 1944 pixels & 141 \\
\hline
\end{tabular}

Sporadic thermal anomalies were scrutinized for the time period of January 11

through January 20. The eruption experienced increased activity prior to the $11^{\text {th }}$, but detection by the MTSAT-2 instrument was not accomplished. There was no apparent pattern relevant to the hot-spot detections.

The January 2014 Sinabung eruption was characterized by an emplacement of a large viscous lava dome in the summit crater with subsequent collapses and 
build-up events occurring in very short intervals $(<1$ day) throughout this period of increased activity. The collapse events resulted in hot pyroclastic flows that were mainly channeled down the southeast slope of the volcanic edifice and traveled for several kilometers. The chronology of events during the period of study is summarized below:

- January 11 - Sinabung is highly active with the emplacement of a new lava dome. The lava dome is subjected to frequent build-up and collapse events. There are some observations pertaining to lava being extruded from the lava dome. The collapse of the lava dome causes pyroclastic flows to generate ash plumes that rise a few kilometers into the atmosphere.

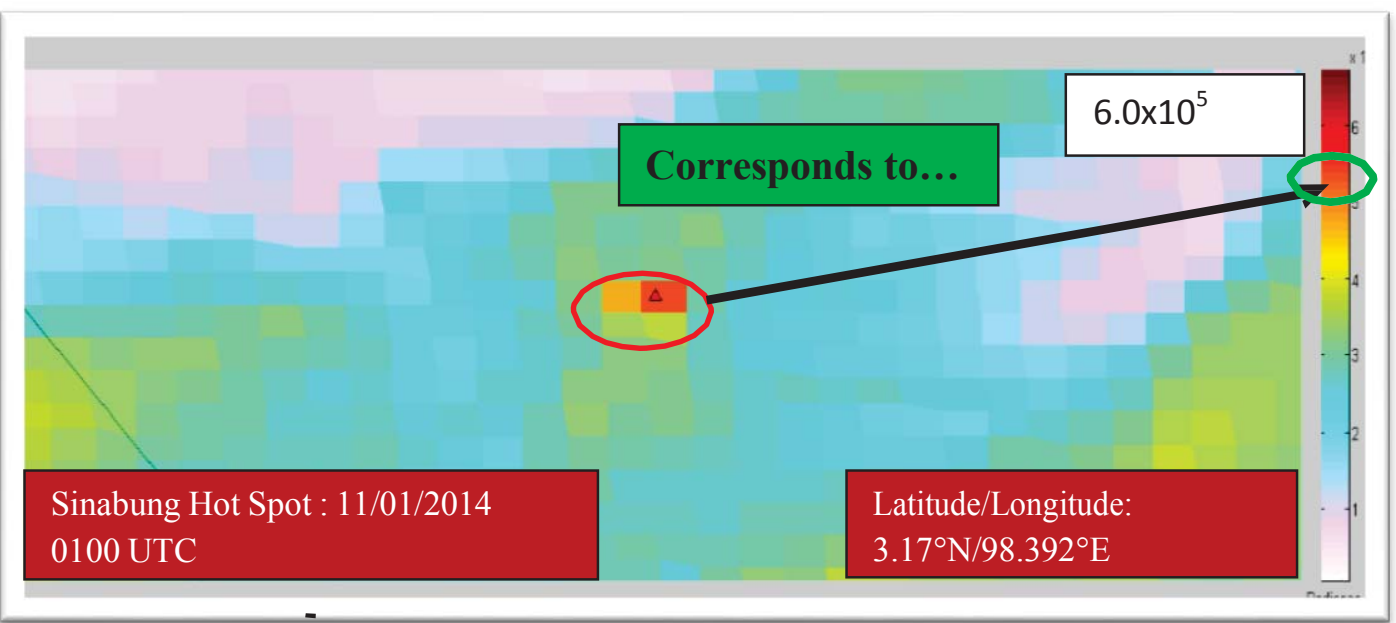

Figure 11. Mount Sinabung volcano spews ash during an eruption, January 11, 2014. The figure is a MATLAB processed image of Sinabung thermal anomaly (01/11/2011_0100 UTC). Morning Image. Moderate emitted radiance.

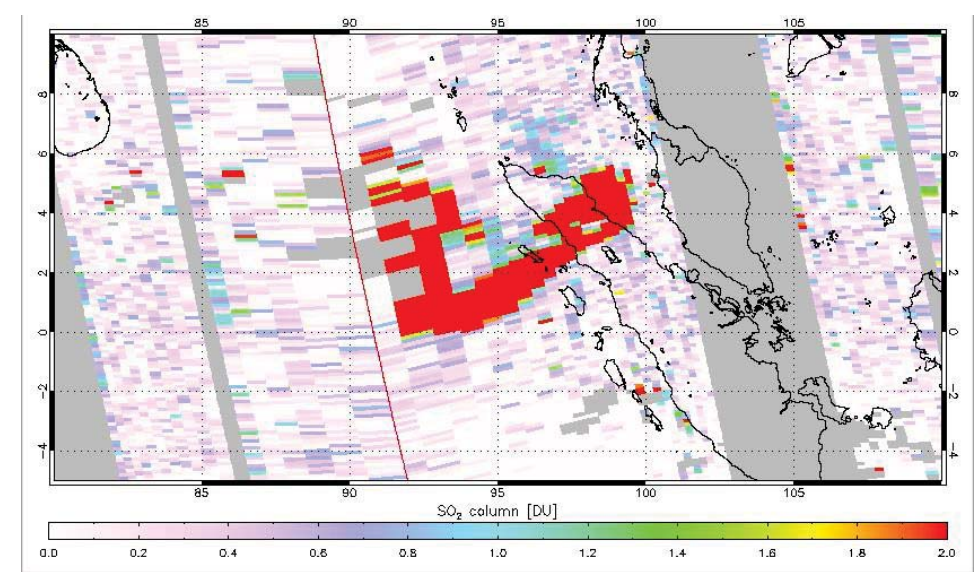


Figure 12. OMIplot processed $\mathrm{SO}_{2}$ image corresponding to the same explosion that produced the above thermal anomaly on January $11^{\text {th }}$. The overpass time for OMI was several hours ( 5-6 hours) after the MTSAT-2 record of the initial thermal anomaly allowing for the sulfur dioxide cloud to disperse as shown in this image.

- January 12 - The lava dome continues to be very active with more dome collapses that produce pyroclastic flows and ash plumes.

- January 13 - A slight decline in the lava dome activity is pertinent. There have been no reports of significant pyroclastic flows for the past couple of days. However, viscous lava is observed flowing from the lava dome evidenced by the image below. A glow is emanating from the hot lava at night.

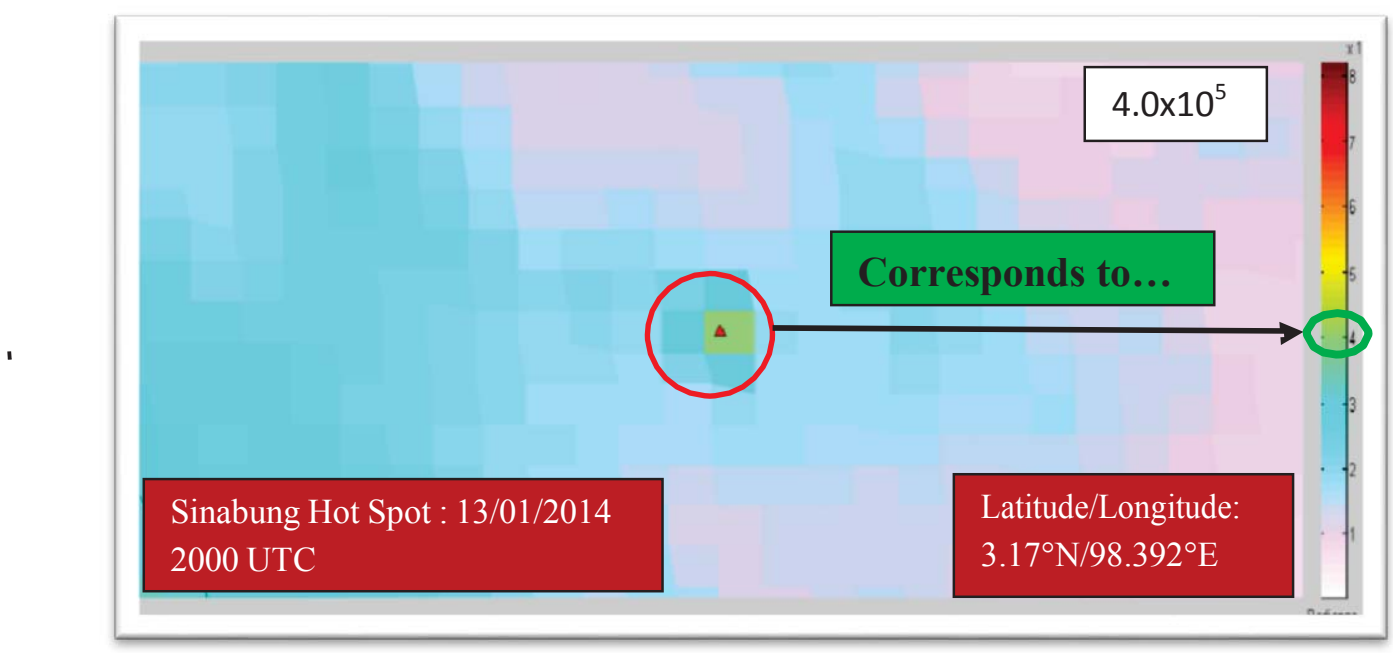

Figure 13. Mount Sinabung volcano spews hot, January 13, 2014. The figure is a MATLAB processed image of Sinabung thermal anomaly (01/13/2011_2000 UTC). Nighttime image. Low emitted radiance.

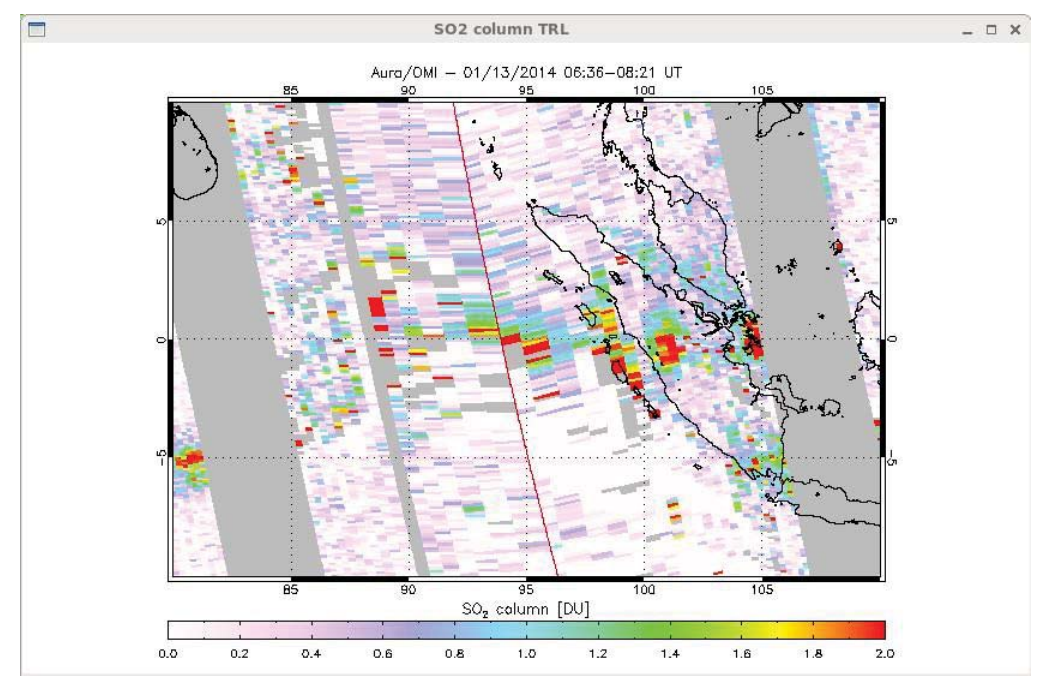

Figure 14. OMIplot processed $\mathrm{SO}_{2}$ image corresponding to the same explosion that produced the above thermal 
anomaly on January $13^{\text {th }}$. The overpass time for OMI was several hours ( 12-13 hours) prior to the MTSAT-2 record of the above thermal anomaly. The intensity of this explosion can be deduced by comparing the two images.

- January 14 - The volcano seemed to have experienced a slight repose period of merely a few days. No significant activity occurred until this day (the $\left.14^{\text {th }}\right)$ when the lava dome collapsed and produced the largest pyroclastic flow of the eruption (i.e. about $5-6 \mathrm{~km}$ ) with an accompanying ash plume rising to about $8 \mathrm{~km}$.

- January 15 - The volcanic activity persists with very frequent dome collapses producing moderate-sized pyroclastic flows extending almost $5 \mathrm{~km}$. A flow was imaged at 1315 local time (0715 UTC).

- January 16 - Large pyroclastic flows produced.

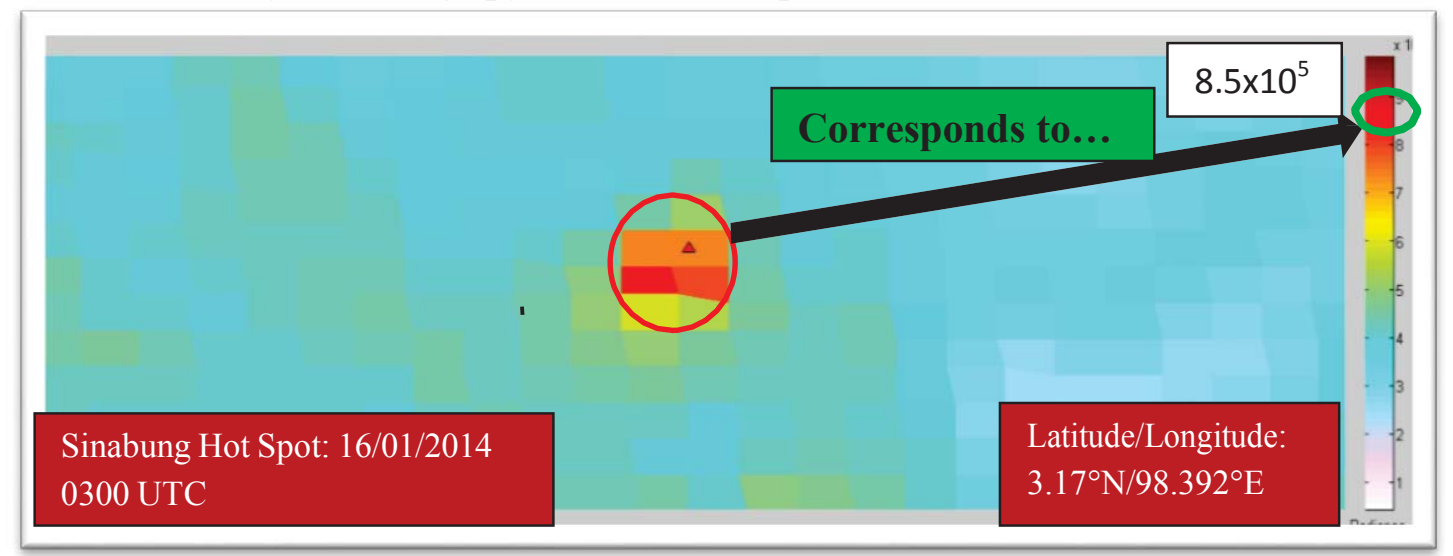

Figure 15. . The Mount Sinabung eruption, January 16, 2014. The figure is a MATLAB processed image of Sinabung thermal anomaly (01/16/2011_0300 UTC). Daytime Image. High emitted radiance.

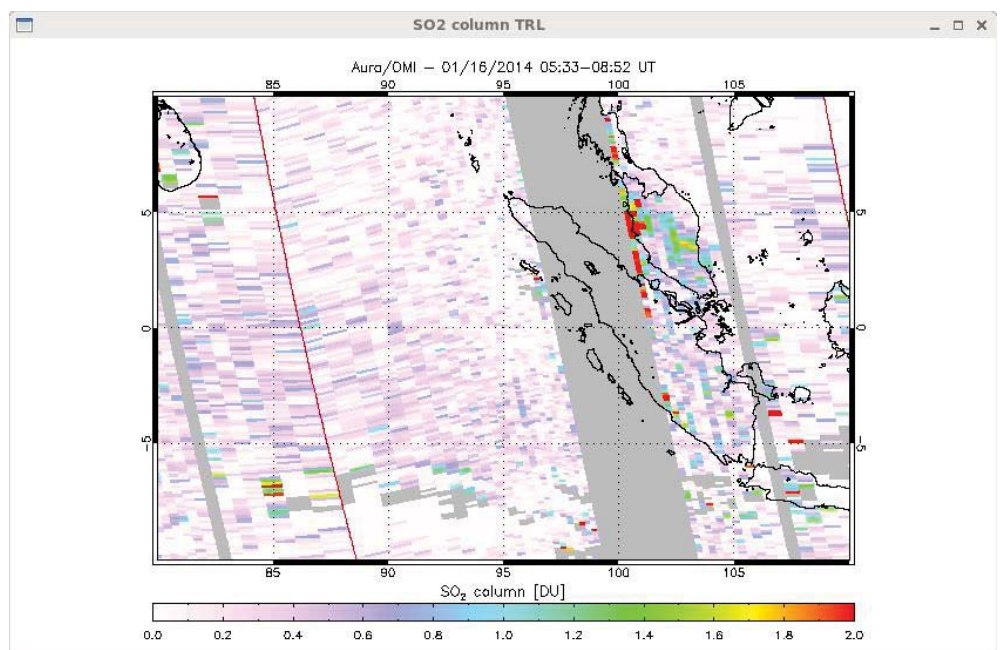

Figure 16. OMIplot processed $\mathrm{SO}_{2}$ image corresponding to the same explosion that produced the above thermal anomaly on January 16 $6^{\text {th }}$. The overpass time for OMI was several hours ( 2-3 hours) after to the MTSAT-2 record of the above thermal anomaly allowing for the cloud to migrate and disperse. The row anomaly is inhibiting imaging of the source and main body of the $\mathrm{SO}_{2}$ cloud; however, the intensity of this explosion can be deduced by 
comparing the magnitude of the column densities and the edge of the row anomaly with the thermal imagery.

- January 17 - The activity at the lava dome perseveres with less frequent dome collapses evident.

- January 18 - No data (very low intensity).

- January 19 - The activity has greatly decreased in the past couple of days. Strong evidence supports the increased activity occurring at the beginning of the week. CVGHM has released their seismic data, which illustrates the marked peak in activity during January $10-15^{\text {th }}$. A tilt meter station located on the slope of the volcano displays a significant inflationary period between January $10^{\text {th }}$ and $14^{\text {th }}$ indicating the emplacement of a new magma body beneath the surface.

- January 20 - The activity at the volcano does not cease with some small moderate sized pyroclastic flows occurring. Ash plumes were observed at a maximum of approximately $6 \mathrm{~km}(20,000 \mathrm{ft}$.) altitude.

Data based on daily reports from the Pusat Vulkanologi \& Mitigasi Bencana Geologi $(P V M B G)$ and the Centre of Volcanology and Geological Hazard Mitigation (CVGHM) uploaded to and from http://www.volcanodiscovery.com/sinabung/news.html.

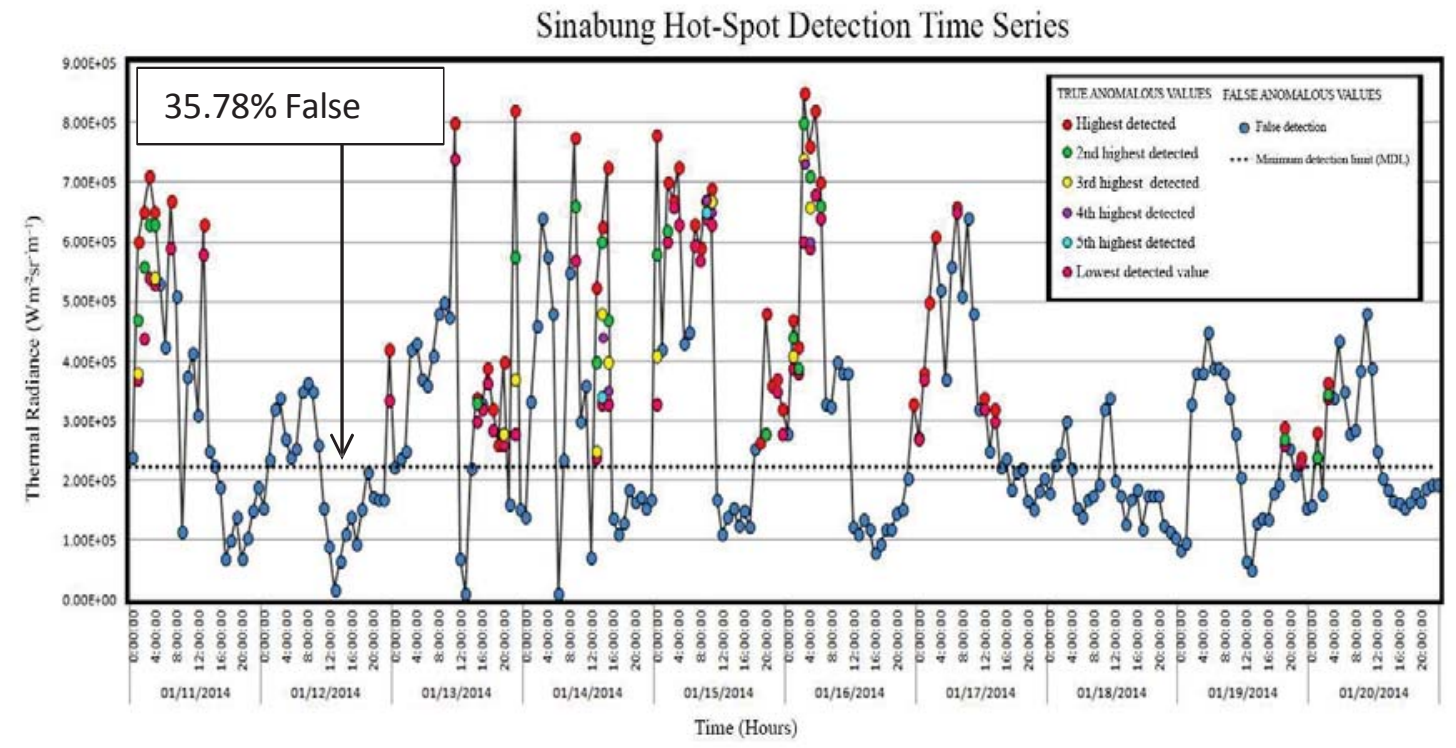

Figure 17. Time series plot for data using only single-channel thermal radiance for the eruption of Sinabung. A dotted line is used to define the base minimum detection limit (MDL) discovered using the MTSAT-2 data. As can be clearly seen, this MDL comes with many false alarms (blue dots above dotted line). A definitive trend for daytime versus nighttime monitoring is evident with the increasing and subsequent decreasing thermal radiance. 
The time-series presented above for the January 2014 Sinabung eruption displays the intensity of thermal radiance that is emitted in the single $3.8-\mu \mathrm{m}$ wavelength, and is very indicative of the activity that persisted during this time. Figure 19 clearly shows trends differing mainly due to daytime (0200-1400 UTC) versus nighttime (1500-0100 UTC) monitoring effects. This result allows for further separation of the data in order to improve the accuracy of our detection system.

Table 6. Table showing the major results obtained from the MTSAT-2 data of the Sinabung eruption. Notice that each "average" is separated into daytime and nighttime values due to the trends observed in Figure 17.

\begin{tabular}{|c|c|c|c|}
\hline \multicolumn{4}{|c|}{$\begin{array}{l}\text { Sinabung Eruption Major Results (Single-channel Thermal } \\
\text { Radiance) }\end{array}$} \\
\hline $\begin{array}{l}\text { Maximum } \\
\text { Radiance }\end{array}$ & & \multicolumn{2}{|c|}{$8.50 \mathrm{E}+05 \mathrm{Wm}^{-2} \mathrm{sr}^{-1} \mathrm{~m}^{-1}(0300 \mathrm{UTC} 16 / 01 / 2014)$} \\
\hline $\begin{array}{l}\text { Minimum } \\
\text { Radiance }\end{array}$ & & \multicolumn{2}{|c|}{$2.30 \mathrm{E}+05 \mathrm{Wm}^{-2} \mathrm{sr}^{-1} \mathrm{~m}^{-1}(1000 \mathrm{UTC} 19 / 01 / 2014)$} \\
\hline $\begin{array}{l}\text { Average } \\
\text { Radiance/Image }\end{array}$ & $3.02 \mathrm{E}+05$ & Daytime Average & $3.72 \mathrm{E}+05$ \\
\hline $\begin{array}{l}\text { (Total, No } \\
\text { Detection) }\end{array}$ & & $\begin{array}{l}\text { Nighttime } \\
\text { Average }\end{array}$ & $2.19 \mathrm{E}+05$ \\
\hline $\begin{array}{l}\text { Average } \\
\text { Radiance/Image }\end{array}$ & $4.92 \mathrm{E}+05$ & Daytime Average & $5.86 \mathrm{E}+05$ \\
\hline (Detection Only) & & $\begin{array}{l}\text { Nighttime } \\
\text { Average }\end{array}$ & $3.69 \mathrm{E}+05$ \\
\hline $\begin{array}{l}\text { Average } \\
\text { Pixels/Image }\end{array}$ & 2.71 & Daytime Average & 2.96 \\
\hline $\begin{array}{l}\text { (Detection } \\
\text { Only) }\end{array}$ & & $\begin{array}{l}\text { Nighttime } \\
\text { Average }\end{array}$ & 2.44 \\
\hline
\end{tabular}

\subsubsection{Define minimum detection limit (MDL)}

In order to facilitate a non-interactive volcano monitoring system for automated detection of thermal anomalies, several possibilities have already been developed to accomplish this feat. The use of the 3.8- $\mu \mathrm{m}$ wavelength band functioning on the MTSAT-2 can be used to detect thermal anomalies. A minimum detection limit 
for the radiance emitted by a single pixel must be established. If the radiance is above a certain threshold, then that particular pixel will be marked as a hot spot. However, a lower threshold for detection will expose the automated system to the potential for a greater false alarm rate. Fortunately, the algorithm that will be used for the MTSAT2 will only consider the nine pixels in the immediate vicinity of the particular volcano for reasons mentioned in Section 3.2. So, the probability to experience a false alarm are greatly reduced since only nine pixels are regarded as opposed to 1276928 pixels, which is the total amount of pixels produced in an MTSAT-2 image. The range of radiance values associated with true anomalies throughout the entire time-series is $2.3 \times 10^{5} \mathrm{Wm}^{-2} \mathrm{sr}^{-1} \mathrm{~m}^{-1}$ to $8.5 \times 10^{5} \mathrm{Wm}^{-2} \mathrm{sr}^{-1} \mathrm{~m}^{-1}$ for individual pixels. In this range, a total of 218 pixels exist, with only 140 being true anomalies, according to visual inspection by a human analyst, leaving 78 pixels as false detections. This method would afford a false alarm rate of $35.78 \%$.

\subsubsection{Daytime}

Sinabung Daytime Detection Time Series

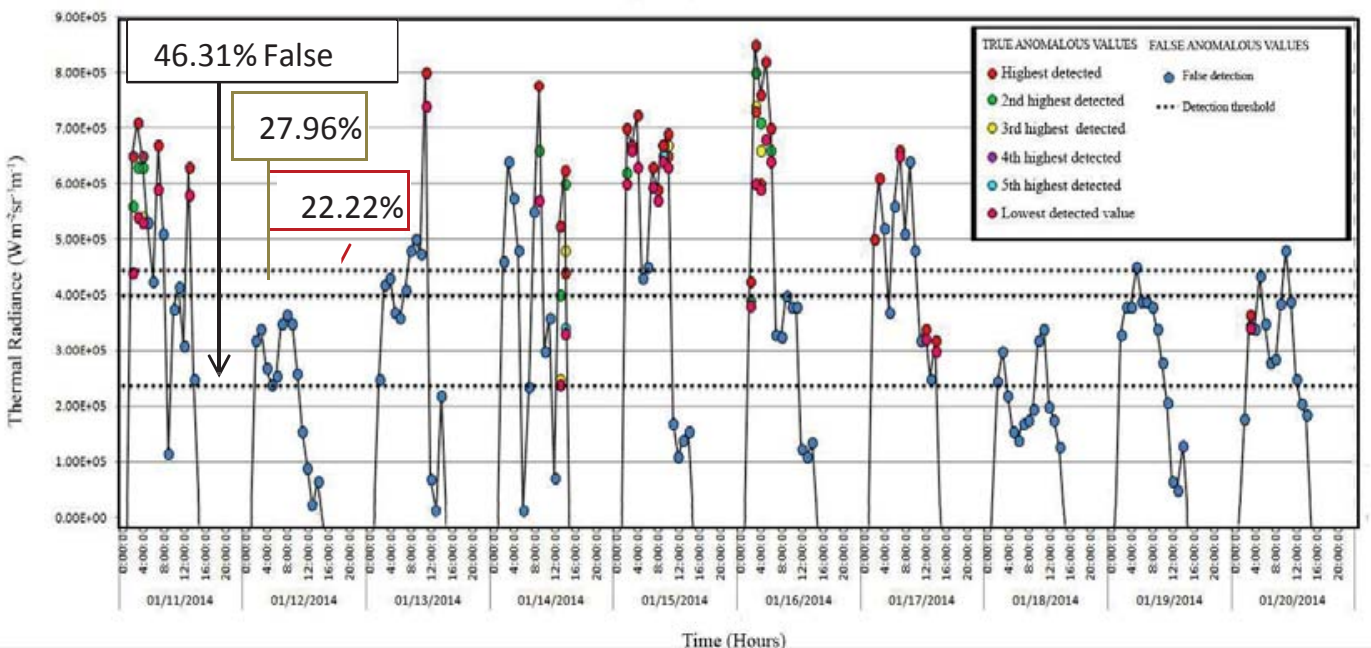

Figure 18. Thermal anomaly detection time series for daytime only. All nighttime (1500-0100 UTC) is zeroed. Each higher MDL corresponds to a lower false alarm rate, but there are a greater amount of true anomalies missed.

An immediate approach to improve the false alarm rate would be to incorporate more than one MDL. According to the time-series, the daytime is characterized by a higher average emitted radiance, while the radiance tends to decrease significantly during the nighttime. In order to account for this discrepancy in radiance output, two minimum detection limits are proposed for the daytime and 
nighttime monitoring. The daytime on the time-series is depicted as being from 0200 to 1400 UTC. The odd timing for daytime hours is because the data downloaded from FTP is in UTC; whereas, the local time at Sinabung volcano in Indonesia is 6 hours ahead. A minimum detection limit is calculated for the daytime by zeroing all values associated with the nighttime. All values between the range of the minimum detected anomaly and the maximum detected anomaly are considered.

Table 7. Table displaying the results for differing minimum detection limits (MDLs) for the daytime only.

\begin{tabular}{|c|c|c|c|c|c|c|}
\hline & & Deteci & resho & Daytime & (Single-ch & \\
\hline $\mathrm{MDL}\left(\mathrm{Wm}^{-2} \mathrm{sr}^{-}\right.$ & Total \# & \# & $\#$ & \# True & False & Misse \\
\hline$\left.{ }^{1} m^{-1}\right)$ & Values & True & Fals & Anomal & Alarm & d \\
\hline & "Flagge & Anomal & e & ies & Rate & Anom \\
\hline $2.40 E+05$ & 149 & 80 & 69 & 0 & $46.31 \%$ & $0.0 \%$ \\
\hline $4.00 E+05$ & 93 & 67 & 26 & 13 & $27.96 \%$ & $16.25 \%$ \\
\hline $4.50 \mathrm{E}+05$ & 81 & 63 & 18 & 17 & $22.22 \%$ & $21.25 \%$ \\
\hline
\end{tabular}

Another method of limiting false alarms is increasing the threshold necessary to establish an anomaly, which will improve the performance of the algorithm, but the detection of some low-intensity hot-spots will be sacrificed.

\subsubsection{Nighttime}

Sinabung Nighttime Detection Time Series

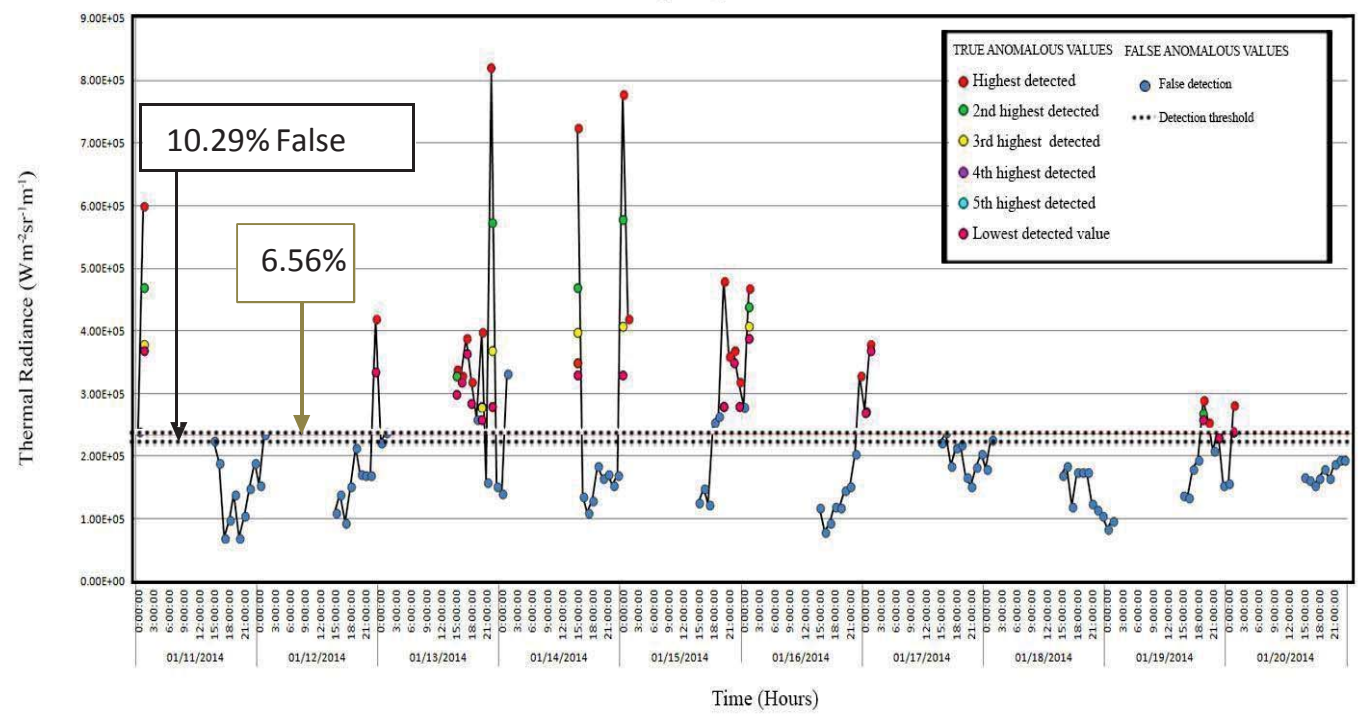

Figure 19. Thermal anomaly detection time series for nighttime only. All daytime (0200-1400 UTC) is zeroed. Each higher MDL corresponds to a lower false alarm rate, but there are a greater amount of true anomalies missed. 
Table 8. Table displaying the results for differing minimum detection limits (MDLs) for the nighttime only.

\begin{tabular}{|ccccccc|}
\hline $\begin{array}{c}\text { MDL }\left(\mathbf{W m}^{-}\right. \\
{ }^{2} \mathbf{c r}^{-} \\
\left.{ }^{1} \mathbf{m}^{-1}\right)\end{array}$ & $\begin{array}{l}\text { Total \# } \\
\text { Values } \\
\text { in this } \\
\text { Region }\end{array}$ & $\begin{array}{c}\text { \# True } \\
\text { Anomalies }\end{array}$ & $\begin{array}{c}\text { \# False } \\
\text { Alarms }\end{array}$ & $\begin{array}{c}\text { \# True } \\
\text { Anomalie } \\
\text { Missed }\end{array}$ & $\begin{array}{c}\text { False } \\
\text { Alarm } \\
\text { Rate } \\
\text { (\%) }\end{array}$ & $\begin{array}{c}\text { Missed } \\
\text { Anomaly } \\
\text { Rate (\%) }\end{array}$ \\
\hline $\mathbf{2 . 3 0 E + 0 5}$ & 68 & 61 & 7 & 0 & $10.29 \%$ & $0.0 \%$ \\
\hline $\mathbf{2 . 5 0 E + 0 5}$ & 60 & 57 & 3 & 4 & $5.0 \%$ & $6.56 \%$ \\
\hline
\end{tabular}

\subsection{Results for Normalized Thermal Index (NTI)}

Results for the analysis of MTSAT-2 thermal data, deciphered utilizing the normalized thermal index algorithm, are presented here. The same images examined using the single $3.8-\mu \mathrm{m}$ method above are used to study the capabilities of the NTI algorithm (i.e. $[3.8 \mu \mathrm{m}-12 \mu \mathrm{m}] /[3.8 \mu \mathrm{m}+12 \mu \mathrm{m}])$.

Table 9. Results for amount of images and pixels included in the data using the NTI algorithm.

\begin{tabular}{||l|l|c|l|l|}
\hline \multicolumn{5}{||}{ Results for NTI for Sinabung Eruption } \\
\hline $\begin{array}{l}\text { Total \# } \\
\text { Images } \\
\text { (1img./1hour/ } \\
\text { 9days) }\end{array}$ & $\begin{array}{l}\text { Images } \\
\text { with } \\
\text { Thermal } \\
\text { Anomaly }\end{array}$ & $\begin{array}{l}\text { \# Pixels } \\
\text { Occupied } \\
\text { by Hot } \\
\text { Spot }\end{array}$ & $\begin{array}{l}\text { Total \# of } \\
\text { Pixels } \\
\text { Evaluated }\end{array}$ & $\begin{array}{l}\text { \# Pixels with } \\
\text { Thermal } \\
\text { Anomaly }\end{array}$ \\
\hline 216 images & 65 images & $\begin{array}{c}\text { 9-pixel } \\
\text { Network }\end{array}$ & 1944 & 160 \\
& & & & \\
& & & & \\
\hline
\end{tabular}


Sinabung NTI Time Series

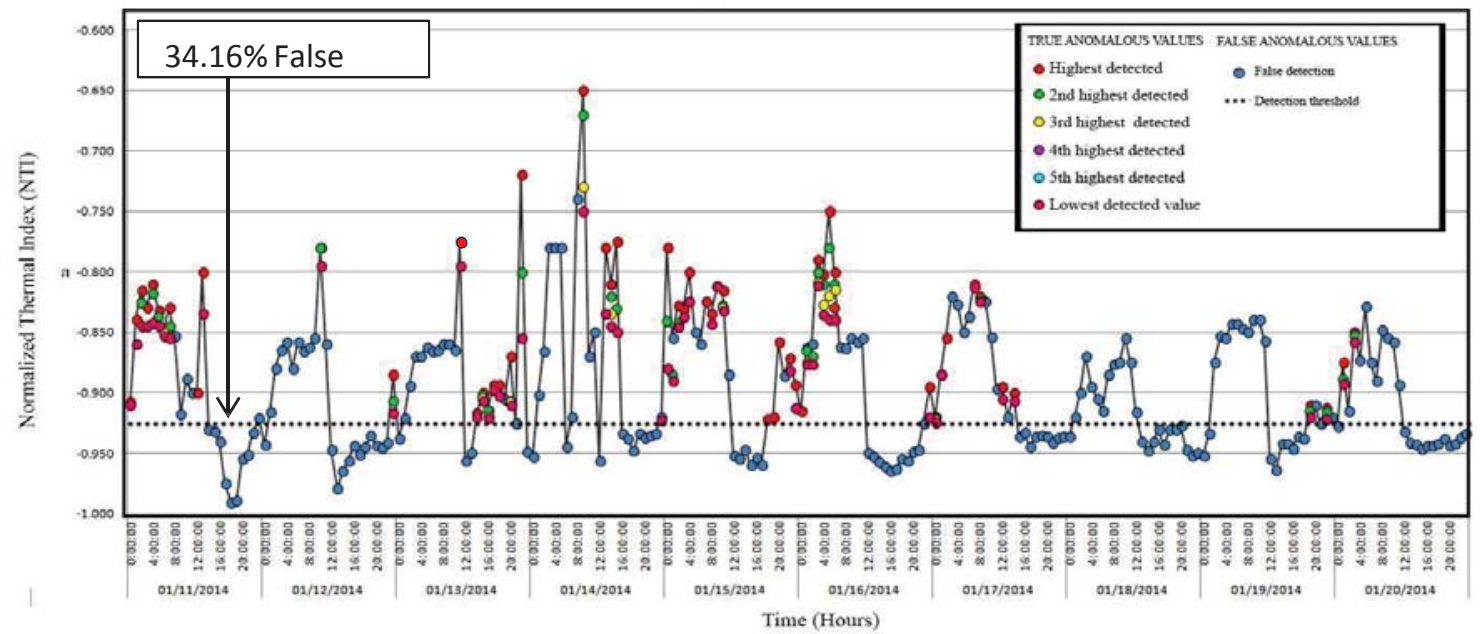

Figure 20. Time series plot for data processed using NTI algorithm for the eruption of Sinabung. The units of the NTI are dimensionless and of a negative value. NTI is merely a "flagging" method to use as a way to confirm or deny a hot spot. The closer the NTI value gets to 0 , the more intense the signal is. The same general trends (daytime/nighttime) are prevalent here in this time series as compared with the Figure 19.

Figure 20 provides a graphical view of the thermal anomalies that the MTSAT2 is capable of detecting. The NTI algorithm is basically a "flagging" method, which sole purpose is to detect if a thermal anomaly is present.

Table 10. Table showing the major results obtained from the MTSAT-2 data processed using NTI. Notice that each "average" is separated into daytime and nighttime values due to the trends observed in Figure 19.

\begin{tabular}{|c|c|c|c|}
\hline \multicolumn{4}{|c|}{ Sinabung Eruption Major Results (NTI) } \\
\hline Maximum NTI & & \multicolumn{2}{|c|}{-0.65 (0900 UTC 14/01/2014) } \\
\hline Minimum NTI & & \multicolumn{2}{|c|}{$-0.925(0600$ UTC 17/01/2014) } \\
\hline Average & \multirow[t]{2}{*}{-0.8938} & \multirow{2}{*}{$\begin{array}{l}\text { Daytime Average } \\
\text { Nighttime }\end{array}$} & -0.8671 \\
\hline Radiance/Image & & & -0.9253 \\
\hline Average & \multirow[t]{2}{*}{-0.8545} & \multirow{2}{*}{$\begin{array}{l}\text { Daytime Average } \\
\text { Nighttime }\end{array}$} & -0.8259 \\
\hline \multirow{3}{*}{$\begin{array}{l}\text { Radiance/Image } \\
\text { Average } \\
\text { (Detection Only) }\end{array}$} & & & -0.8895 \\
\hline & 2.35 & Daytime Average & 2.51 \\
\hline & & Nighttime Avg. & 2.18 \\
\hline
\end{tabular}

\subsubsection{Define minimum threshold for NTI}

A histogram of the NTI values for each true detected pixel distributed throughout the study period for the Sinabung eruption is illustrated below. 


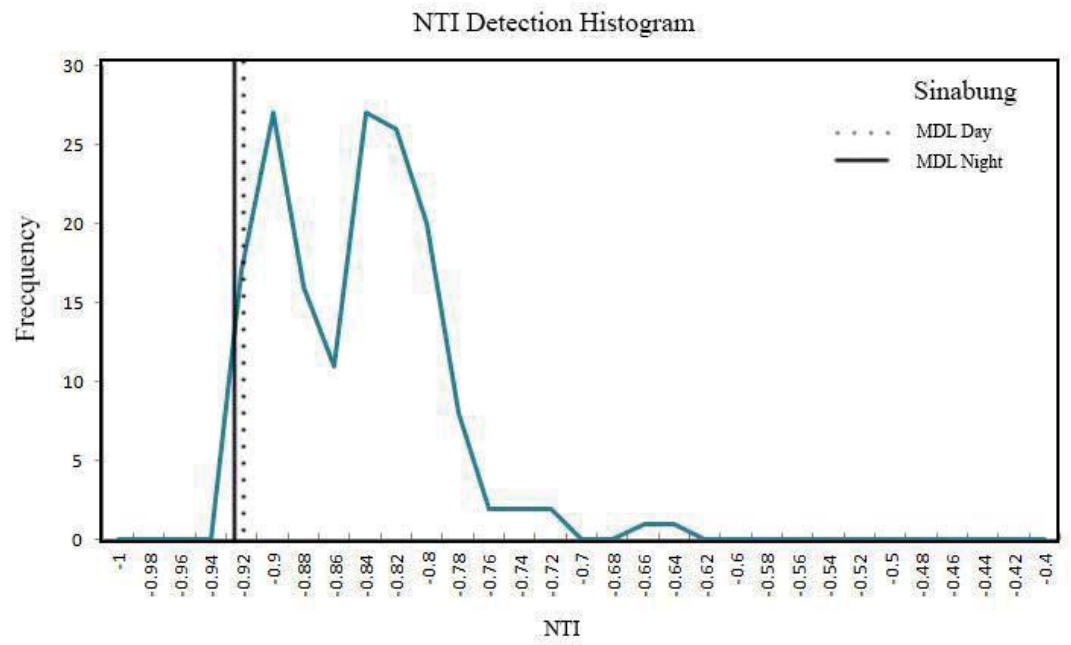

Figure 21. Histogram showing the frequency of output values for individual pixels when analyzing thermal anomalies utilizing the NTI algorithm. The lowest MDLs for day (-0.92) and night (-0.925) are plotted, which incorporate every true anomaly.

Following the logic used for the automated detection of the single 3.8- $\mu \mathrm{m}$ thermal radiance, a minimum threshold must be developed to implement the NTI algorithm into a non-interactive monitoring campaign.

\subsubsection{Daytime}

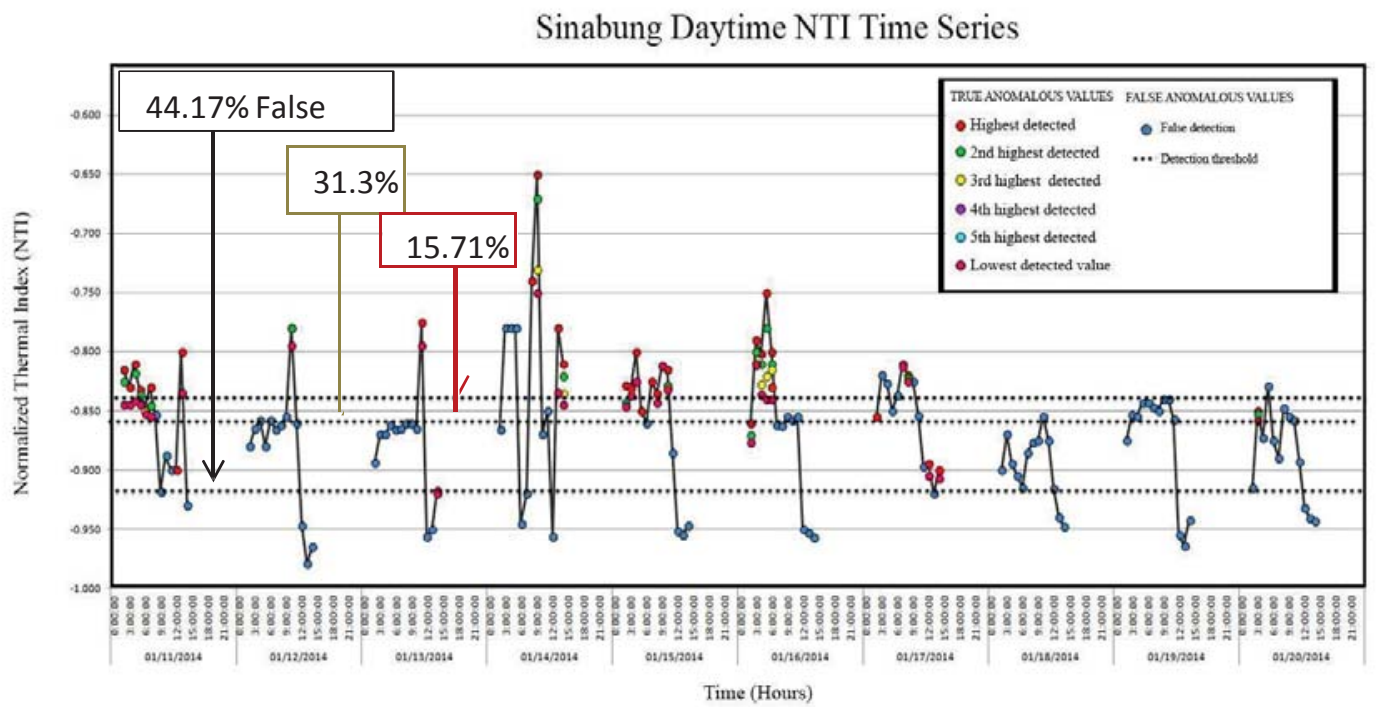

Figure 22. Thermal anomaly detection time series for daytime only. All nighttime (1500-0100 UTC) values are zeroed. Each higher MDL corresponds to a lower false alarm rate, but there are a greater amount of true anomalies missed. 
Table 11. Table displaying the results for differing minimum detection limits (MDLs) for the daytime only using NTI.

\begin{tabular}{|c|c|c|c|c|c|c|}
\hline \multirow{2}{*}{$\begin{array}{c}\mathrm{MDL}\left(\mathrm{Wm}^{-2} \mathrm{sr}\right. \\
\left.{ }^{1} \mathrm{~m}^{-1}\right)\end{array}$} & \multicolumn{6}{|c|}{ Detection Thresholds for Daytime Only (NTI) } \\
\hline & $\begin{array}{c}\text { Total \# } \\
\text { Values } \\
\text { "Flagge } \\
\text { d" }\end{array}$ & $\begin{array}{l}\quad \# \\
\text { True } \\
\text { Anomal } \\
\text { ies }\end{array}$ & $\begin{array}{l}\# \\
\text { Fals } \\
\text { e } \\
\text { Alar }\end{array}$ & $\begin{array}{l}\text { \# True } \\
\text { Anomal } \\
\text { ies } \\
\text { Missed }\end{array}$ & $\begin{array}{l}\text { False } \\
\text { Alarm } \\
\text { Rate } \\
(\%)\end{array}$ & $\begin{array}{l}\text { Misse } \\
\text { d } \\
\text { Anom } \\
\text { aly }\end{array}$ \\
\hline-0.92 & 163 & 91 & 72 & 0 & $44.17 \%$ & $0.0 \%$ \\
\hline-0.86 & 115 & 79 & 36 & 12 & $31.30 \%$ & $13.90 \%$ \\
\hline-0.84 & 70 & 59 & 11 & 17 & $15.71 \%$ & $35.16 \%$ \\
\hline
\end{tabular}

\subsubsection{Nighttime}

Sinabung Nighttime NTI Time Series

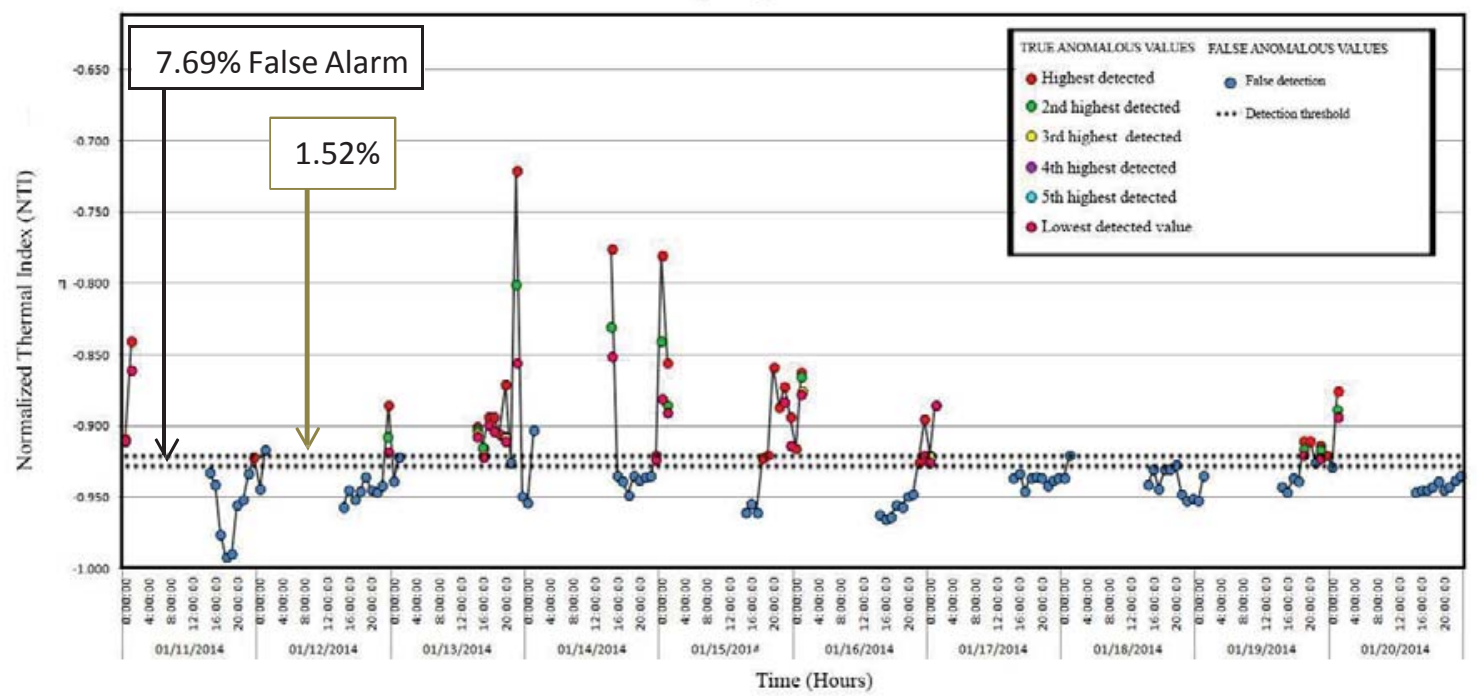

Figure 23. Thermal anomaly detection time series for nighttime only using NTI. All daytime (0200-1400 UTC) is zeroed.

Table 12. Table displaying the results for differing minimum detection limits (MDLs) for the nighttime only using NTI.

\begin{tabular}{|c|c|c|c|c|c|c|}
\hline \multirow[b]{2}{*}{$\begin{array}{l}\mathrm{MDL} \\
\left(\mathrm{Wm}{ }^{-}\right. \\
{ }^{2} \mathrm{sr}^{-}\end{array}$} & \multirow[b]{2}{*}{$\begin{array}{c}\text { Total \# } \\
\text { Values in } \\
\text { this }\end{array}$} & \multicolumn{5}{|c|}{ Detection Thresholds for Nighttime Only (NTI) } \\
\hline & & $\begin{array}{l}\text { \# True } \\
\text { Anomali } \\
\text { es }\end{array}$ & $\begin{array}{l}\# \\
\text { False } \\
\text { Alar }\end{array}$ & $\begin{array}{c}\text { \# True } \\
\text { Anomali } \\
\text { es }\end{array}$ & $\begin{array}{l}\text { False } \\
\text { Alarm } \\
\text { Rate }\end{array}$ & $\begin{array}{l}\text { Misse } \\
\text { d } \\
\text { Anoma }\end{array}$ \\
\hline- & 78 & 72 & 6 & 0 & $7.69 \%$ & $0.0 \%$ \\
\hline-0.92 & 66 & 65 & 1 & 7 & $1.52 \%$ & $9.72 \%$ \\
\hline
\end{tabular}

\subsection{Results for $\mathrm{OMI} \mathrm{SO}_{2}$ Sinabung Eruption}

All of the $\mathrm{OMI} \mathrm{SO}_{2}$ data presented here are used for comparison and validation of the MTSAT-2 thermal data. The data have been developed and interpreted using post- 
processing capabilities of the OMIplot software mentioned in Section 3.2. Daily reports from the PVMBG and the CVGHM in Indonesia indicated that diurnal explosions from Sinabung produced approximately $3 \mathrm{~km}$ gas and ash plumes during this period of increased activity; therefore, all $\mathrm{SO}_{2}$ parameters were calculated using the TRL altitude.

\subsection{1 $\mathrm{SO}_{2}$ Mass Burden}

The following graph depicts the total mass of $\mathrm{SO}_{2}$ produced during each individual diurnal explosion from Sinabung. This data is not a measure of the continuing degradation a single $\mathrm{SO}_{2}$ cloud. Each data point represents a new eruption plume generated from Sinabung.

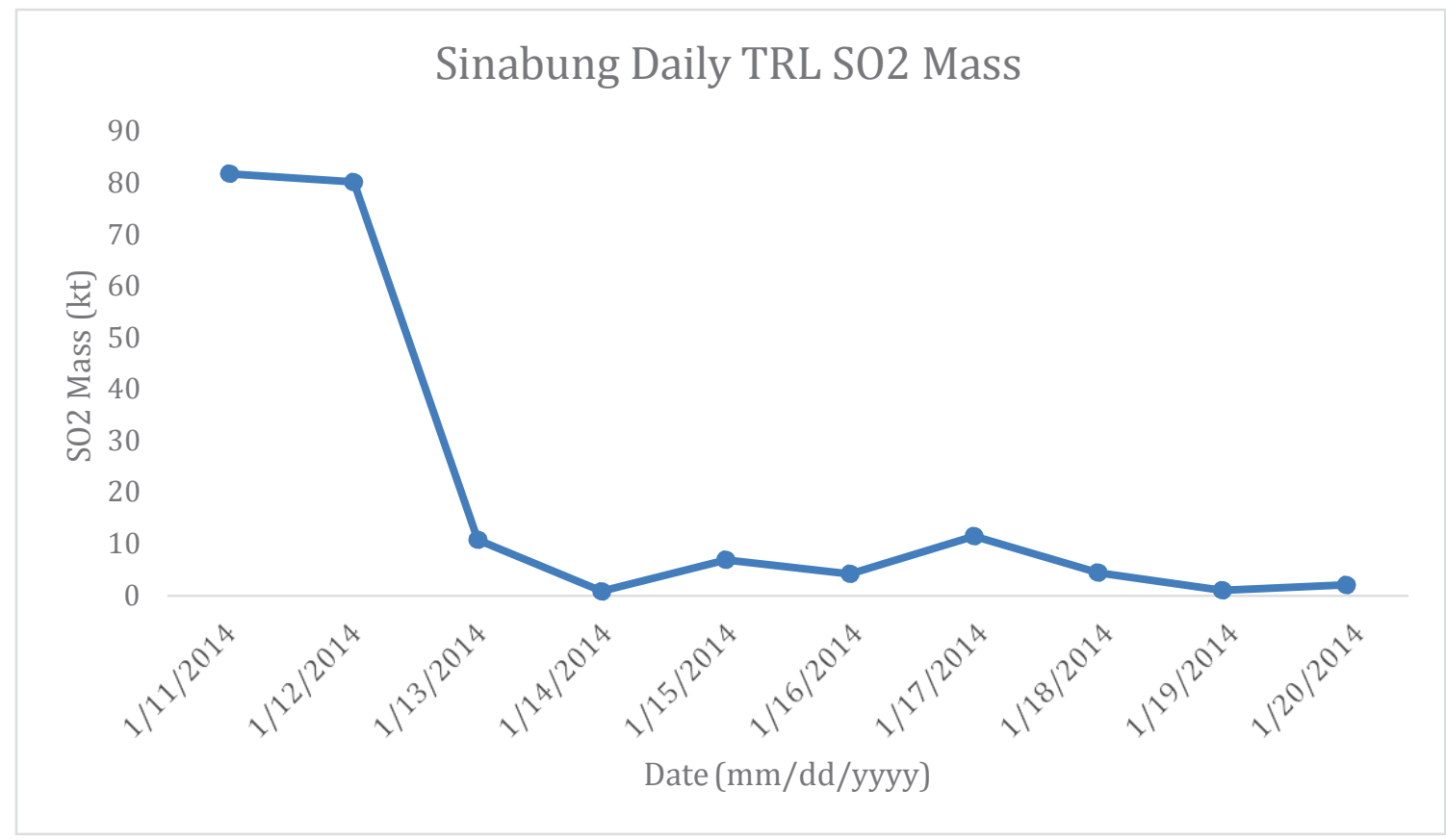

Figure 24. Daily $\mathrm{SO}_{2}$ masses generated from the Sinabung eruption during January 11 - 20, 2014. Data generated using OMIplot.

Figure 24 displays a trend of decreasing magnitude of $\mathrm{SO}_{2}$ masses from the start of the increased activity with a maximum of 82 kilotons (kt) on January 11, 2014. Accounting for all the $\mathrm{SO}_{2}$ emitted from Sinabung during this period equates to a total mass of $204 \mathrm{kt}$, which represents a significant contribution to the local atmosphere.

\subsection{2 $\mathrm{SO}_{2}$ Cloud Area}

The graph presented below illustrates the total area for the $\mathrm{SO}_{2}$ cloud produced during each individual explosion. Similar to the previous graph, each data point represents 
a new cloud generated from a subsequent explosion.

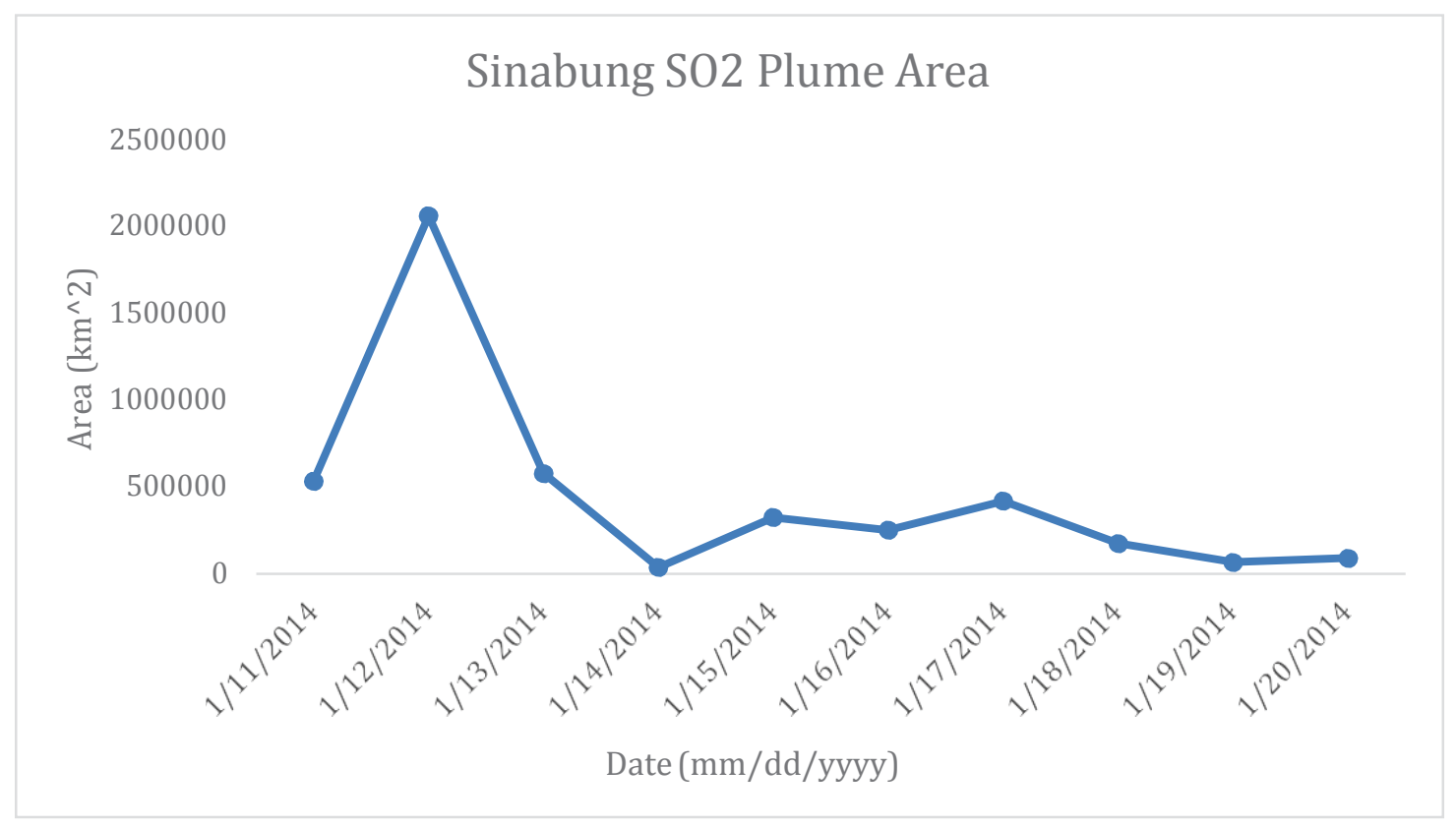

Figure 25. Areas of the $\mathrm{SO}_{2}$ clouds produced daily during the period of increased activity for Sinabung. Data acquired using OMIplot.

Figure 25 depicts a trend differing slightly from the $\mathrm{SO}_{2}$ masses. The cloud area for the second day of increased activity is substantially larger than during the first day with a maximum of 2,063,000 $\mathrm{km}^{2}$. The maximum area rapidly descends for the subsequent days and hovers around the same magnitude.

\subsection{3 $\mathrm{SO}_{2}$ Concentration}

The following figure demonstrates the concentrations of $\mathrm{SO}_{2}$ present in the individual explosive plumes. As with the previous two graphs, each data point represents the individual explosive events. 


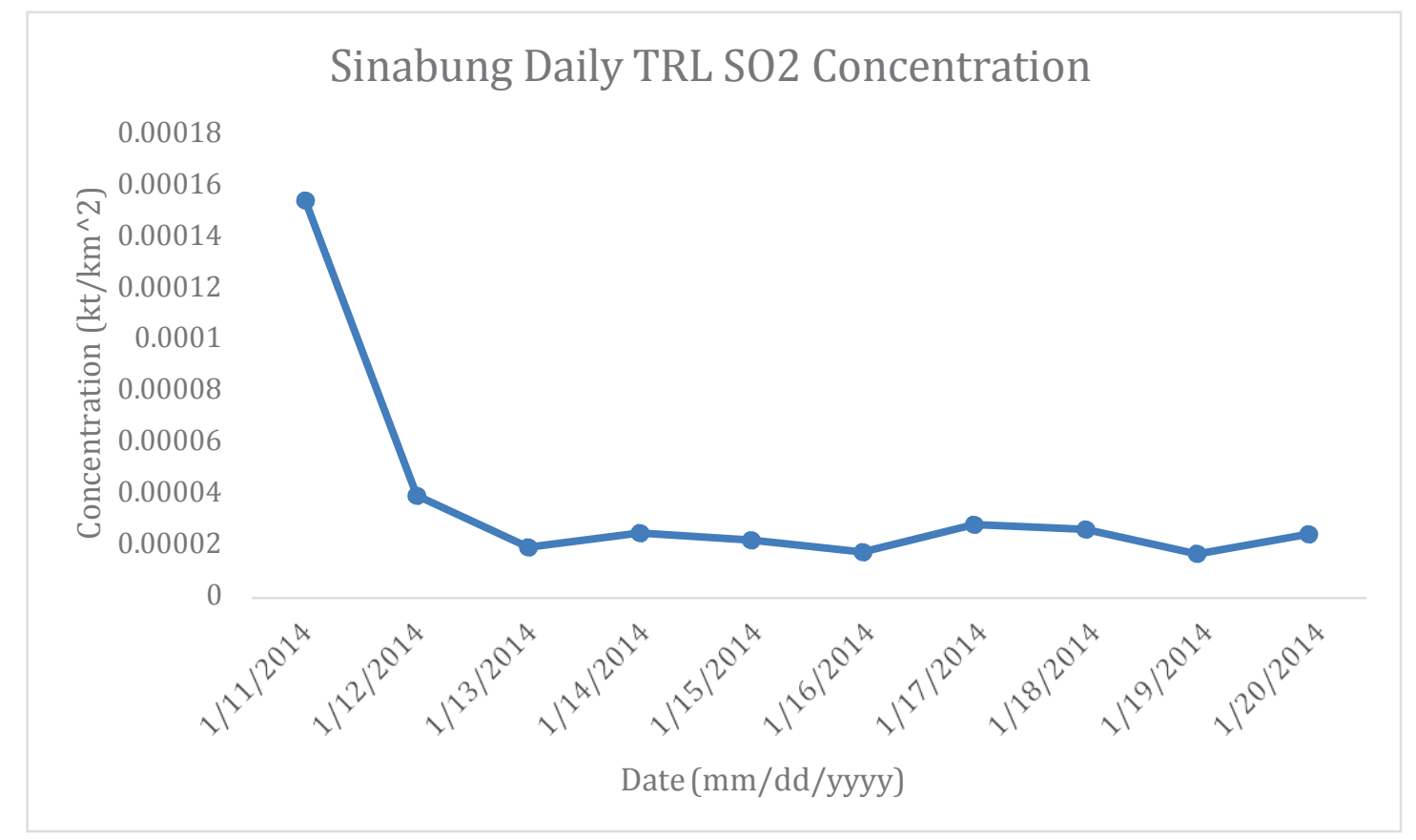

Figure 26. $\mathrm{SO}_{2}$ concentrations for individual explosions at Sinabung during January 2014. Data obtained using OMIplot.

Figure 26 displays a trend similar to that of the $\mathrm{SO}_{2}$ masses in which the maximum value occurs on the first day of increased activity equating to $0.00015 \mathrm{kt}^{*} \mathrm{~km}^{-2}$. The successive concentrations decrease in magnitude following the initial explosion.

\subsection{4 $\quad \mathrm{SO}_{2}$ Max and Mean Column Density}

The final figures for the Sinabung $\mathrm{SO}_{2}$ data elucidate the column densities of each individual explosion at Sinabung volcano. Along with every graph in Section 3.5, each data point is indicative of a single explosive event. 


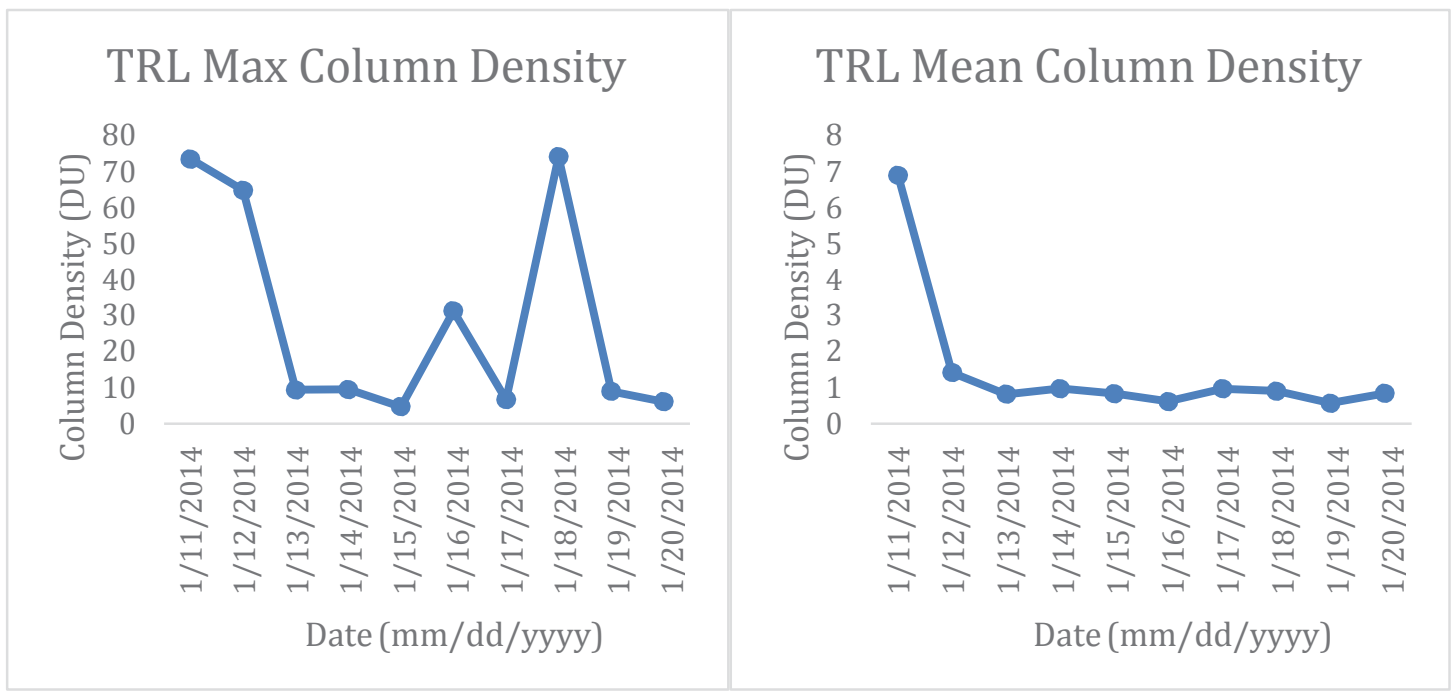

Figure 27. Column densities of $\mathrm{SO}_{2}$ for the Sinabung eruption in January 2014; Data processed using OMIplot.

The maximum column density for the Sinabung eruption has a sporadic trend throughout the eruption sequence. However, the mean column density of $\mathrm{SO}_{2}$ for the Sinabung eruption portrays the same trend as the $\mathrm{SO}_{2}$ mass and concentration plots.

\subsection{Comparison of the Single-channel Thermal Radiance with the NTI Method}

According to the principles of the NTI algorithm, by normalizing the difference between the $4-\mu \mathrm{m}$ and the $12-\mu \mathrm{m}$ radiance by the sum of the radiances emitted in the same wavelengths, the index obtained should be weighted to surfaces that emit substantial levels of radiance at $4-\mu \mathrm{m}$ (i.e. active lava) rather than the colder features emitting at a lower magnitude (i.e. cold clouds) (Wright et al. 2004). Based on this principle, the NTI algorithm should be able to identify more thermal anomalies than the mere utilization of the single $4-\mu \mathrm{m}$ radiance method even in the presence of other radiant features such as minor cloud cover. 


\section{- Single-Channel Thermal Radiance}

\begin{tabular}{|ccccccc|}
\hline $\begin{array}{c}\text { MDL }\left(\mathrm{Wm}^{-2} \mathrm{sr}\right. \\
\left.{ }^{1} \mathrm{~m}^{-1}\right)\end{array}$ & $\begin{array}{c}\text { Total \# } \\
\text { Values } \\
\text { "Flagged" }\end{array}$ & $\begin{array}{c}\text { \# True } \\
\text { Anomalies }\end{array}$ & $\begin{array}{c}\text { \# False } \\
\text { Alarms }\end{array}$ & $\begin{array}{c}\text { \# True } \\
\text { Anomalies } \\
\text { Missed }\end{array}$ & $\begin{array}{c}\text { False Alarm } \\
\text { Rate (\%) }\end{array}$ & $\begin{array}{c}\text { Missed True } \\
\text { Anomaly } \\
\text { Rate (\%) }\end{array}$ \\
\hline $\mathbf{2 . 4 0 E + 0 5}$ & 149 & 80 & 69 & 0 & $46.31 \%$ & $0.0 \%$ \\
\hline $4.00 E+05$ & 93 & 67 & 26 & 13 & $27.96 \%$ & $16.25 \%$ \\
\hline $4.50 E+05$ & 81 & 63 & 18 & 17 & $22.22 \%$ & $21.25 \%$ \\
\hline
\end{tabular}

- NTI

\begin{tabular}{|ccccccc|}
\hline $\begin{array}{c}\text { MDL }\left(\mathrm{Wm}^{-2} \mathrm{sr}\right. \\
\left.{ }^{1} \mathrm{~m}^{-1}\right)\end{array}$ & $\begin{array}{c}\text { Total \# } \\
\text { Values } \\
\text { "Flagged" }\end{array}$ & $\begin{array}{c}\text { \# True } \\
\text { Anomalies }\end{array}$ & $\begin{array}{c}\text { \# False } \\
\text { Alarms }\end{array}$ & $\begin{array}{c}\text { \# True } \\
\text { Anomalies } \\
\text { Missed }\end{array}$ & $\begin{array}{c}\text { False Alarm } \\
\text { Rate (\%) }\end{array}$ & $\begin{array}{c}\text { Missed True } \\
\text { Anomaly } \\
\text { Rate (\%) }\end{array}$ \\
\hline-0.92 & 163 & 91 & 72 & 0 & $44.17 \%$ & $0.0 \%$ \\
\hline-0.86 & 115 & 79 & 36 & 12 & $31.30 \%$ & $13.90 \%$ \\
\hline-0.84 & 70 & 59 & 11 & 17 & $15.71 \%$ & $35.16 \%$ \\
\hline
\end{tabular}

Figure 28. Comparison of Single-Channel and NTI methods for accurately detecting volcanic thermal anomalies.

According to the results listed above in Figure 28, this phenomenon is not evident, because the difference between the two methods seems negligible. The single-channel thermal radiance and the NTI algorithms both sampled the same amount of images (216) acquired by the MTSAT-2. Among the 216 images analyzed, the single-channel thermal radiance technique detects thermal anomalies in 52 images, while the NTI algorithm is capable of identifying hot-spots in 65 images. Also, among the 1944 pixels inspected, 141 pixels were determined to be anomalies using the single-channel thermal method opposed to 160 pixels using NTI, despite its lower average detected pixel/image (2.71 pixel/image for single-channel thermal and 2.51 pixel/image for NTI). The reason for the lower average detected pixel per image for the NTI algorithm is due to the fact that the normalization of the two wavelengths causes the output data to become more susceptible to features emitting large amounts of radiation at $4-\mu \mathrm{m}$. The source of the thermal anomalies at Sinabung must be relatively small in size or not very hot. The single-channel thermal radiance method can cause data to be influenced by the radiance emitted by other features such as clouds and warm land providing the illusion of a volcanic heat source. Both methods can be greatly influenced by external radiators, mostly solar reflection, but the NTI algorithm can 
expel small amounts of radiation contributed by non- volcanic heat sources (lower heat amounts).

\section{Single-Channel Thermal Radiance}

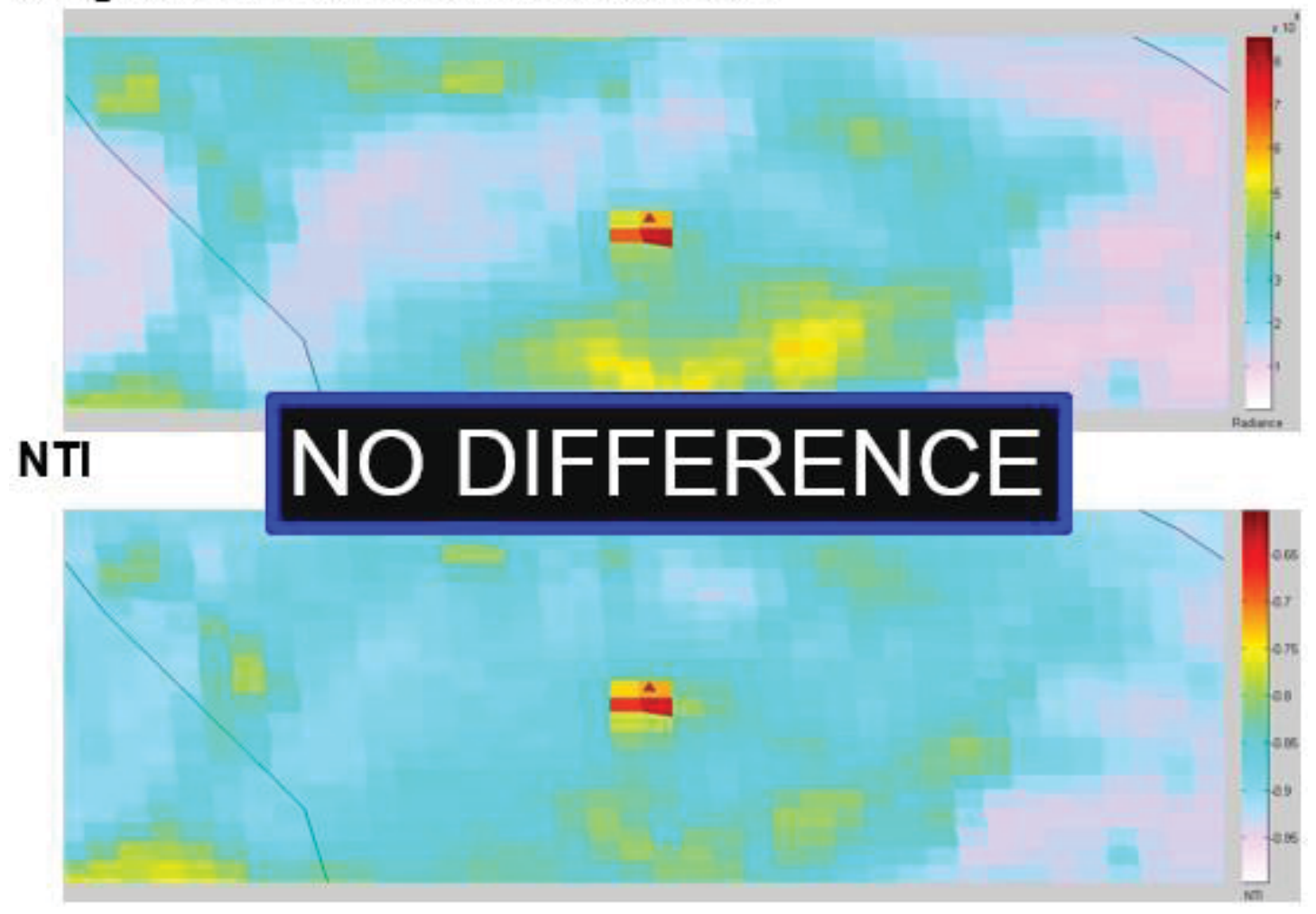

Figure 29. Visual inspection of the Single-Channel and NTI methods in identifying thermal anomalies displays no marked difference.

The single-channel thermal method is strongly affected by meteorological cloud cover. If there are even relatively thin clouds obscuring the volcanic heat source, the radiance from that heat source will become absorbed by the cloud and re-emitted at a much longer wavelength, which ultimately will afford a non-detection by utilizing the single $4-\mu \mathrm{m}$ band only. The NTI method can dampen the influence a thin cloud has upon the transmittance of the $4-\mu \mathrm{m}$ radiance through the atmosphere by incorporating the longer $12-\mu \mathrm{m}$ wavelength into the calculations.

The only marked difference between the two methods is the moment when they recorded their respective maximum values (0300 UTC on 16/01 for single-channel thermal and $0900 \mathrm{UTC}$ on 14/01 for NTI). This difference is due to the extreme solar reflection that occurred on January $14^{\text {th }}$. The NTI algorithm is not affected as severely 
as the single-channel thermal radiance yielding a more mild value for that time.

The efficiency of the NTI algorithm to better detect thermal anomalies is further obscured when defining a minimum threshold for the two methods. At the base minimum detection limits for both algorithms (i.e. when there are 0 missed true anomalies), the NTI method has a false alarm rate of $34.16 \%$, which is only slightly better than $35.78 \%$ with the single-channel technique. According to the results presented in this report, the two methods used are of the same competence when attempting to detect thermal anomalies. Setting a threshold that works for all images, obtained from all locations at all times is the major obstacle associated with automated hot spot detection algorithms. Fortunately, the proposed topic for this study is to define a suitable threshold for only the tropical region of Indonesia, so one threshold should be sufficient for the entire year and every volcano in the region.

\subsection{Spatial Comparison Method}

Despite the technique of increasing the MDL for either algorithm stated previously (single- channel or NTI), the false alarm rate is still unacceptably high for daytime monitoring hours. The data would be unreliable given the frequency of false detections. In order to obtain a reasonable level of false alarms of under $10 \%$, the sacrifice of missed weaker true thermal anomalies is too great. This option could prove hazardous for some communities in Indonesia that do not have a dependable early warning network established. 
There are certain automated algorithms developed and popularized by the wild fire community in the mid-1980s utilizing spatial comparison techniques to identify true thermal anomalies (Flasse and Ceccato 1996). The algorithms basically exploit the respective brightness temperature differences between an analyzed pixel and its surrounding pixels. These algorithms; however, were applied to data acquired by the AVHRR and GOES-VAS data (Harris 2013). The MTSAT-2 is calibrated differently than the AVHRR and GOES-VAS satellites. Being that the instrument (MTSAT-2) from which this data is obtained is different, combined with an unrelated specific region (i.e. Indonesia) for application, there are some key differences in the algorithm that is used in this study. The algorithm still requires the use of a fixed threshold (single-channel thermal or NTI) to flag potential anomalous pixels. The second step is depicted in Figure 30.
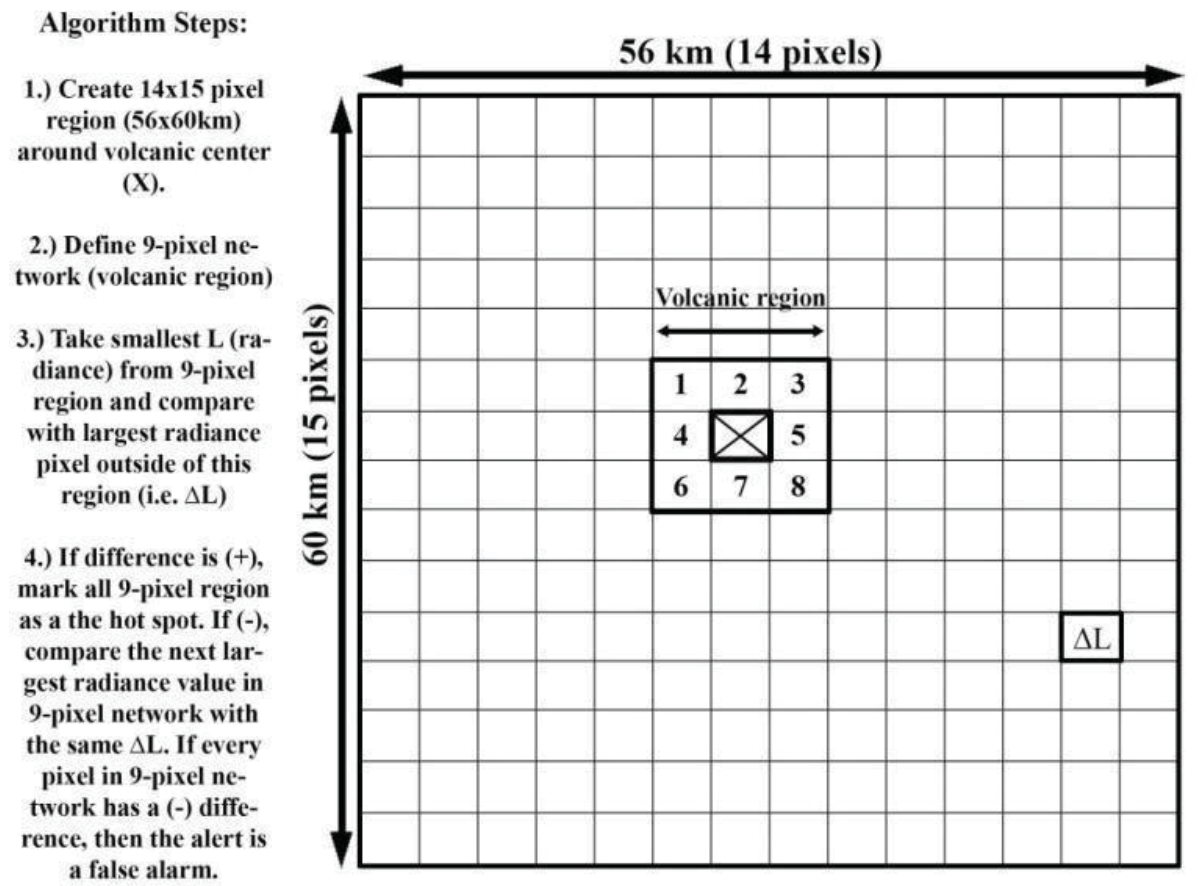

Figure 30. Sketch describing the spatial comparison method used as a second parameter to minimize false alarms. The $(X)$ is the location of the volcanic vent. The DL is the pixel outside of the volcanic region with the largest radiance value. It will always be the pixel used for comparison with the volcanic region.

The algorithm still requires the use of a fixed threshold (single-channel thermal or NTI) to flag potential anomalous pixels. The second step is depicted in Figure 32. The 56 x $60 \mathrm{~km}$ scale is resolved in a reasonably ad-hoc manner, while considering the principles stated above. At a $4 \mathrm{~km}$ pixel resolution, the $14 \mathrm{x} 15$ pixel 
grid is a total area of $3360 \mathrm{~km}^{2}$. On this relative scale, the solar radiation can still have large effects on the pixels. However, given that radiance is an extensive property in thermodynamics, meaning that it has additive properties, the solar radiation coupled with the radiation from the volcanic heat source should be the largest emitter at this localized scale. This area is large enough as to not be biased toward obtaining true detections, but the dimensions also allow for proper determination of false alarms.

True Anomaly

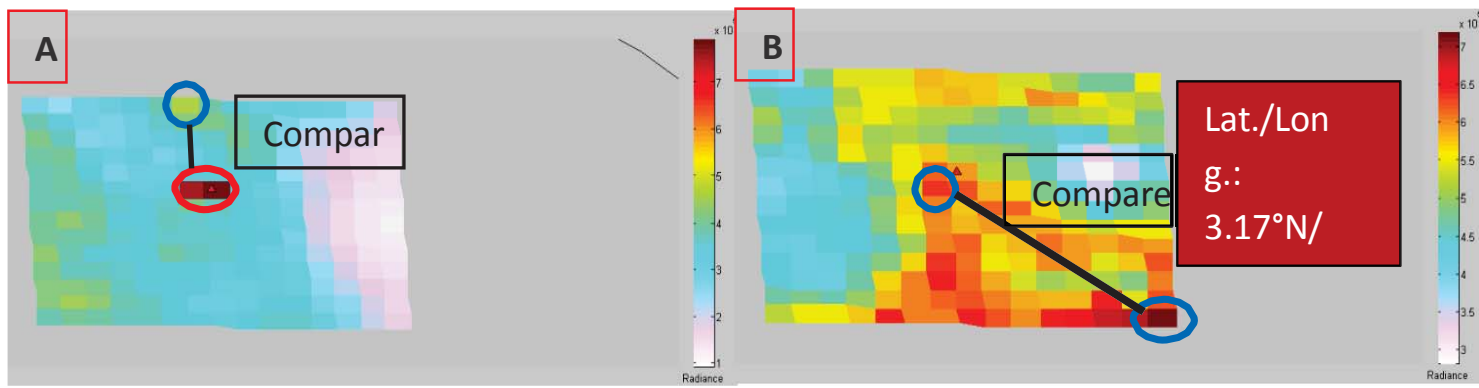

Figure 31. (A) True anomaly verified through spatial comparison method. There are 2 pixels corresponding to a thermal anomaly in this image. The 2 pixels in the center of the image are all greater than every individual pixel surrounding them. (B) A false detection verified using the spatial comparison method. At least one or more of the original nine pixels near the "triangle" (Sinabung location) emitted radiance higher than the minimum threshold. The spatial comparison method is able to verify the false alarm.

Table 13. Results using the spatial comparison method as a second parameter to the fixed threshold methods.

\section{Results for Spatial Comparison Method (for Daytime Only)}

\begin{tabular}{ccccccc}
\hline Method & $\begin{array}{c}\text { \#True } \\
\text { Anomalies } \\
\text { using 1 } \\
\text { Step }\end{array}$ & $\begin{array}{c}\text { \# False } \\
\text { Alarms } \\
\text { using 1 } \\
\text { Step }\end{array}$ & $\begin{array}{c}\text { False } \\
\text { Alarm } \\
\text { Rate }\end{array}$ & $\begin{array}{c}\text { \# True } \\
\text { Anomalies } \\
\text { Missed using } \\
\text { Spatial } \\
\text { Comparison }\end{array}$ & $\begin{array}{c}\text { False } \\
\text { Alarms } \\
\text { Rate } \\
\text { (\%) } \\
\text { with }\end{array}$ & $\begin{array}{c}\text { False Alarm } \\
\text { Rate(\%) } \\
\text { using } \\
\text { Spatial } \\
\text { Comparison }\end{array}$ \\
$\begin{array}{c}\text { Single- } \\
\text { channel } \\
\text { Thermal }\end{array}$ & 80 & 69 & $46.31 \%$ & 0 & 0 & $0.0 \%$ \\
NTI & 91 & 72 & $44.17 \%$ & 0 & 2 & $<1 \%$ \\
\hline
\end{tabular}

According to the results, using the two parameter method allows for the lowest threshold limit to be set meaning no true anomalies would be missed, while maintaining faith in the data provided by keeping an astronomically low false alarm rate. This detection has great success due to the limited spatial scale that the 
MTSAT-2 is applied in this study. All the volcanoes are located in the tropical region of Indonesia, so the parameters can all be set equally according to the climate and atmospheric conditions.

\subsection{Processes and Interpretation}

Interpreting the data outputted by the two thermal detection techniques (i.e. single-channel and NTI) presented in this report can imply different behaviors associated with active volcanism. Since the single-channel method provides information on direct radiance emitted from a single pixel, volcanic eruptive processes can be directly interpreted from an extensive time-series. The advantages offered by the high temporal resolution (1 full-disk scan/hour) of the MTSAT-2 are evident through the time- progressed interpretation of volcanic processes. Being able to analyze certain features that are short- lived and non-repetitive is a benefit gained by having a short revisit time not offered on high spatial resolution instruments.

\subsubsection{Single-channel Result Discussion}

The single-channel time-series clearly shows a trend with higher thermal radiance emitted during daytime hours versus nighttime. The increased radiance emitted during the day is due to the influence from solar reflection. Solar reflection emits a lot of radiance in the 4- $\mu \mathrm{m}$ wavelength region causing the sensor to record peak levels during daytime hours. The average detected pixel/image ( 2.71 pixels/image) for single-channel-thermal radiance can be interpreted effectively, especially given the 4$\mathrm{km}$ pixel resolution. This average can be construed as a localized volcanic event that does travels moderately far from the summit vent of Sinabung, respectively. Additionally, the average radiance per detected pixel $\left(4.92 \times 10^{5} \mathrm{Wm}^{-2} \mathrm{sr}^{-1} \mathrm{~m}^{-1}\right)$ is moderately higher than the average radiance per image for the entire segment $\left(3.02 \times 10^{5}\right.$ $\mathrm{Wm}^{-2} \mathrm{sr}^{-1} \mathrm{~m}^{-1}$ ). The $4.92 \times 10^{5} \mathrm{Wm}^{-2} \mathrm{sr}^{-1} \mathrm{~m}^{-1}$ would equate to a brightness temperature of about $302 \mathrm{~K}$, while the $3.02 \times 10^{5} \mathrm{Wm}^{-2} \mathrm{sr}^{-1} \mathrm{~m}^{-1}$ would equal a brightness temperature of about 292K. According to Harris et al. 1997a, sub-pixel hot-spots can be detected using AVHRR 3.7- $\mu \mathrm{m}$ data if the object causes the entire pixel to become elevated by $5^{\circ} \mathrm{C}$ relative to the surrounding pixels. This would require the object to have 
temperatures between 100 and $1000^{\circ} \mathrm{C}$ that cover only 0.7 to $0.0005 \%$ of the pixel. The spatial resolution available on the AVHRR is 1-km at nadir (Kidwell 1995). The rougher spatial resolution on the MTSAT-2 of 4-km signifies that a volcanic feature must either occupy a much greater surface area or be hotter to be labeled as a hot spot by the MTSAT-2. Since the hottest andesitic lavas (Sinabung-type) extrude at temperatures between $950-1200^{\circ} \mathrm{C}$ (Francis 1993), the first option is more probable. A difference of ultimately $10^{\circ} \mathrm{C}$ between the average brightness temperatures in images containing hot spots and not containing them signifies that the dominant volcanic processes during the Sinabung eruption are moderately large in scale.

It is known that the Sinabung eruption was dominated by an increase in activity of its summit lava dome between January 10 and 14. A lava dome is not consistent with a volcanic feature that is spatially expansive, but the pyroclastic flows they produce are. Additionally, the thermally anomalous pixels are very sporadic throughout the time period of increased activity. There is no discernable pattern among the pixels. If an extensive lava flow is causing the hot-spot, consistent detection every hour would be expected until the flow field cooled (Gouhier 2014). However, the MTSAT-2 is inundated by instances of occasional singular detections followed by no detections for several hours. It is likely that the MTSAT-2 only records thermal anomalies when the lava dome destabilizes and collapses to form hot pyroclastic flows and exposes the molten material beneath. When stable, a lava dome contains an outer crust of cooled material that encompasses molten material beneath. The cooled outer crust does not emit enough radiance in the $4-\mu \mathrm{m}$ region to be detected by the MTSAT-2. Of course cloud cover, associated ash plumes from pyroclastic flows, and the masking by solar reflectance can obscure the detection of a thermal anomaly. However, it is more likely that the scattered nature of detections for this eruption is due to the activity of the lava dome. For example, the largest radiance values recorded were during the period of the largest pyroclastic flows (January $13-16$ ). Similarly, the lower recorded radiance values toward the end of the time-series (January $18-20$ ) are imaged when the activity greatly decreased, but the lava dome still existed. Compiling a more extensive time-series of single-channel radiance behavior will allow for 
characteristic thermal data to be determined and compared against future observations.

\subsubsection{NTI Result Discussion}

The reasons for improved detection using the NTI algorithm compared with the single-channel thermal method have been described in Section 3.4. The NTI method is used solely as a "flagging" technique for identifying the presence of a thermal anomaly. The NTI histogram presented in Section 3.3.1 defines the range of values that hot-spots are detected using the MTSAT-2 at Sinabung. There are two main peaks positioned at -0.83 and -0.9 that are associated with diurnal and nocturnal monitoring cycles. The two vastly different peaks are further evidence for the need for different threshold considerations to be given for daytime and nighttime monitoring. Although the instruments are vastly different, comparison with the MODIS minimum detection limit of -0.82 would prove vastly insufficient for the monitoring of Indonesia with the MTSAT-2 instrument. Mostly all of the nighttime hot-spots would be missed given this conservative threshold. Understandably for MODIS, the minimum detection limit was set high to avoid false alarms near the equator; however, many true anomalies may be missed near the poles due to the lower ambient surface temperatures. Fortunately for this project, only one region in a tropical setting is analyzed, so atmospheric and climate considerations can be made together.

\subsubsection{Comparison of $\mathrm{SO}_{2}$ and Thermal Datasets Discussion}

The correlation between the thermal and sulfur dioxide data not only provides additional resources for the determination of the physical volcanic process occurring (i.e. lava dome activity), but it may also provide valuable insight into the mechanism of lava dome development. A valuable asset of remote sensing is the ability to interpolate physical processes from the data acquired when the conditions are too precarious for direct observations. The $\mathrm{OMI} \mathrm{UV} \mathrm{SO} 2$ results obtained during the increased activity of Sinabung volcano in mid-January 2014 clearly provide strong reinforcements for the interpretation of lava dome activity originally afforded by the MTSAT-2 infrared thermal data.

The $\mathrm{SO}_{2}$ mass, concentration, and mean column density time series all exhibit trends that are indicative of volcanic gas emissions at a lava dome. Lava domes are 
characterized by the emplacement of extremely viscous lava that has been previously degassed to allow for rigid structure to build-up within the crater of an active volcano. The absence of the volatile gas in the magma allows for the viscous material to form the lava dome structure without being ejected into the air, which is the result of rapid exsoltuion of the volatile species. The $\mathrm{SO}_{2}$ mass, concentration, and mean column density time series all demonstrate that the majority of the gas species (i.e. $\mathrm{SO}_{2}$ ) was expelled during the first 2 days of increased activity allowing for the subsequent diurnal build-up and collapse events. The masses and concentrations plateaued at minimal values for the remainder of the study period, which corresponds to lava dome activity. The area plot is significant to explain the concentration data. The area data for January 12, 2014 is considerably the largest merely because the gas plume had sufficient time to disperse prior to the overpass time of OMI.

Lava dome generation can be the product of either endogenous or exogenous growth. Endogenous dome growth is characterized by intrusive magma emplacement below the surface. Exogenous growth results from the extrusive emplacement of lava onto the surface of the dome. The mechanisms for lava dome emplacement (i.e. intrusive or extrusive) can have direct implications on the volcanic hazard produced (Kaneko et al. 2002). Periods of endogenous dome growth could allow for the increase in accumulation of magmatic gas beneath the surface resulting in more infrequent violent explosive events (Fink et al. 1990). In contrast, exogenous activity produces a steeper edifice that is highly unstable, which generates larger, more frequent block-and-ash flows due to the constant resupply of magma (Nakada 1996). It is assumed that the exogenous growth and subsequent lava dome collapse would exhibit more prolonged thermal radiance events due to the hot material being exposed directly during the build-up and subsequent collapse; whereas, the magma controlling dome growth in endogenous events is located beneath a layer of cooled outer crust. There have been reports of dome growth that fluctuates between endogenous and exogenous mechanisms during the same eruptive period (Fink and Griffiths 1998).

The accompaniment of the thermal with the $\mathrm{SO}_{2}$ data leads to the interpretation that the Sinabung lava dome generated through endogenous growth prior to collapse 
events during the first two days of the period of increased activity. The following days were subjected to a transition to exogenous lava dome growth as the primary mechanism leading to the volcanic hazards experienced in Indonesia during January 2014. The $\mathrm{SO}_{2}$ mass results show that the largest magnitude of gas occurred during January $11^{\text {th }}$ and $12^{\text {th }}$ (i.e. $\sim 80 \mathrm{kt}$ ). The release of this gas measured by OMI was due to destabilization events during this time. According to the PVMBG, increased activity had been occurring at Sinabung since December 2013. There are report of pyroclastic flows transpiring on January 4 and 5; however, MTSAT-2 data did not detect any thermal anomalies in January 2014 prior to the $11^{\text {th }}$. This short repose period of only 6 or 7 days could have allowed for the accumulation of the magmatic gas beneath the lava dome edifice. The lack of thermal data acquired by the MTSAT-2 indicates that the magma must have been covered by the cooled outer layer of the lava dome alluding to endogenous growth. The endogenous growth culminated in an explosive event on January $11^{\text {th }}$ that provided only 4 continuous hours of thermal data due to the hot material being exposed.

Once the majority of the sulfur dioxide gas was expelled on the January $11^{\text {th }}$ event, the magma supply was forced onto the surface through exogenous growth. The period from January $13^{\text {th }}-17^{\text {th }}$ of 2014 was subjected to highly decreased $\mathrm{SO}_{2}$ emissions (i.e. $\sim 8 \mathrm{kt}$ ), extended continuous thermal detection (i.e. average of 8 continuous hours), and extremely short-lived repose periods between lava dome collapses ( $<1$ day). The combination of these three parameters suggest to lava dome growth through an exogenous mechanism. The remaining days exhibit only 5 sporadic hours of thermal imagery and almost no $\mathrm{SO}_{2}$ emissions indicating a transition back to endogenous dome growth. 


\section{Chapter 4 Volcanic Ash and $\mathrm{SO}_{2}$ Case Studies: February 2014 Kelut Eruption}

\subsection{Identifying Volcanic Clouds}

As described in Chapter 2, any pixel exhibiting a Brightness Temperature Difference (BTD) value that is less than 0 is regarded as containing ash particles. This task can be complicated by the issues related to the BTD method previously discussed in Section 2.4.2.1. Usually, pure and small radii (1-30 $\mu \mathrm{m})$ ash particles are represented by the most negative BTD values. When the BTD values are in the range from -0.5 to +0.5 , the BTD value can be convoluted by the presence of water/ash or ice/ash aggregates. It becomes more difficult to determine a true ash cloud even by a human analyst. The need for alternative sources of information such as geolocation, visible proof, VAAC reports, and ground- based observations should always be utilized to substantiate satellite imagery of an eruption cloud.

\subsection{Scientific Findings for $\mathrm{Ash}$ and $\mathrm{SO}_{2}$ in Volcanic Clouds Using} Satellite Data

Utilizing various spectroscopic satellite data to understand and interpret the dynamics and implications of an evolving eruptive plume have been studied for decades. (Rose et al. 2000) have compiled a comprehensive overview of studies considering ash and $\mathrm{SO}_{2}$ dynamics in volcanic clouds which include the following:

- $\mathrm{SO}_{2}$ masses erupted from convergent plate boundary volcanoes are excessive and variable

- $\mathrm{SO}_{2}$ masses calculated during their second day of atmospheric residence exhibit larger magnitudes than the first day suggesting either $\mathrm{H}_{2} \mathrm{~S}$ oxidation to $\mathrm{SO}_{2}$ (Bluth et al. 1995) or the subsequent release of $\mathrm{SO}_{2}$ from the sequestration by ice particles (Rose et al. 1995)

- $\mathrm{SO}_{2}$ conversion to sulfate aerosol $\left(\mathrm{H}_{2} \mathrm{SO}_{4}\right)$ in the stratosphere has an e-folding time of $\sim 120$ days, while the e-folding time for $\mathrm{SO}_{2}$ removal from the stratosphere is only 35 days due to a multiple reaction series leading to the sulfate aerosol that cannot be imaged by satellites. Volcanic clouds that barely reach the stratosphere diminish the $\mathrm{SO}_{2}$ removal e-folding time to only a few days, which drastically 
depletes the potential for aerosol build-up in the stratosphere

- Fine ash imaged in volcanic clouds after 10 hours represent a small fraction of ash erupted ( 20\%) probably due to aggregation processes

- Self-removal processes cause fine ash to deplete faster in larger eruptions

- Ice participation in volcanic clouds for fallout and aggregation is evident

- Separation of the $\mathrm{SO}_{2}$ and ash portion has been reported in many volcanic clouds. These two parts can become vertically distributed which causes wind shear to separate them laterally as well.

\subsection{Volcanology of the Kelut Eruption}

Preliminary judgment of the erupted ash suggests that the explosion was a magmatic event, triggered by a new batch of fresh magma that seems to have risen very quickly to the surface. There were only 2 hours between shallow earthquake warnings and the explosion. The information is provided by the CVGHM in Indonesia and obtained through the VolcanoDiscovery.com portal.

Table 14. Table explaining some of the eruption statistics from the February 13, 2014 Kelut eruption in Indonesia.

\begin{tabular}{|c|c|}
\hline \multicolumn{2}{|c|}{ February 13, 2014 Kelut Eruption Statistics } \\
\hline Volume of Eruption & $120-140{\text { million } \mathrm{m}^{3} \text { tephra }}^{\mid 2}$ \\
\hline Volcanic Explosivity Index & 4 \\
\hline Noise Level & $\begin{array}{c}\text { Created one of the largest volcanic- } \\
\text { related infrasound waves }\end{array}$ \\
\hline Total Amount of Data Collected & 24 continuous hours \\
\hline Height & Section reached $26 \mathrm{~km} ;$ \\
& Main umbrella region $\sim 18 \mathrm{~km}$ \\
\hline
\end{tabular}

\subsubsection{Kelut $\mathrm{SO}_{2}$ Plume Evolution}

The Kelut eruption on February 13, 2014 produced a stratospheric sulfur dioxide 
eruption plume that migrated through the atmosphere guided by regional wind shear velocities and directions. Local meteorological systems affected the $\mathrm{SO}_{2}$ cloud assisting in the explanation of its migration as well as its degradation. There was no reported precipitation that occurred during the study period (NOAA 2015). The magnitude of the eruption was such that daily inspections of the $\mathrm{SO}_{2}$ plume by OMI could be recorded for 14 consecutive days (i.e. Feb. 14 - Feb. 27, 2014). While the OMI STL files were used for the calculations of the various $\mathrm{SO}_{2}$ parameters, since accurate height information is necessary for these calculations, the TRL images are depicted below to aid in visual observations of the Kelut plume. The following OMI images describe the chronological evolution of the Kelut $\mathrm{SO}_{2}$ plume below:

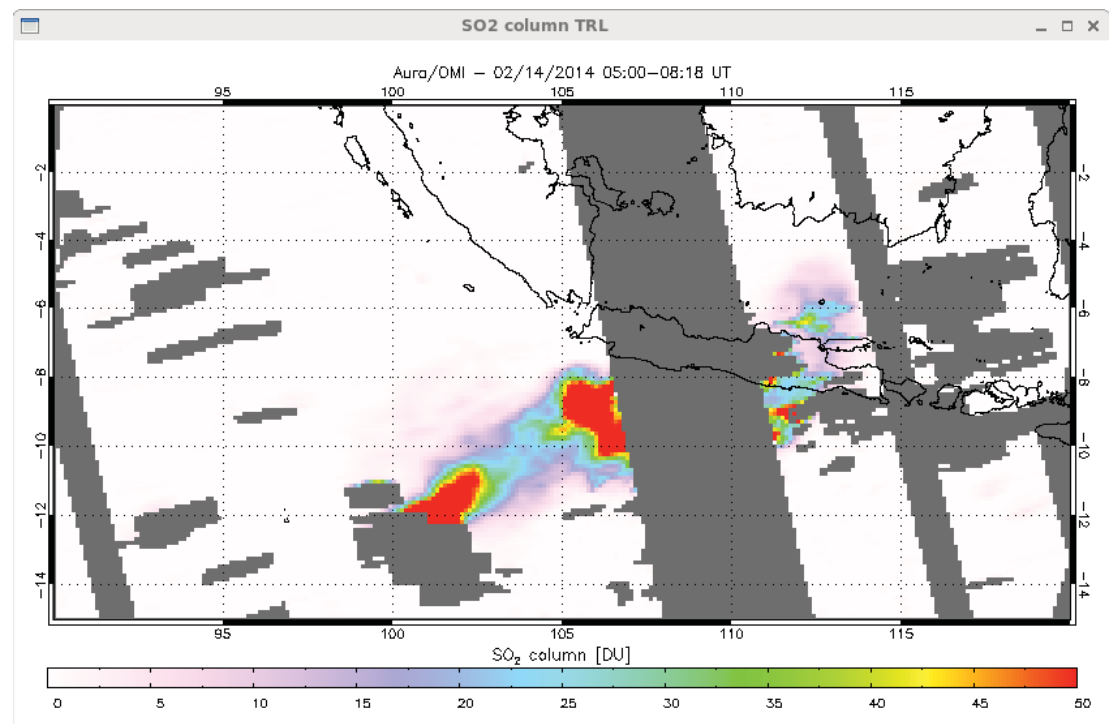

Figure 32. First OMI SO 2 column density image of the Kelut plume on February 14, 2014. OMIPLOT software was used to generate this image. The overpass time of the Aura platform was between 0500 and 0818 UTC.

- February 14 - OMI first detected the Kelut $\mathrm{SO}_{2}$ plume around 0600 UTC on February 14, 2014, which is about 14 hours after the start of the eruption. The plume had already migrated a considerable distance (about $1460 \mathrm{~km}$ ) in the southwest direction by this time. Traveling this distance in less than a day corresponds to a migration speed of about $16 \mathrm{~m} \mathrm{~s}^{-1}$. The $\mathrm{SO}_{2}$ was still highly concentrated with mass concentrations peaking over 50 Dobson Units (DU) in the plume interior. As seen in Figure 35, some separation of the leading edge of the cloud is apparent. Also, the 
ROW anomaly can be clearly discerned as affecting various $\mathrm{SO}_{2}$ calculations.

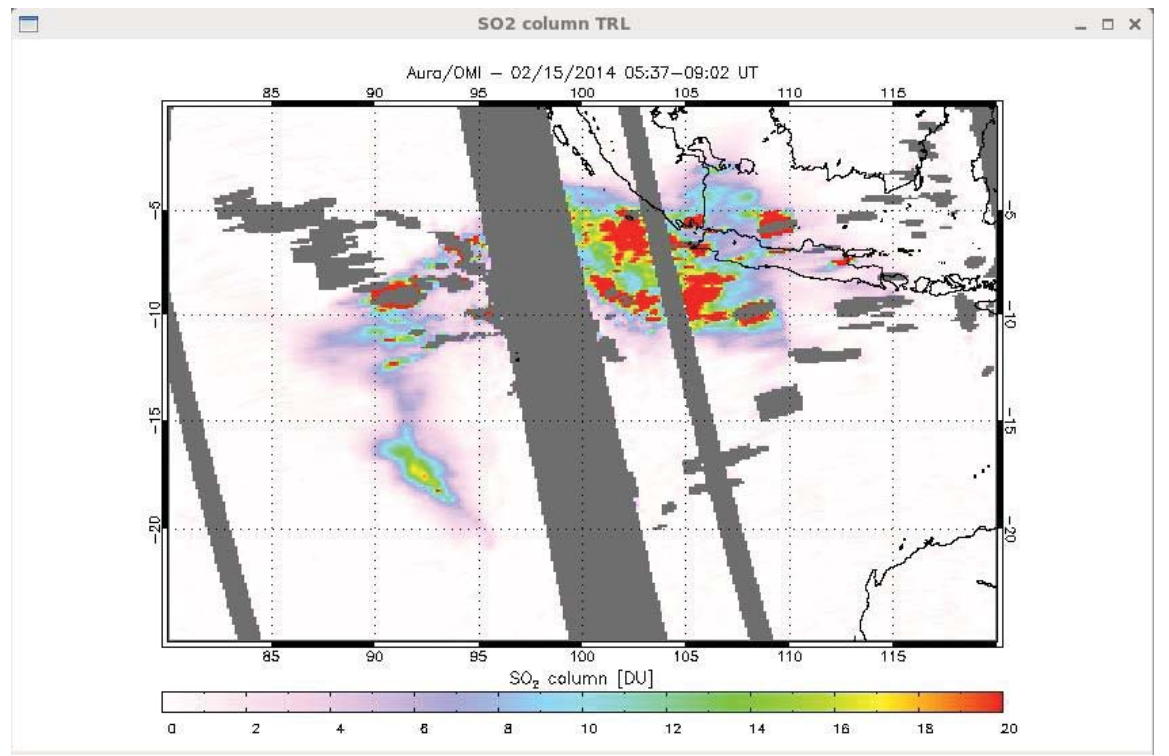

Figure 33. Second OMI image of the Kelut $\mathrm{SO}_{2}$ eruption plume recorded on February 15, 2014. The overpass time used to acquire this image is from 0537 to 0902 UTC.

- February 15 - The $\mathrm{SO}_{2}$ plume continues to migrate at the speed and direction of the prevailing wind shears to a distance of about $2420 \mathrm{~km}$ from its source. Traveling this distance in about 2 days corresponds to an average wind speed of about $11 \mathrm{~m}^{*} \mathrm{~s}^{-}$ ${ }^{1}$. Regional meteorological systems are prevalent in evidenced by the shape the $\mathrm{SO}_{2}$ cloud is assuming. The plume entered a high-pressure system depicted by the counterclockwise rotation of the leading edge of the cloud, which is the characteristic rotational direction of high-pressure systems in the southern hemisphere. High-pressure systems force cold air masses to sink, which generates clear, sunny weather. The presence of a high-pressure system correlates with the lack of precipitation recorded by the NOAA instruments in the Indonesian area. 


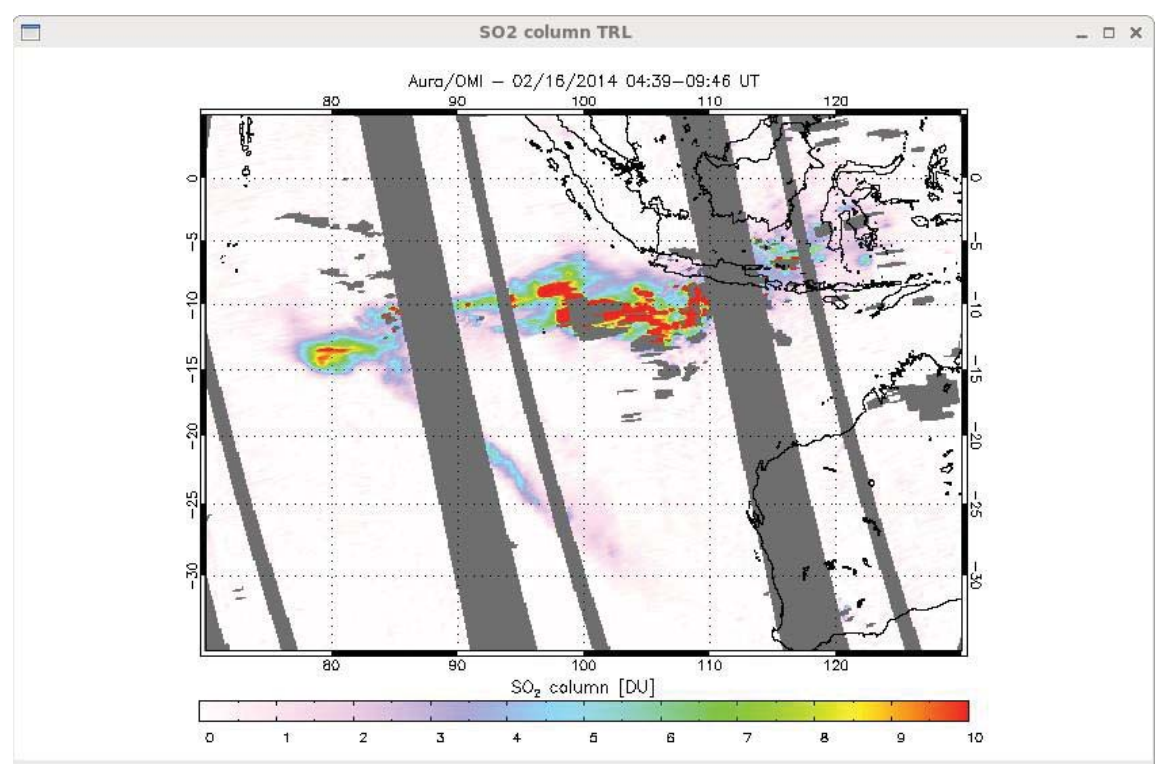

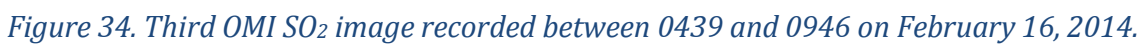

- February 16 - The high-pressure system forced the leading edge of the Kelut $\mathrm{SO}_{2}$ plume to descend allowing for a different wind shear to control its migration. The front lobe is seen in traveling in the southeast direction toward Australia at an altitude lower than the main body of the plume. The main body continues to migrate in the WSW direction. The total distance that the plume has traveled is about 3880 $\mathrm{km}$ corresponding to an average wind speed of about $17 \mathrm{~m}^{*} \mathrm{~s}^{-1}$ from the previous day.

- February 17-24 - The diverging lobe of the $\mathrm{SO}_{2}$ plume continued in the $\mathrm{SE}$ direction reaching the southwestern tip of Australia by February $17^{\text {th }}$. The main body of the plume continued to migrate in an almost westerly direction toward Africa. The main body of the $\mathrm{SO}_{2}$ plume reached Madagascar by February $20^{\text {th }}$, corresponding to a distance traveled of about $7270 \mathrm{~km}$ and an average wind speed of about $7 \mathrm{~m} \mathrm{~s}^{-1}$ from the previous day. The main body was dissected into sections of increased $\mathrm{SO}_{2}$ concentrations with the largest pockets residing at the leading edge and near the source. The dispersion of the divergent lobe completely dissipated the $\mathrm{SO}_{2}$ signal making OMI unable to detect it by February $22^{\text {nd }}$. An interesting observation is that this lobe never dissected from the main body of the plume. 

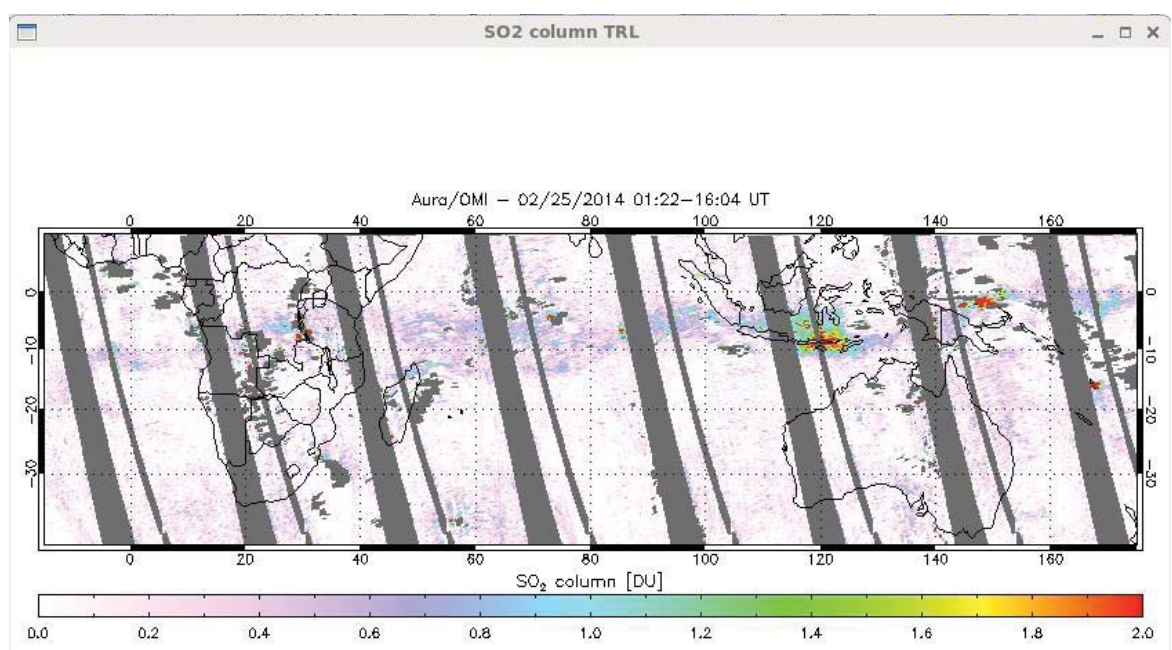

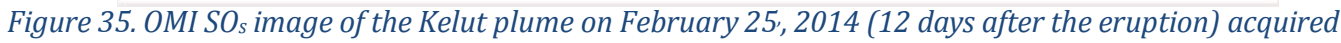
between 0122 and 1604 UTC.

- February 25-27 - The Kelut $\mathrm{SO}_{2}$ plume reached its furthest detectable extent on February $25^{\text {th }}$ entering the Atlantic Ocean off of the western coast of the African continent. The furthest distance traveled from the Kelut volcanic source is approximately $14,870 \mathrm{~km}$ corresponding to an average wind speed of about $27 \mathrm{~m} \mathrm{~s}^{-}$ ${ }^{1}$ from the previous day and $14 \mathrm{~m} \mathrm{~s}^{-1}$ for all the days since the eruption. Sulfur dioxide continued to be detectable by the OMI sensor until February 27, 2014 when the $\mathrm{SO}_{2}$ in the plume either dispersed below detectable signal for OMI or was removed from the atmosphere by depositional processes.

\subsection{Results for Kelut Ash Plume Parameters}

\subsubsection{Area and Maximum BTD}



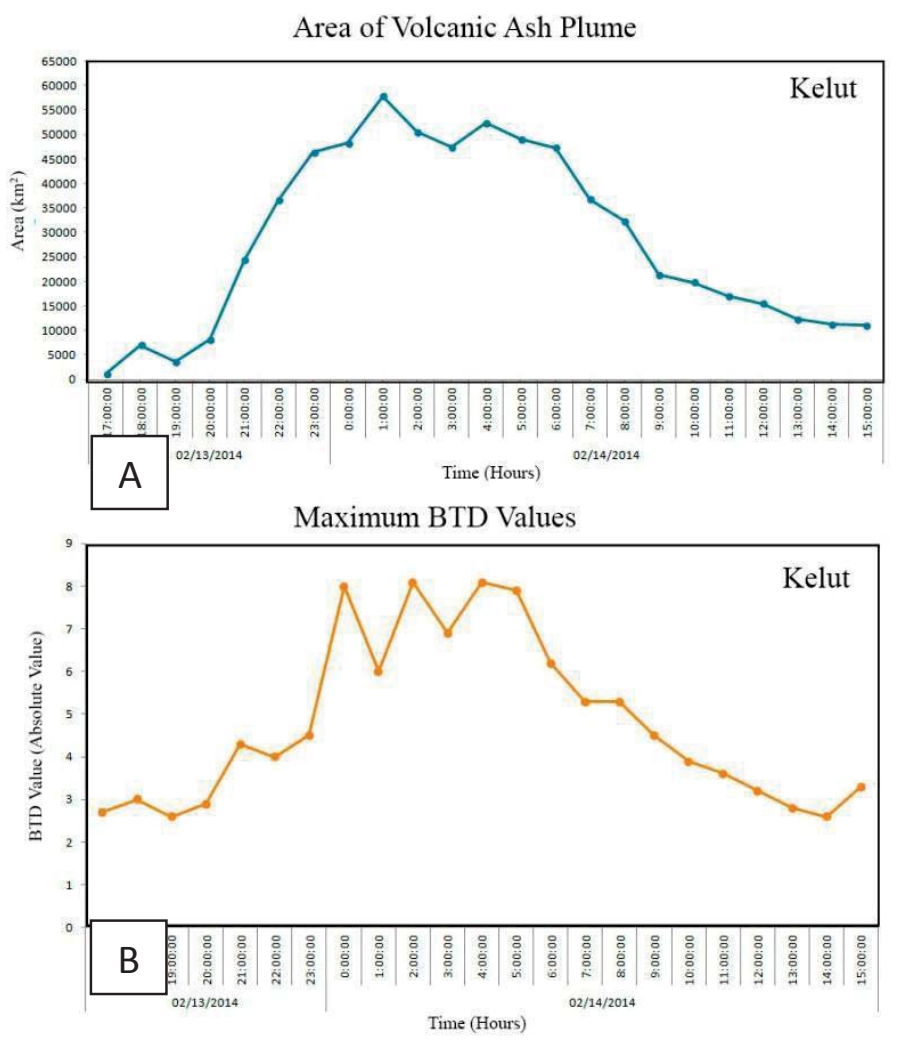

Figure 36. (A) The evolution of the area with time for the February 2014 Kelut ash cloud. Notice the steep incline in the area followed by a subsequent plateau between 2300 UTC on Feb. 13 and 0600 UTC on the 14 ${ }^{\text {th }}$. (B) Graph representing the maximum BTD value for an individual pixel in the Kelut ash plume. Each value corresponds to a single image taken every hour from the start of the eruption. Presented in absolute value.

A significant parameter of a volcanic cloud that has many implications on the surrounding populous is the area. The area is affected by the transport, dispersion and subsequent dilution of the ash cloud. The evolution of two-dimensional area and the accompanying maximum BTD value (in absolute value) of the Kelut ash cloud is presented in Figure 36 A\&B.

An area of $1184 \mathrm{~km}^{2}$ defines the beginning of the eruption. The two-dimensional area continues to increase until a peak of $57,824 \mathrm{~km}^{2}$ at 0100 UTC on February 14, 2014, about 9 hours after the eruption commenced. The area plateaus for a period of about 7 hours, and then declines gradually until it levels out around 0900 UTC on February 14, 2014 with an area of about 21,328 $\mathrm{km}^{2}$. Data after about 1500 UTC is unreliable because the ash plume became too dispersed for definitive detection.

A parameter that can help to create a perception of the processes occurring in the Kelut ash plume is the maximum BTD per image. The maximum BTD value 
during the start of the eruption is 2.7. The maximum BTD value dramatically increases to 8 at 0000 UTC on February 14, 8 hours after the start of the eruption. The maximum BTD values then plateau, along with the area, for the subsequent 5 hours before they gradually decrease throughout the remainder of the ash cloud tracking.

\subsubsection{Area Ash vs. Water}

As discussed previously, the reason for the effectiveness of the BTD method is that the main constituent of meteorological clouds, water, has opposite absorption and scattering properties than ash. Volatile-rich magmas contain a substantial source of $\mathrm{H}_{2} \mathrm{O}$ being that water is one of the major eruptive gases. The Kelut eruption was caused by an input of volatile-rich magma. The area of water displays a similar trend to that of the area of ash; however, the evolution of the water occurs prior to that of the ash trend. For instance, the area of the water, shown in Figure 37, experiences a plateau around 1900 UTC, while the area of ash experienced a similar plateau but not until 2300 UTC, 4 hours later.

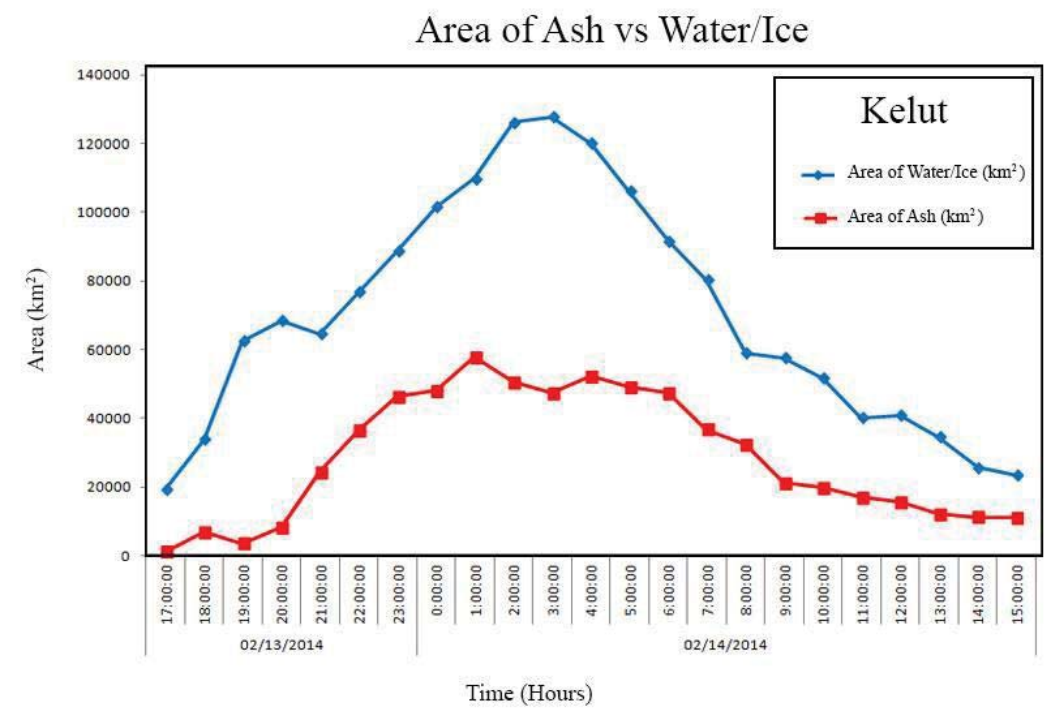

Figure 37. Area of ash versus the area of water/ice evolving progressively with time in the Kelut volcanic cloud.

\subsubsection{Concentration}

It is assumed that the magnitude of the brightness temperature difference is 
proportional to the amount of ash (negative) or water $(+)$ residing in the volcanic cloud.

$$
\begin{gathered}
\text { BTD } \alpha \mathrm{ND}^{\mathrm{n}} \sim \text { concentration } \\
\text { BTD }_{\text {MAX } \sim \text { Maximum Concentration }}
\end{gathered}
$$

where $N$ refers to the number of particles present, $D$ refers to the diameter of each particle and $n$ is a function defined by the Mie scattering law. The simple Mie scattering expression indicates that the diameter of an ash particle can have significant variations on the BTD value. Therefore, a slightly larger ash particle diameter will lead to a large increase in the BTD value.

A noteworthy, complimentary parameter to that of the ash cloud is the concentration of the volcanic cloud $\left(\mathrm{BTD} / \mathrm{km}^{2}=\Sigma \mathrm{BTD} /\right.$ Total Area). The concentration can be assumed on the basis that the magnitude of BTD condensed in the ash cloud is indicative of the amount of ash present. Therefore, the sum of the negative BTD values dictates the quantity of ash. The first image processed at the beginning of the eruption possesses a concentration of $0.0411 \mathrm{BTD} / \mathrm{km}^{2}$ of ash. The concentration continues to augment until its peak value of $0.1214 \mathrm{BTD} / \mathrm{km}^{2}$ of ash at 0300 UTC. It is interesting to mention that the ash concentration peaks two hours after the maximum ash area. Figure 38 represents the progression of water and ash concentration with time. 


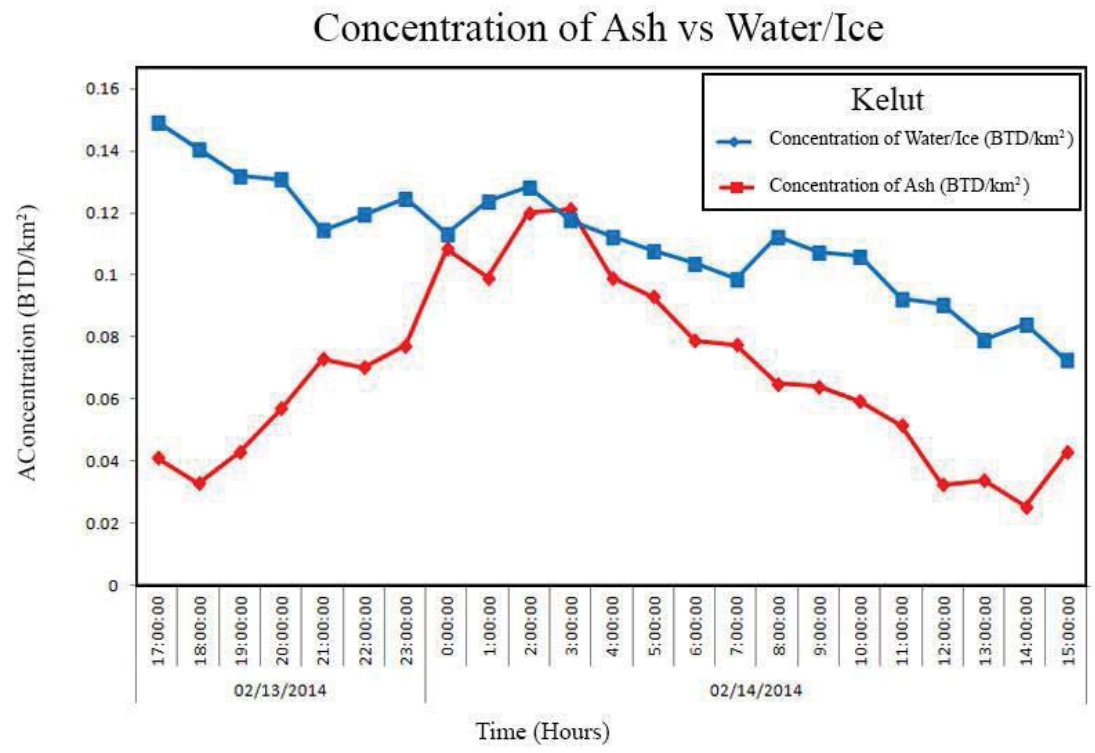

Figure 38. Graph of ash BTD $/ \mathrm{km}^{2}$ versus water/ice BTD $/ \mathrm{km}^{2}$.

The development of the water/ice concentration displays a markedly different trend than the ash concentration. For instance, the maximum concentration of water is $0.15 \mathrm{BTD} / \mathrm{km}^{2}$ at the start of the eruption on February 13, while the ash continued to increase in concentration for the next 10 hours until 0300 UTC on February 14 where it obtained a maximum value of $0.12 \mathrm{BTD} / \mathrm{km}^{2}$. Zone of High Reflectivity

An interesting phenomenon occurred dynamically within the migrating ash cloud at 0300 UTC on February 14, 2014. A measurement of the radiance being reflected by the ash cloud is obtained using solely the 4- $\mu \mathrm{m}$ wavelength band on the MTSAT-2 satellite. Three images were processed including:

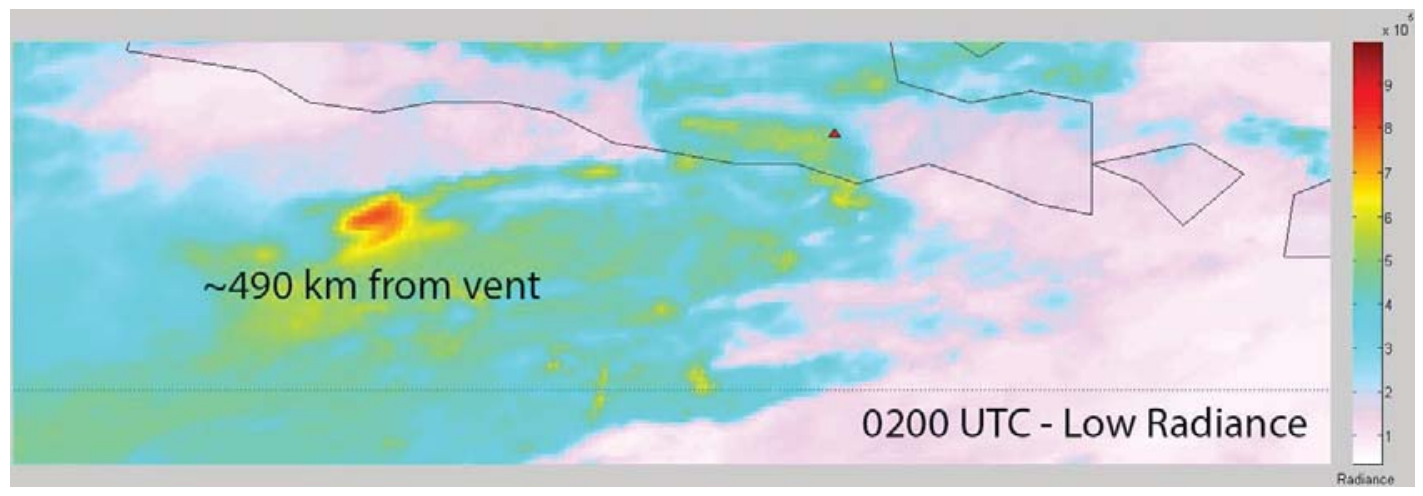



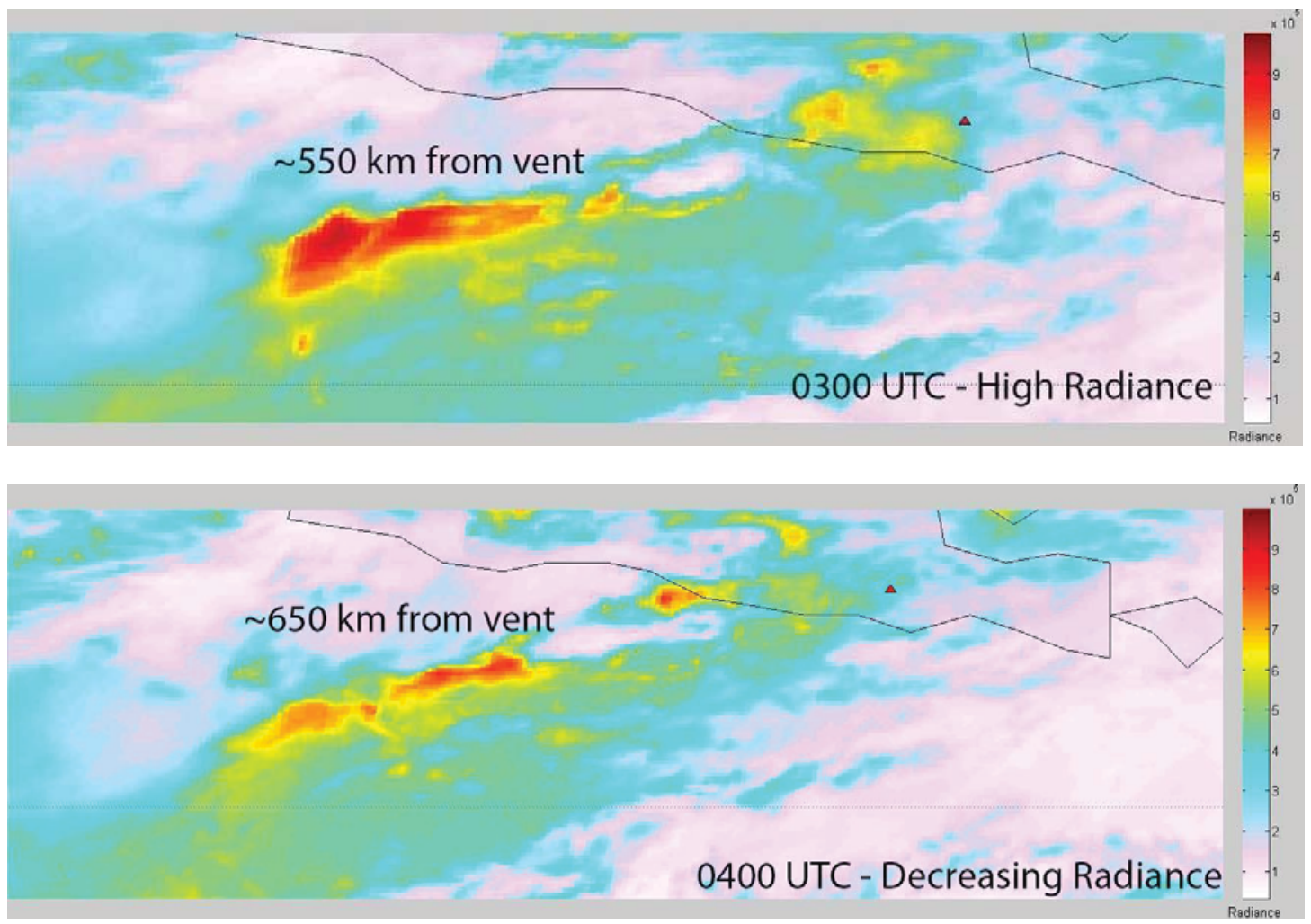

Figure 39. Three consecutive images (0200, 0300, 0400 UTC) showing the reflected radiance values in the 4- $\mu$ m wavelength region for the migrating Kelut ash cloud. All three radiance scales are equivalent (E10+5). The only difference in the images are the times that they were recorded. MATLAB processed MTSAT-2 images.

The three images display varying reflectance values as a function of the dynamic processes occurring in the volcanic cloud. According to Figure 39, all of the radiance scales are the same for the three images. The data at 0200 UTC indicates very little reflectance coming from the volcanic cloud. The image at 0300 UTC elucidates maximum reflectance (i.e. $>9 \mathrm{E} 10^{5} \mathrm{Wm}^{-2} \mathrm{sr}^{-1} \mathrm{~m}^{-1}$ ) occurring throughout the cloud with the highest reflectance occurring towards the interior. The reflectance is displayed rapidly dissipating just one hour later at $0400 \mathrm{UTC}$ as the cloud is seen with much lower reflectance values that are spatially inhibited.

\subsubsection{Summation of BTD}

As conferred previously, the magnitude of the BTD determines the amount of ash present in a given image. The BTD associated with ash is presented in its absolute value in order to encourage simpler interpretation. The trend of the sum of BTD demonstrates a simple Bell-shaped curve with a maximum value of 6076.7 BTD at 0200 on February 14. 


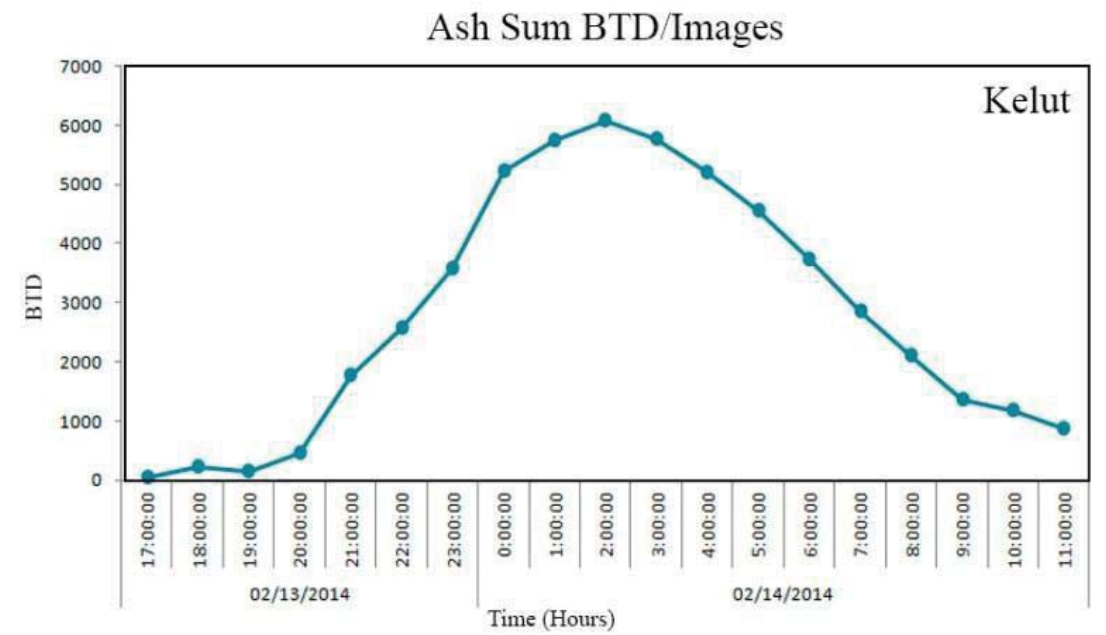

Figure 40. The evolution of the sum of (-) BTD values with time for the Kelut eruptive cloud. The numbers displayed are absolute values. The maximum sum of BTD during this Kelut eruption occurred between the maximum area and concentration of ash at 0200 UTC. Just as stated in Section 4.4.3 regarding the Mie scattering expression, the diameter of the ash particles greatly affect the magnitude of the BTD values. Therefore, the sum of BTD values can be regarded as the maximum diameter of the ash constituents.

\subsection{Results for Kelut $\mathrm{SO}_{2}$ Cloud Parameters}

The following results pertain to the Kelut volcanic cloud $\mathrm{SO}_{2}$ component obtained by OMI. They will serve to compare, validate, and expand upon the volcanic ash data acquired by the MTSAT-2 instrument. The data has been processed with the same software (i.e. OMIplot) and techniques used for the Sinabung $\mathrm{SO}_{2}$ data. It is very clear through various sources (i.e. satellite data, Volcanic Ash Advisory Centers, local observatories, etc.) that the Kelut volcanic plume pierced the stratosphere; therefore, all of the data for $\mathrm{SO}_{2}$ has been processed using the $\mathrm{STL}(15 \mathrm{~km})$ parameter.

\subsection{1 $\mathrm{SO}_{2}$ Mass Burden}

Figure 41 represents the time-series for the evolution of the $\mathrm{SO}_{2}$ mass present in the Kelut volcanic cloud. Each data point is indicative of the same eruptive plume and represents the development of the constituent. 


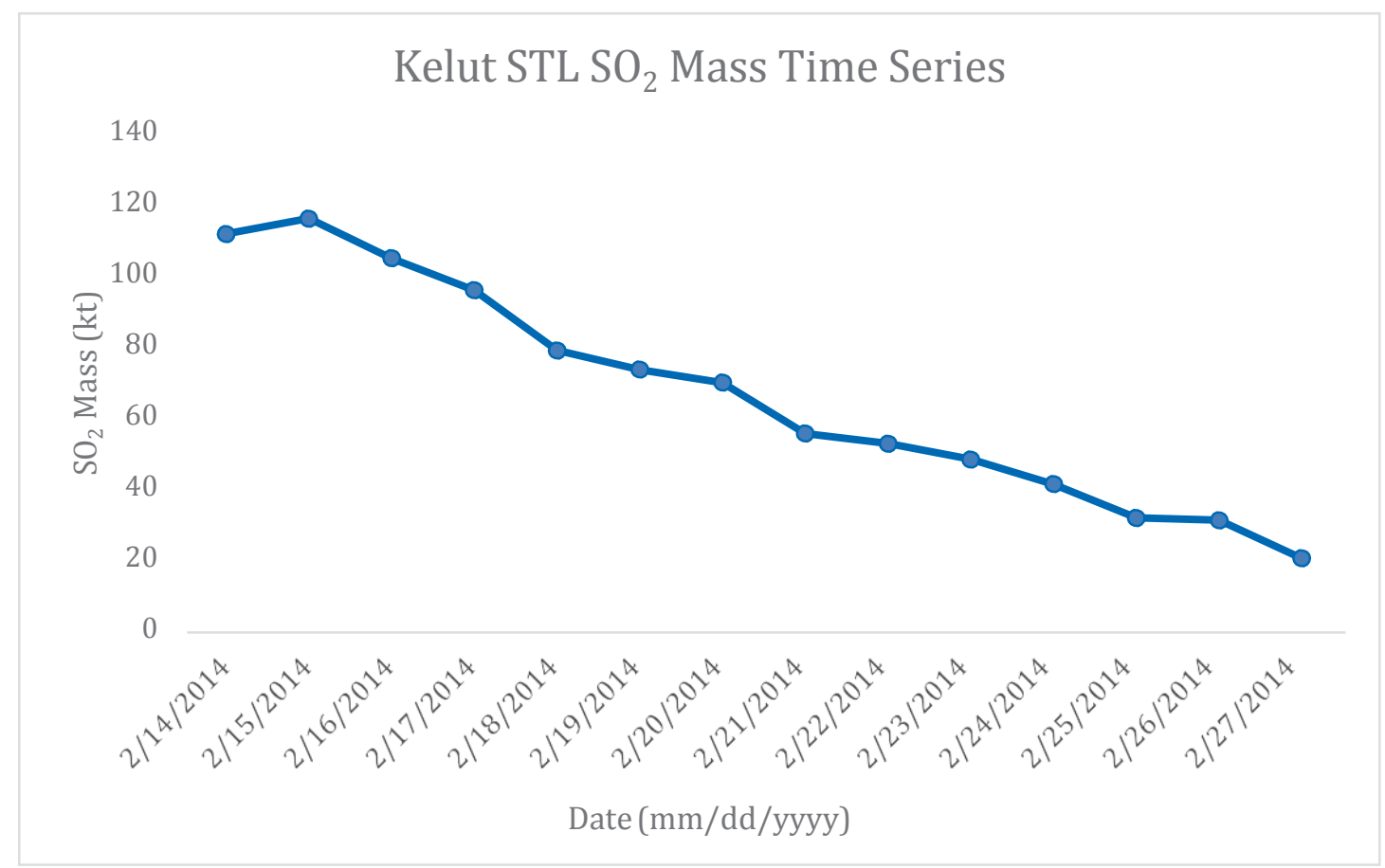

Figure 41. The evolution of the sulfur dioxide in the Kelut eruptive plume from January 14-27, 2014. Data processed using OMIplot.

The trend of the $\mathrm{SO}_{2}$ mass experiences an increase in the total mass during the second day (i.e. February $15^{\text {th }}$ ) of residence time for the volcanic cloud to a maximum value of $116 \mathrm{kt}$. The $\mathrm{SO}_{2}$ mass subsequently descends steadily during the remaining days of its atmospheric residence to its minimum value of $20 \mathrm{kt}$ on January $17^{\text {th }}$.

\subsection{2 $\quad \mathrm{SO}_{2}$ Cloud Area}

Figure 42 illustrates the area of the evolving volcanic $\mathrm{SO}_{2}$ cloud throughout the entirety of its atmospheric lifetime. Each data point represents the daily progression of the sulfur dioxide cloud. 


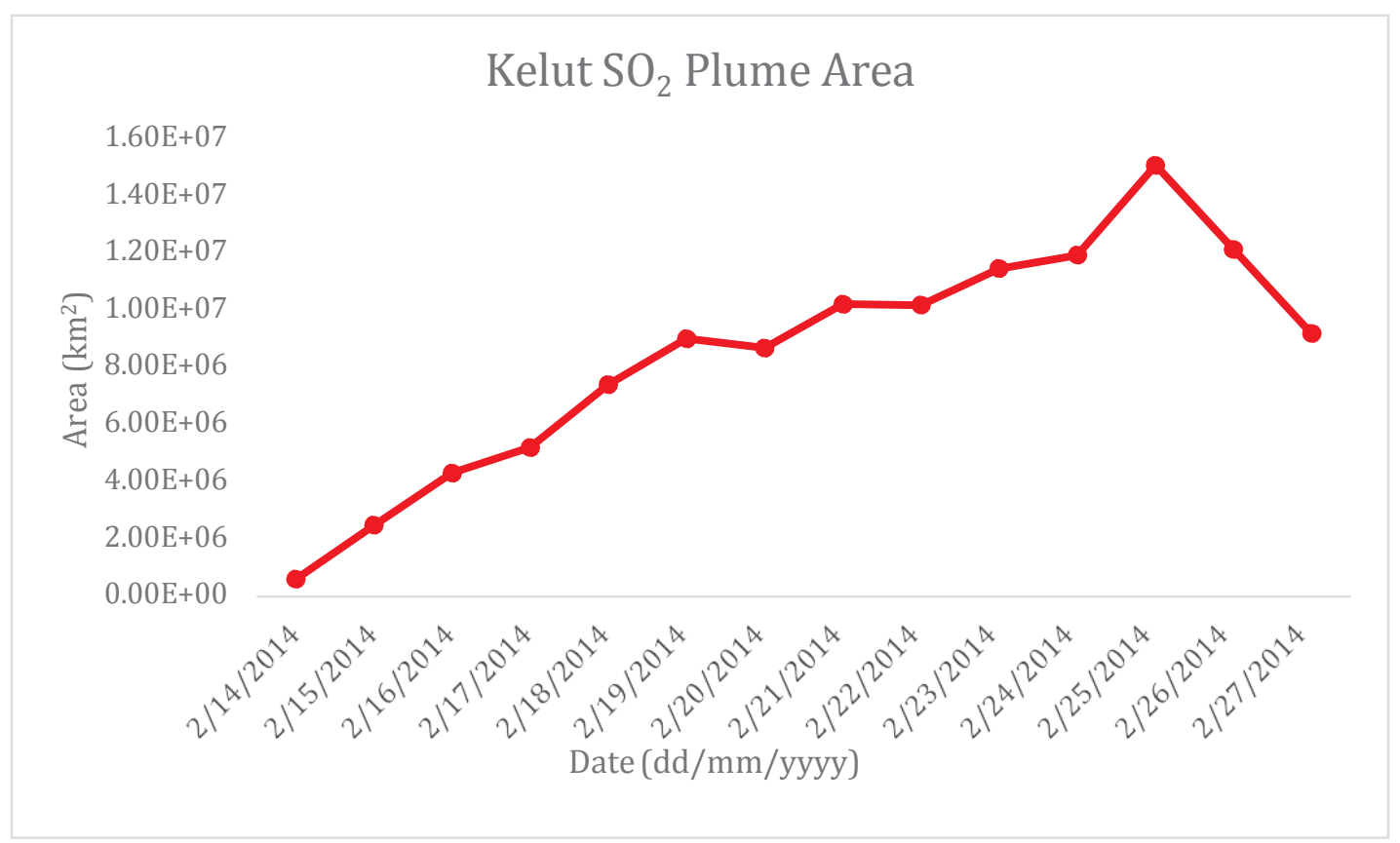

Figure 42. The sulfur dioxide plume area time-series for the February 13, 2014 eruption of Kelut. Data processed using OMIplot.

The trend depicted in Figure 42 is steadily increasing throughout the atmospheric residence of the volcanic sulfur dioxide plume. The first day of residence boasts a minimum value of $6.05^{*} 10^{5} \mathrm{~km}^{2}$, while the maximum area of $1.51 * 10^{7} \mathrm{~km}^{2}$ is reached on February $25^{\text {th }}$. The final two days of available monitoring data show a slight decline in the area of the volcanic $\mathrm{SO}_{2}$ cloud.

\subsection{3 $\quad \mathrm{SO}_{2}$ Plume Concentration}

Figure 43 depicts the time series of the $\mathrm{SO}_{2}$ concentration in the Kelut volcanic plume with time. Each data point represents the progression of sulfur dioxide concentration on a daily basis. 


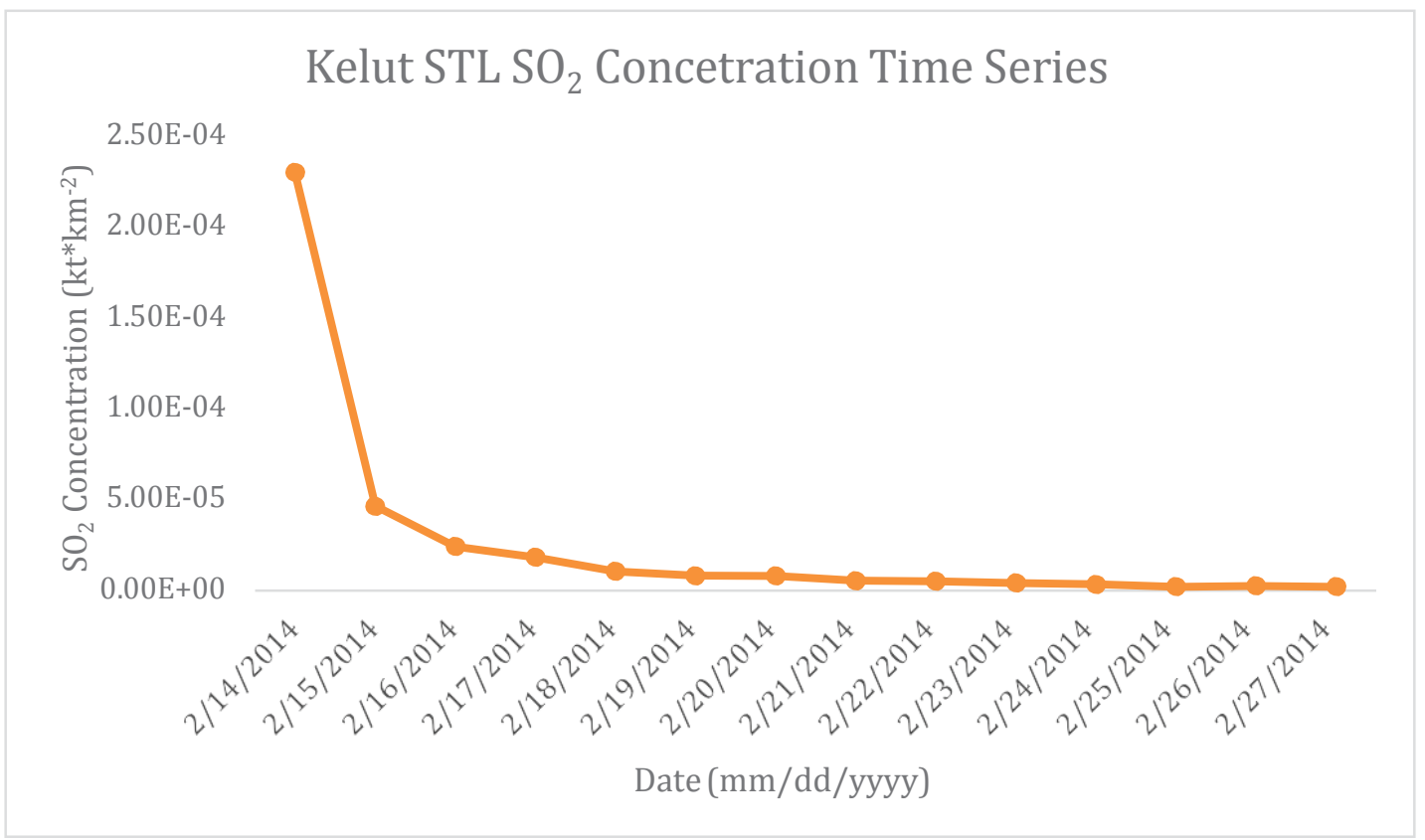

Figure 43. Time series of the evolution of the sulfur dioxide concentrations in the Kelut eruption plume. Data processed using OMIplot.

The trend depicted in Figure 43 is quite simple. The concentration of $\mathrm{SO}_{2}$ rapidly decays after its initial maximum of $2.3 * 10^{-4} \mathrm{kt}^{*} \mathrm{~km}^{-2}$ to plateau by the third day of residence at the minimum values for the remainder of the lifetime of the plume.

\subsubsection{Max and Mean $\mathrm{SO}_{2}$ Column Densities}

The max and the mean column densities, calculated in Dobson Units (DU), elucidate the amount of $\mathrm{SO}_{2}$ present in a very thin layer in the atmosphere. The graph below depicts these values after the Kelut eruption.

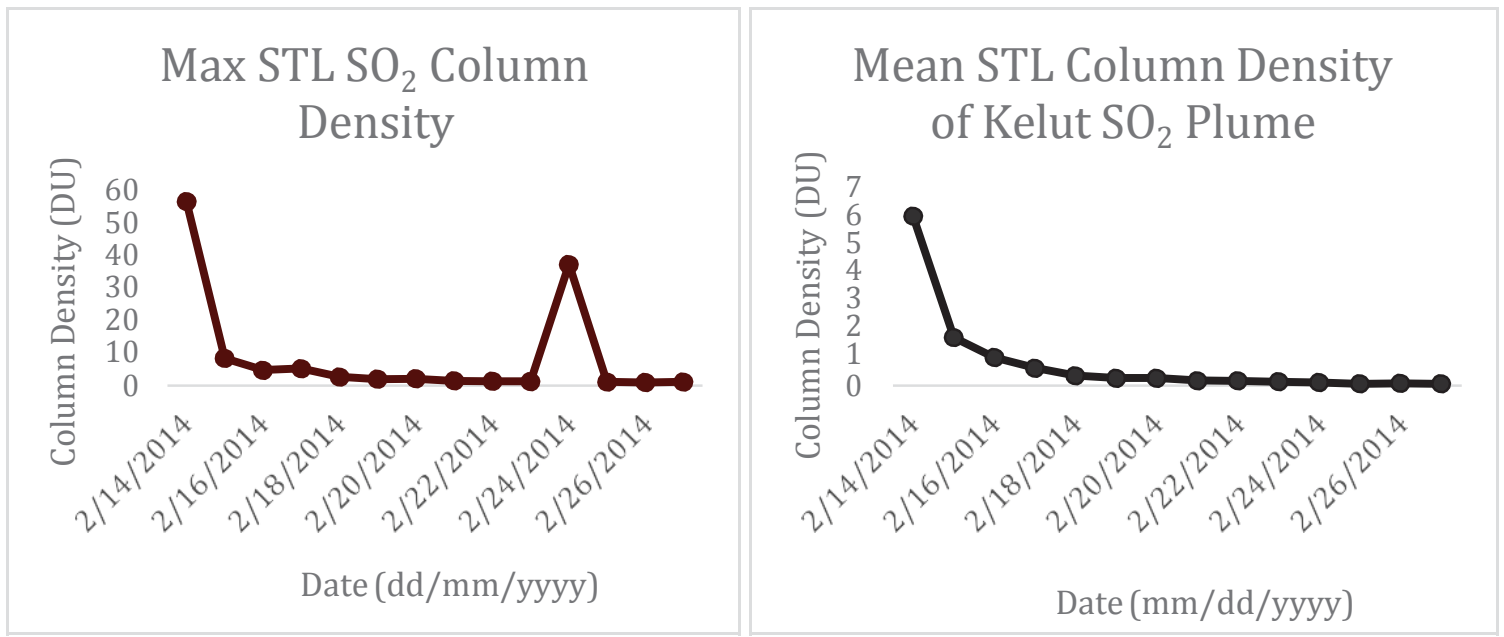

Figure 44. Time series of the maximum and mean column densities for $\mathrm{SO}_{2}$ in the Kelut eruption. Data processed using 
OMIplot.

The trends of both the maximum and the minimum column densities resemble the development of the $\mathrm{SO}_{2}$ concentrations in that there is rapid decay followed by a plateau of minimum values. There is an exception in the maximum column density data, in which there is one data point on January $24^{\text {th }}$ that has an abrupt increase.

\subsection{5 $\mathrm{SO}_{2}$ Removal and Dilution Rates (i.e. Mass and Concentration)}

The removal and dilution rates of the $\mathrm{SO}_{2}$ from the Kelut eruption describe the atmospheric residence time of the constituent, which has direct implications on the atmospheric chemistry and potential climatic effects. Figure 45 and 46 describe the removal and dilution rates for each day of residence.

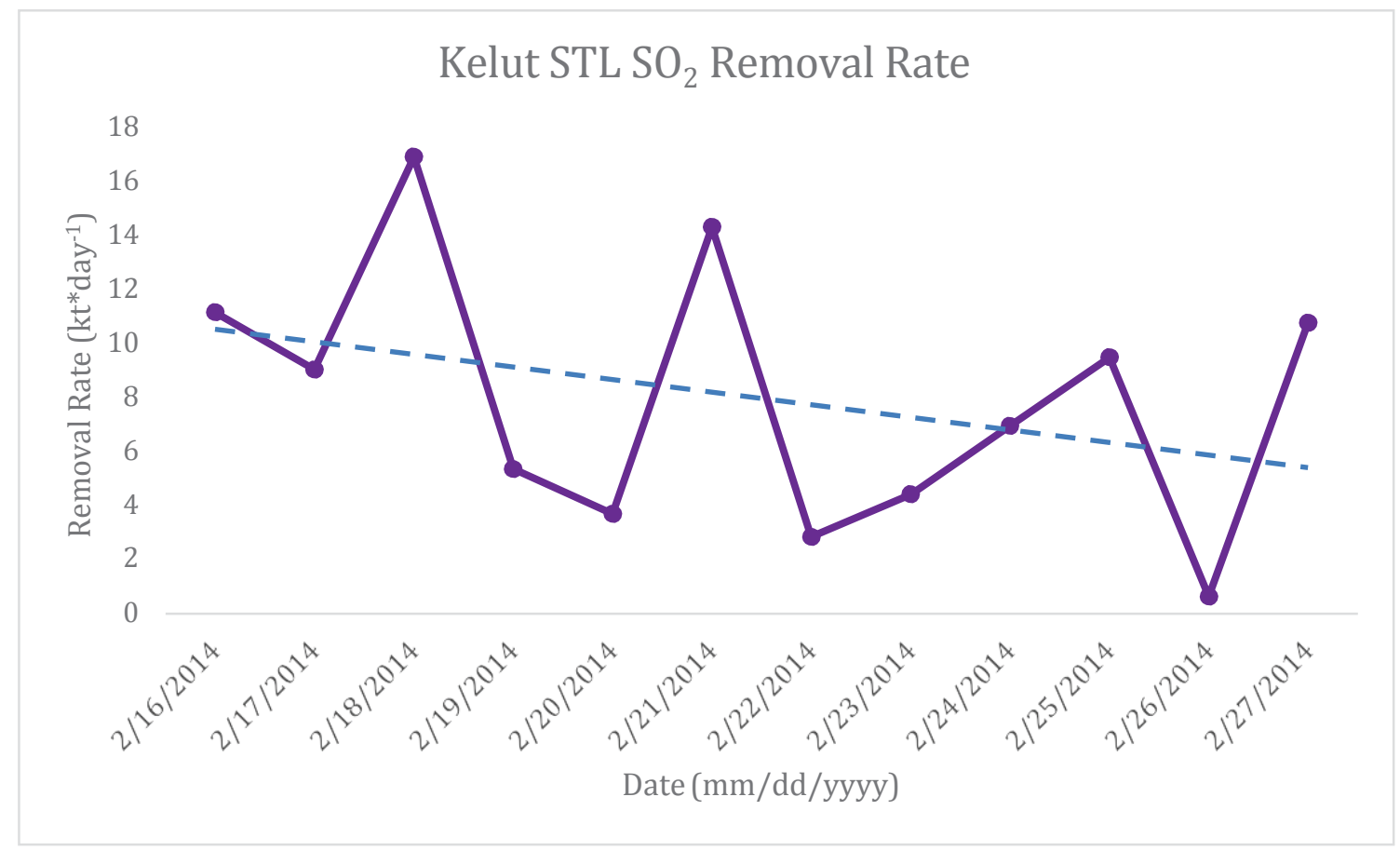

Figure 45. Time series of the daily removal rates for the $\mathrm{SO}_{2}$ mass in the Kelut eruptive plume. Data processed with OMIplot. 


\section{Kelut STL $\mathrm{SO}_{2}$ Dilution Rate}

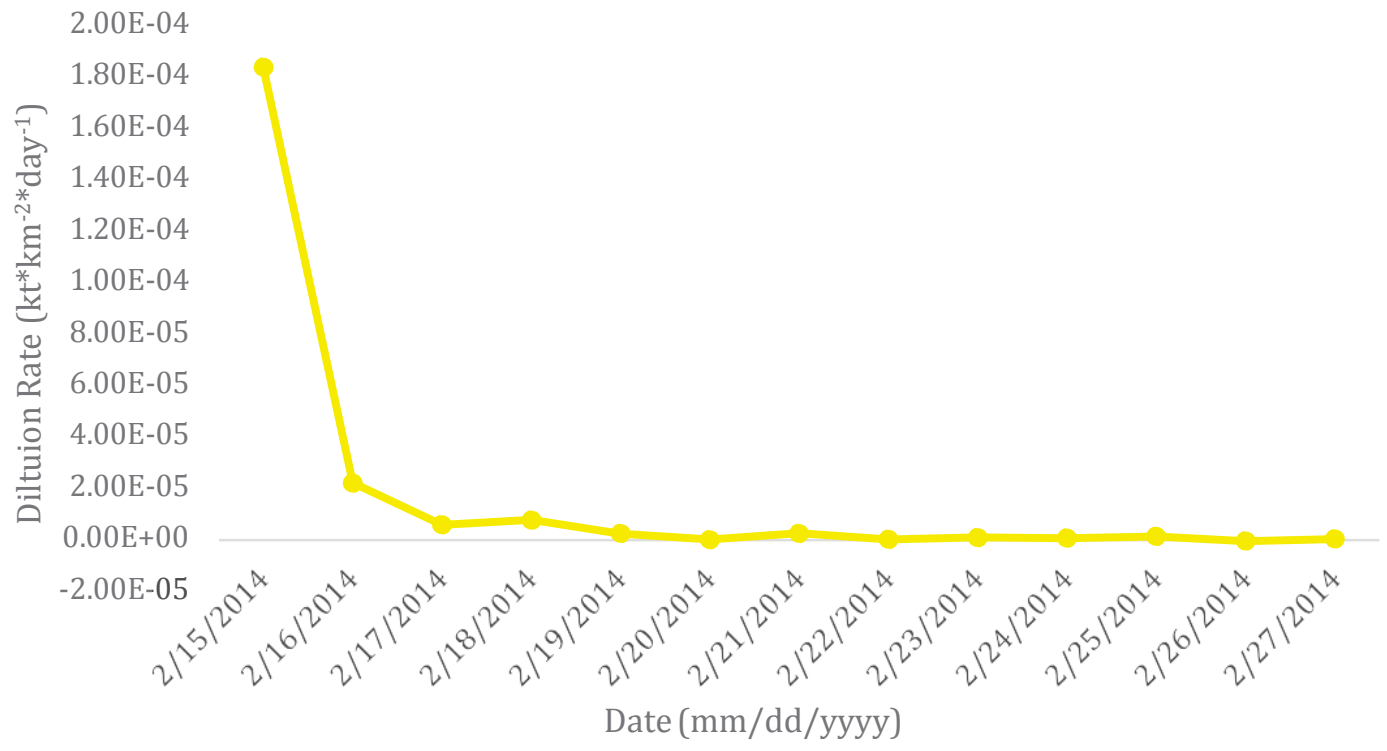

Figure 46. Time series of the daily dilution rates for the $\mathrm{SO}_{2}$ concentrations in the Kelut plume. Data processed using OMIplot.

The removal and dilution rates for the masses and concentrations of $\mathrm{SO}_{2}$ differ drastically. The removal rate is quite sporadic with several peaks occurring every few days throughout the residence time of the plume most likely due to the interference of the row anomaly on the days with decreased removal rates. However, the overall trend for the removal rate is a subtle decline and is still statistically significant. The average removal rate calculated from the OMSO2 data is about $8 \mathrm{kt}^{*} \mathrm{day}^{-1}$. This removal rate compared against the initial $\mathrm{SO}_{2}$ erupted mass of $112 \mathrm{kt}$ yields an e-folding time of about 13.98 days for the $\mathrm{SO}_{2}$ at the altitude of injection and dispersion.

The dilution rate resembles the degradation of the $\mathrm{SO}_{2}$ concentration exactly, in which there is a drastic decline after the first day of residence followed shortly by a plateau. The average dilution rate acquired from OMSO2 data is about $1.75^{*} 10^{-5} \mathrm{kt}^{*} \mathrm{~km}^{-}$ $2 *$ day $^{-1}$. This dilution rate compared against the initial erupted $\mathrm{SO}_{2}$ concentration of $2.3 * 10^{-4} \mathrm{kt}^{*} \mathrm{~km}^{-2}$ yields an e-folding time of about 13.13 days for the $\mathrm{SO}_{2}$ at the height of injection and residence. The e-folding rates calculated using the two separate methods for the Kelut $\mathrm{SO}_{2}$ cloud have an agreement ratio of $94 \%$. 


\subsection{Plume Height}

Several parameters are obtained from satellite ash detection data (ash cloud location and extent through time, ash cloud radiance and temperature, and ash cloud brightness temperature difference) that are critical for calculating ash dispersion models. These parameters include plume height, ash concentration, and ash total mass (Labazuy et al. 2012). If these parameters are obtained in a near-real time fashion, an ash dispersion model can then be used to warn the aviation and local communities of the impending distribution. Volcanic Ash Advisory Centers (VAACs) use these factors during volcanic crises. The easiest of these parameters to acquire in real-time is the plume height. Cloud heights acquired from satellite data can also be useful to measure the relative intensity of activity (Rose and Mayberry 2000).

The simplest, most-widely used and accepted method for obtaining the plume height using thermal infrared satellite data is termed the Cloud Top Temperature (CTT) method. The CCT method utilizes the brightness temperature of an ash pixel determined from the $11-\mu \mathrm{m}$ wavelength band. The CTT method assumes that the top of the cloud is in complete thermal equilibrium with the ambient atmosphere. The temperature attained from the $11-\mu \mathrm{m}$ brightness temperature can then be correlated with radiosonde observations that procure a vertical, local atmospheric temperature profile. Radiosondes measure the vertical profiles of atmospheric variables from the surface to the lower stratosphere and transmit the data via radio to ground-based receiving systems (Free 2002).

The coldest individual pixel brightness temperature is used to attain the maximum height by correlation with the radiosonde data. The coldest temperature associated with the eruptive cloud is assumed to be the most accurate because the troposphere decreases in temperature with increasing altitude. The higher the altitude for an ash cloud means a smaller path length and probability for the radiant signal to become obscured before reaching the satellite sensor. Only a single height determination is necessary for a specific time because volcanic clouds move with the prevailing winds present at the maximum height attained. Once the initial maximum height is reached, the ash cloud can travel laterally extensively, but the vertical 
distribution is contrarily quite small and confines to 1 to $2 \mathrm{~km}$ (Prata 2009).

Using the MTSAT-2 11- $\mu$ m brightness temperature data for the February 2014 Kelut eruption, an ash cloud height profile was obtained for every hour of detection. The profile is presented below.

\section{Height of Plume}

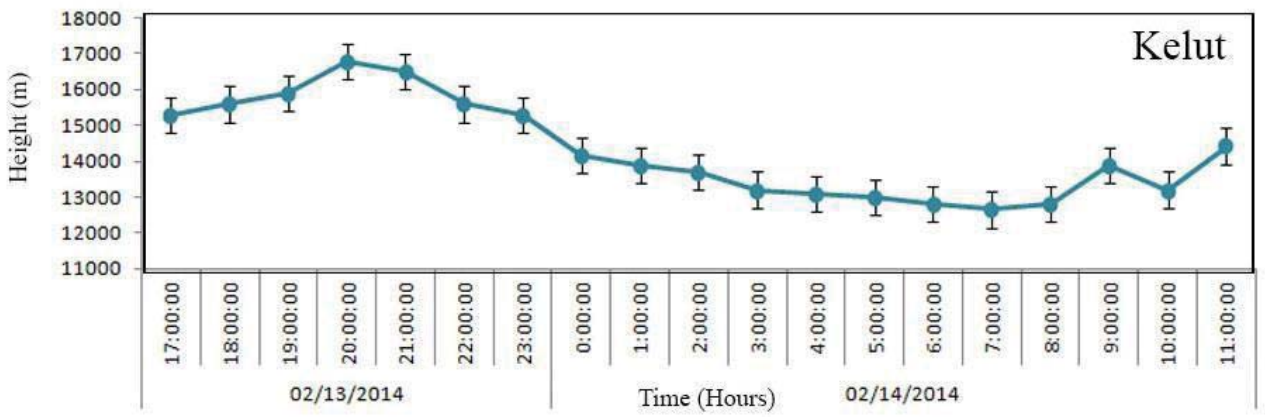

Figure 47. Profile of the evolution of the ash plume height from the Kelut eruption determined using the CTT method. Error bars of $0.5 \mathrm{~km}$ are associated with the $11 \mu \mathrm{m}$ brightness temperature. The error bars are calculated based on (Hamada and Nishi 2010) utilizing brightness temperatures of the pixels. Any brightness temp. below 240K has an error of about $0.5 \mathrm{~km}$. All pixels used in this study had brightness temperatures of around $200 \mathrm{~K}$.

Since radiosonde data is collected only twice per day at $00 \mathrm{Z}$ and $12 \mathrm{Z}$, the $00 \mathrm{Z}$ data on February 14 most closely resembles the atmospheric conditions at the time of the Kelut eruption.

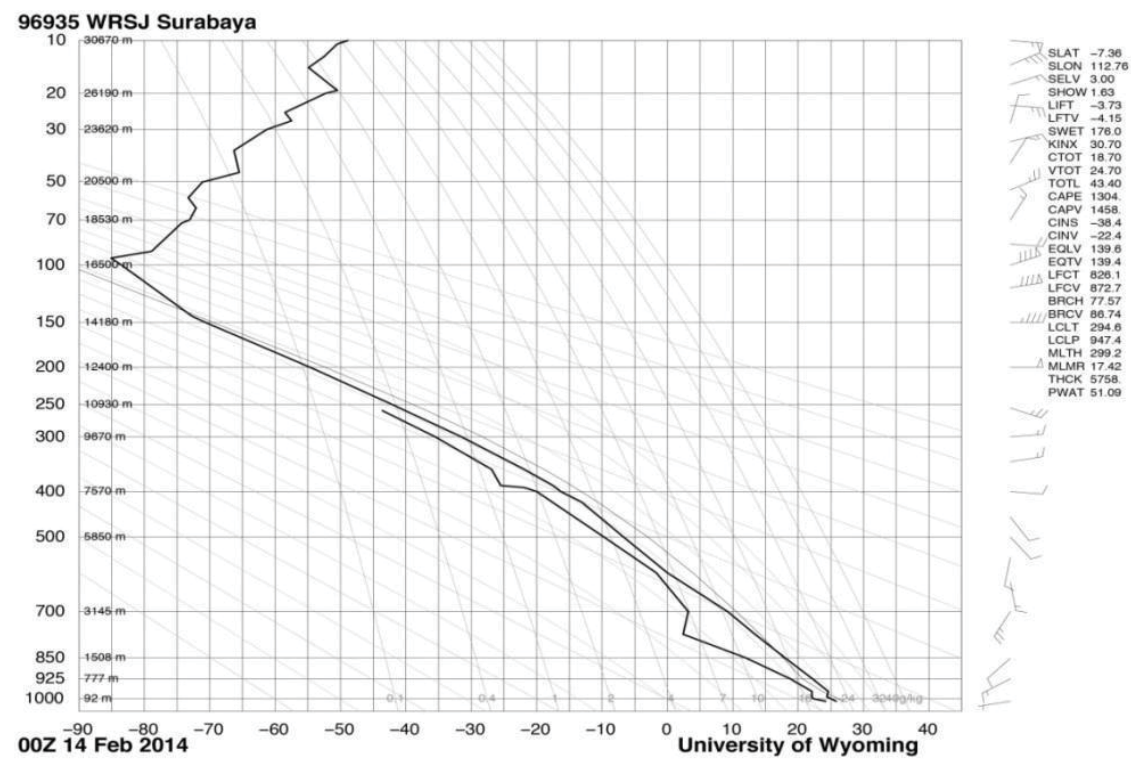

Figure 48. Atmospheric profile of the conditions indicative of the tropical region near Kelut volcano recorded on February 14, 2014 at 0000 UTC. X-axis is temperature in ${ }^{\circ} \mathrm{C}$. Y-axis is altitude in meters. Image obtained from University of Wyoming, Department of Atmospheric Science 
There are several limiting factors associated with the use of the CTT method for cloud height determination that mostly rely upon the physical principles of the cloud and the atmosphere involved. According to (Oppenheimer and Francis 1997), these factors include assumptions made about the emissivity of volcanic ash, potential "undercooling" of stratosphere piercing clouds, and inaccuracies with the temperature profile. The CTT method can be successful if the cloud behaves as a black body (i.e. high optical thickness) and the radiosonde profile is accurately defines the conditions. The physical nature of the differing layers of the atmosphere induces a temperature inversion at the boundary between the troposphere and the stratosphere. The troposphere decreases in temperature as altitude increases, while the stratosphere exhibits the opposite behavior. If a cloud enters the stratosphere, the brightness temperature will appear warmer than portions of the cloud that remain in the troposphere due to this temperature inversion. It is reasonable to assume the cloud is absorbing more radiation than it is emitting (i.e. not a blackbody); therefore, the resultant pixel would yield higher brightness temperature and hence a lower altitude estimate (Prata and Grant 2001).

According to the atmospheric profile obtained from the University of Wyoming, the temperature inversion, and therefore the stratosphere, exists around 17 $\mathrm{km}$. The maximum height of the Kelut ash cloud is 16,783 meters in altitude. Some of the surrounding pixels displayed warmer temperatures signifying that either portions of the cloud could have penetrated the stratosphere or the cloud is transparent. It becomes impossible to create certainty of either situation using only IR data from the MTSAT-2. The CTT method should be proofed with other sources of data like the NOAA developed HYSPLIT trajectory model and satellite-based LIDAR data provided by the CALIPSO instrument, but it is an excellent first order approach. It must be mentioned that no unique solution for very high altitude plumes exist, so the CTT method is perfectly suitable and efficient for identifying cloud heights remaining in the troposphere. 


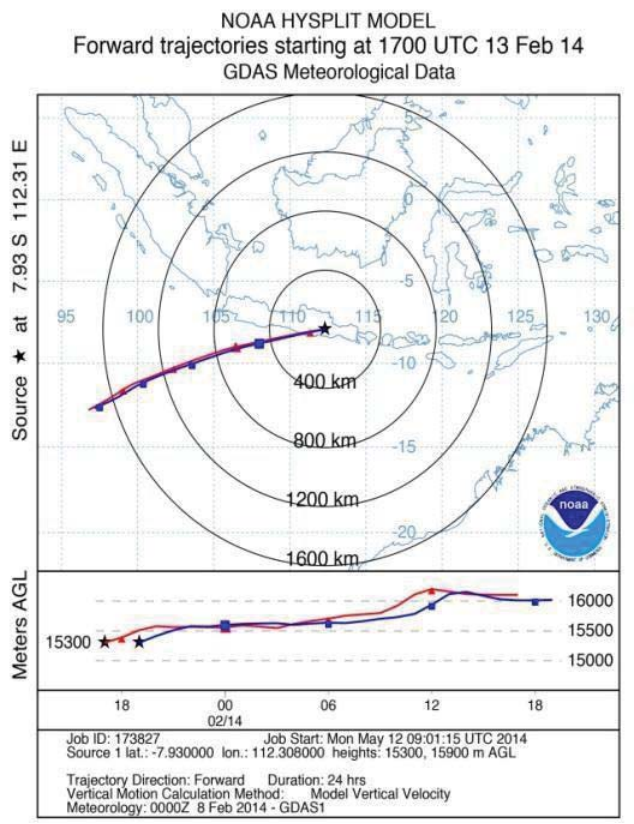

Figure 49. HYSPLIT Trajectory Model obtained from NOAA for the Kelut ash plume on February 13, 2014. The use of these results obtained from the online version of HYSPLIT requires the citations of [(Draxler and Rolph 2015); (Rolph 2015)].

The HYSPLIT model is a Lagrangian integrated trajectory model that incorporates cloud altitude with wind and other atmospheric data in order to predict the projected location [Draxler and Rolph 2015) and (Rolph 2015)]. A HYSPLIT model is ran for the Kelut eruption with the CTT method column heights as input parameters. As seen from the Figure 51, the trajectory of the ash plume correlates extremely well with the model. This outcome suggests that the majority of the cloud propagates around $17 \mathrm{~km}$ in altitude. CALIOP is a lidar instrument onboard the CALIPSO, which measures radiance in the visible part of the electromagnetic spectrum. During its polar orbiting campaign, CALIOP imaged the ash plume from Kelut shortly after the start of the eruption from 18:11 to 18:25 UTC on February 13, 2014. 


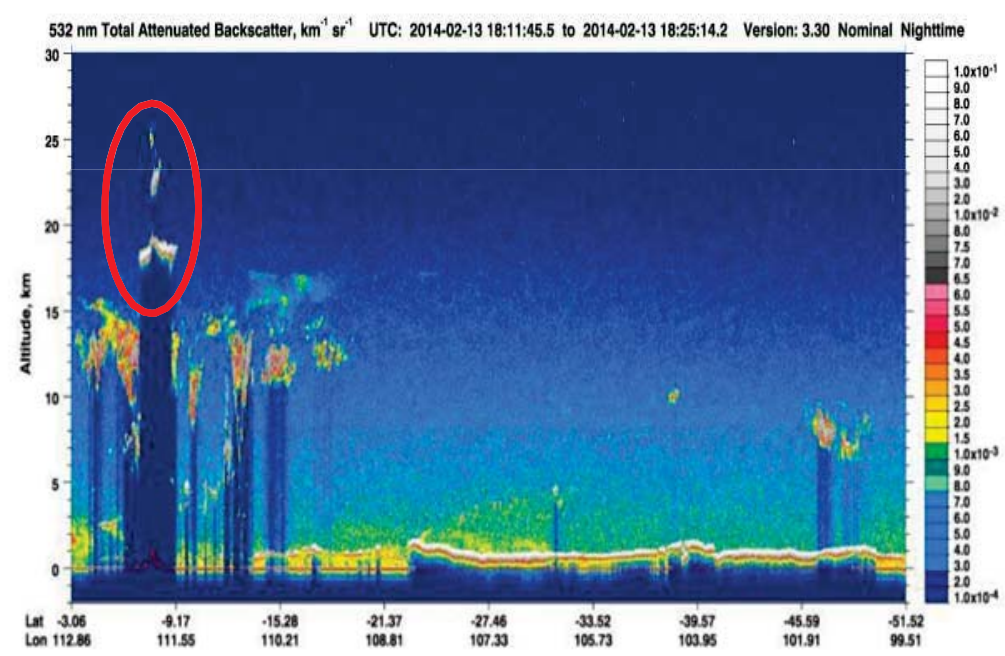

Figure 50. CALIPSO LiDAR image of Kelut ash plume taken from NASA's CALIOP instrument at 18:11 UTC on February 13, 2014. "Red circle" indicates location of ash plume. While the major cloud attenuation occurred 18 $\mathrm{km}$, portions of the cloud can be seen ejected to $\sim 26 \mathrm{~km}$. Image courtesy of NASA (NASA 2014). See Appendix for reuse permission from NASA.

The majority of the ash plume reaches a maximum altitude of about $18 \mathrm{~km}$, according to Figure 50. There is total attenuation under this portion of the cloud. Being that the image is taken only 2 hours after the start of the eruption, some of material is seen to have forced through the center of the plume into the lower stratosphere reaching about $26 \mathrm{~km}$ altitude. During the first 3 hours of data acquisition from the MTSAT-2 instrument, a small cluster of warmer pixels is located near the volcanic center point, and they are surrounded by colder pixels. Since the CTT method utilizes the coldest brightness temperature to determine a cloud height, the highest portions of the cloud are located at the leading edge of the cloud dispersion around $15.6 \mathrm{~km}$ in altitude. This feature persists until the image obtained at 2000 UTC, 4 hours after the start of the eruption. It is logical to assume that the highest portion of an ash cloud should be located directly above the volcanic vent before gravity forces settling of the denser particles. Given these circumstances, the CTT method is applied to the warm cluster of pixels on the MTSAT-2 1800 UTC image, which is taken only 11 minutes prior to CALIPSO overpass. A warm pixel was chosen in the center of this cluster of pixels, and it is determined to have a brightness temperature of $220 \mathrm{~K}$ or $-53^{\circ} \mathrm{C}$. This temperature is correlated to an altitude of $26 \mathrm{~km}$ or $12 \mathrm{~km}$ (due to same temperature in tropopause) using the same atmospheric profile from the University of Wyoming. The 
altitude obtained from the CTT method utilizing the MTSAT-2 data correlates perfectly with the LIDAR data.

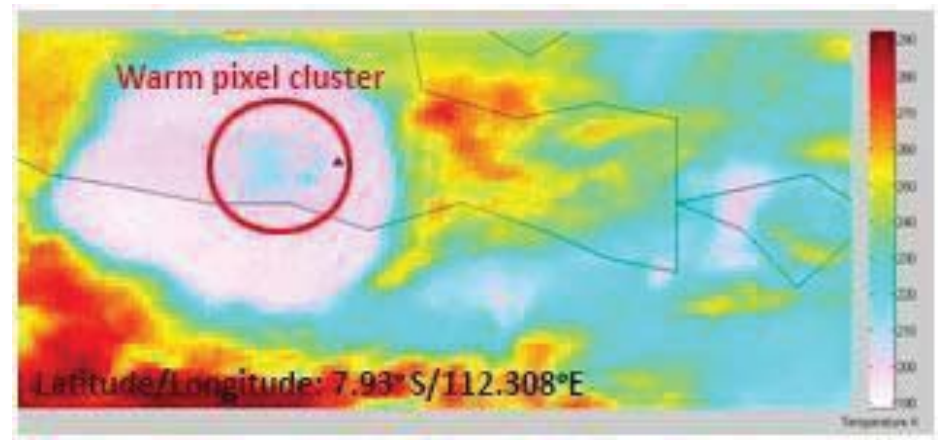

Figure 51. An MTSAT-2 image of the Kelut eruption taken at 1800 UTC. The red circle encompasses the warm cluster of pixels near the vent whose brightness temperatures correspond to a height of $26 \mathrm{~km}$.

Even though the CTT method has little validity being used in this fashion, it is an interesting observation.

\subsection{Processes and Interpretation \\ 4.7.1 Maximum BTD Interpretation}

Many physical processes occurring in a volcanic ash cloud during and after the main eruptive phase can be implied through the information provided by the BTD method and corresponding $\mathrm{SO}_{2}$ data. During the early stages of the Kelut eruption, an opaque cloud was present due to the high concentration of particulate matter persisting near the vent. The maximum negative BTD values remain on the fringe of negative values. They range from -2.7 to -4.5 during this period, which corresponds to the first 7 hours of the ash cloud tracking. The nominal negative BTD values are a consequence of the volcanic cloud being enriched in water/ice droplets that mask the ash signal as well as the majority of the ash particles present are too large for detection by an IRsensor. 


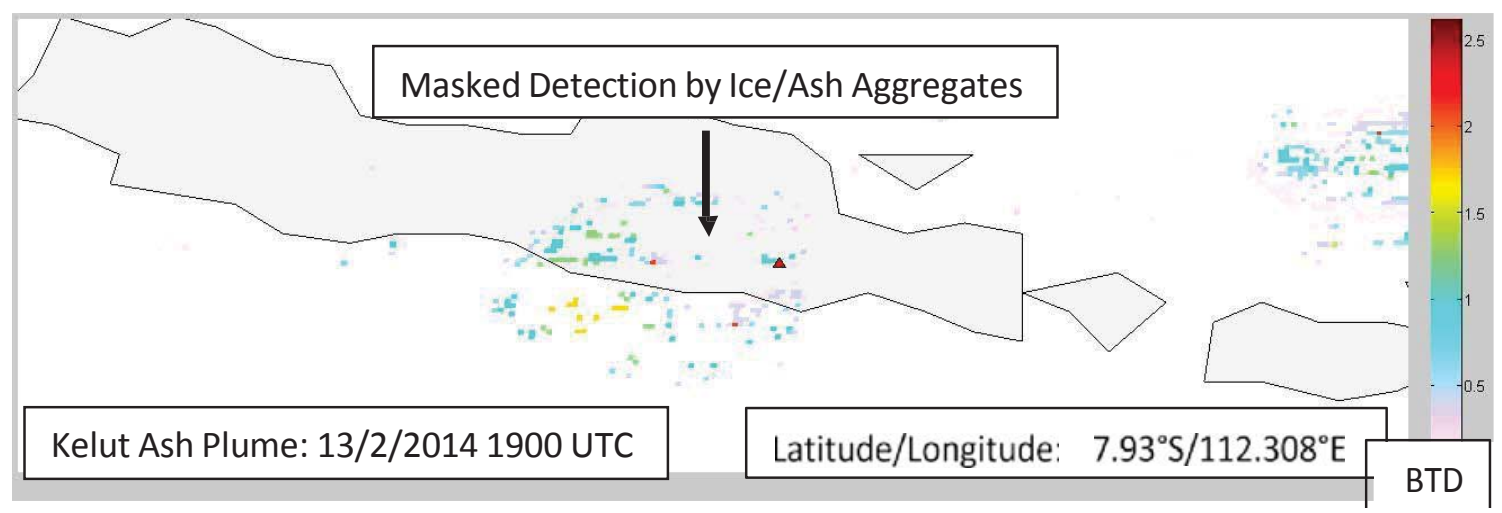

Figure 52. MATLAB processed image of early stage in cloud migration. Ash particles masked by ice/ash aggregate formation.

As the eruption ceases, the cloud detaches from the vent and dispersion of the particles coupled with sedimentation of water/ice and large ash particles is evident causing proper detection of the ash. Also, infrared remote sensing instruments (i.e. MTSAT-2) are only capable of detecting fine ash particles ranging in size from $\sim 1-30$ $\mu \mathrm{m}$ in diameter because the functioning of the sensor is predicated upon the Mie scattering theory. The Mie scattering theory dictates that particles scattering radiation at wavelengths approximately equal to the size of the particle. Since infrared remote sensors operate in $\sim 1-25 \mu \mathrm{m}$ range, only ash particles of this size can be detected. Therefore, the combination of exorbitant amounts of water and very large ash particles (i.e. $>2 \mathrm{~mm}$ ) that persist immediately after the start of a volcanic eruption caused the fine ash constituents to be masked from the sensor.

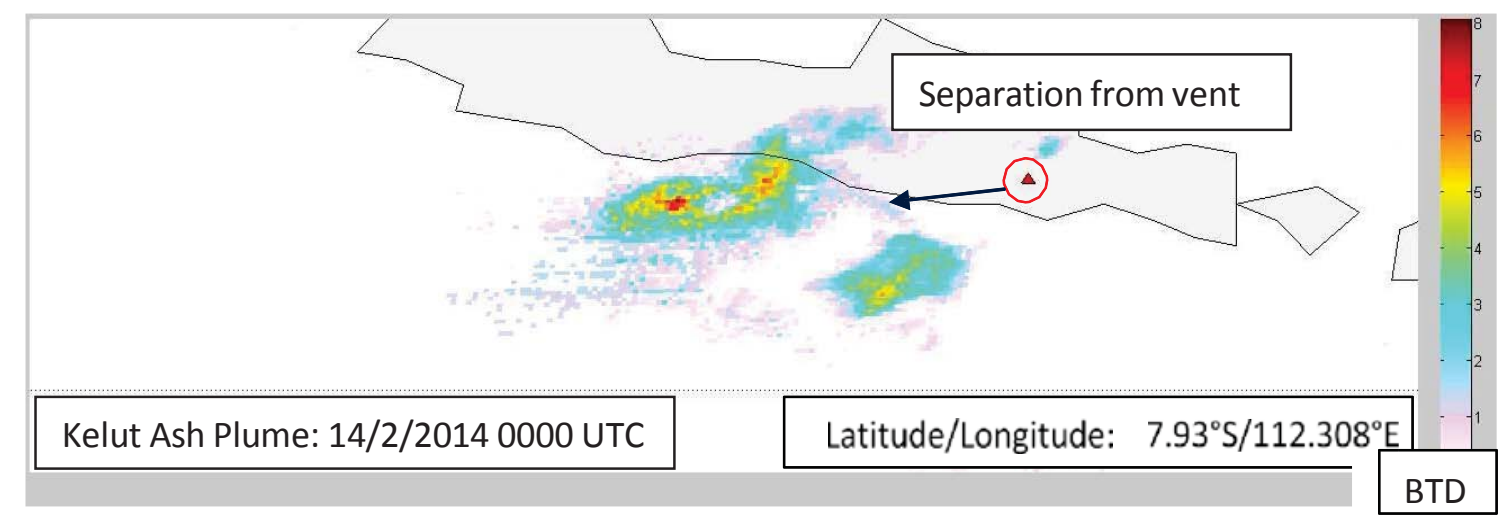

Figure 53. MTSAT-2 processed image from 0000 UTC of the Kelut ash cloud tracking. The magnitudes of the BTD values are very high, as the cloud detaches from the vent.

As dispersion processes affect the ash cloud, the area of the negative BTD values 
as well as the magnitude of the BTD values increased dramatically. According to Figure 37, the area of the negative BTD values, which correspond to the presence of ash, becomes $48,224 \mathrm{~km}^{2}$ at 0000 UTC when its initial area above the vent is 1184 $\mathrm{km}^{2}$ at 1700 UTC the previous day. The magnitude of the BTD values becomes -8 at 0000 UTC as opposed to -2.7 at 1700 UTC the previous day.

The trend for the summation of the BTD values is sensible, since the maximum value occurs between the maximums for the area and $\mathrm{BTD} / \mathrm{km}^{2}$. The summation of the BTD values denotes the amount of ash present, but more importantly, it demonstrates the diameter of the fine ash particles. It is quite logical that the maximum value occurs between the highest concentration and largest surface area that the volcanic cloud experienced, and it is most likely a result of aggregation processes occurring in the volcanic cloud during transport.

\subsubsection{Principles of Ash Aggregation/Sedimentation}

Figure 37 and Figure 38 can denote important processes such as aggregation and sedimentation. Ash aggregation is of fundamental importance to fine-ash sedimentation after a volcanic eruption, and many studies have recently been conducted on this phenomenon. Ash aggregation reduces the residence time of volcanic ash in the atmosphere by increasing particle diameter and settling velocity; thereby, reducing its radiative effects and hazardous implications on air traffic. Particles comprising aggregates are bound either hydrodynamically (i.e. wet aggregation) or electrostatically (i.e. dry aggregation). Ash particles will preferentially aggregate via wet aggregation dependent on the availability of water (Brown et al. 2011). Other parameters effecting the aggregation efficiency and growth include residence time, relative humidity, and collisional kinetic energy.

The magnitude and duration of airborne hazards generated by volcanic ash is dependent upon its residence time in the atmosphere. One of the major factors controlling the residence time of volcanic ash in the atmosphere is the poorly understood process of ash aggregation, in which ash particles adhere to each other. Fine-ash $(<63-\mu \mathrm{m})$ particle aggregation can cause increased sedimentation near the vent and decreased distal (100s to $1000 \mathrm{~s}$ of $\mathrm{km}$ ) sedimentation due to the subsequent increase in the diameter of the 
particles. The terminal settling velocities of very fine ash (i.e. ranging from $10^{-1}$ to $10^{-3}$ $\mathrm{m} \mathrm{s}^{-1}$ ) would result in much longer atmospheric residence (i.e. days to weeks) than observed if they were to remain as individual particles (Rose and Durant 2011). However, mounting evidence supports that the fine ash fraction of explosive eruptions settles out in less than one day (Guo et al. 2004), inferring that these simple particles must be aggregating to decrease the drag coefficient and increase their settling velocities. Aggregate deposits at distal locations from the vent have been extensively documented in the geological record (Sarna-Wojcicki et al. 1981). Taddeucci et al. 2011 presented a breakthrough by actually imaging particle aggregation in situ during the 2010 Eyjafjallajökull eruption using a high-speed camera.

Despite all of the evidence determining that ash aggregation effects the residence time and concentration in the atmosphere, most operational ash cloud models [(Armienti et al. 1988); (Bonadonna et al. 2005); (Costa et al. 2010)] do not include any description of ash aggregation due to the complexities of defining the microphysical and chemical aspects involved. Failure to include aggregation into the forecasting model will cause underestimation of ash concentration in the atmosphere proximal to the vent and overestimation distally. These miscalculations can hinder flight patterns that would be otherwise safe for air travel.

\subsubsection{Area/Concentration of Ash}

Only a small fraction of the airborne ash is sensed by the infrared satellite detector because much of it is coarser and fell out very quickly after the eruption before the first image was obtained. Rose et al. 2000 estimates that only about $20 \%$ of the total erupted mass is the fine ash component, and of this component, about $75-90 \%$ falls out within 36 hours probably due to aggregation processes. Figure 37 displays the area of the volcanic cloud evolving with time. The area is very low for the first 3 hours of detection, followed by a dramatic increase to a maximum area of $57,824 \mathrm{~km}^{2}$ and subsequent plateau, and then eventually steadily declines. The initial small area is partially due to the confinement of a large amount of ash in a small space, and the area is calculated in only 2 dimensions from above the plume. The subsequent increase in the area is due to dispersion of the fine-ash particles at the umbrella region of the 
ash plume. The final decline in the area is partially due to the fall-out of ash particles, but it is also because the edges of the plume disperse enough for the concentration of ash particles to drop below the detection limit of the MTSAT-2.

The $\mathrm{BTD} / \mathrm{km}^{2}$ is a parameter that potentially defines aggregation as much as concentration. The BTD $/ \mathrm{km}^{2}$ parameter responds to the following rules for scattering: the Mie Domain (Mie Domain $=\mathrm{NxD}^{\mathrm{n}}$ (for a radius of particle $\sim \lambda$ )) is a law describing how particles scatter light. "N" corresponds to the number of particles present, and "D" denotes the diameter of the particles, while the superscript can equate to a value usually greater than 1 . The equation signifies that the diameter of a particle has a larger impact on the scattering of light than the number of particles. Therefore, during aggregation in an eruptive plume, the increased BTD $/ \mathrm{km}^{2}$ indicates that the ash particles are becoming more concentrated, and the process that explains a higher concentration of ash with decreasing water/ice concentration is aggregation.

\subsubsection{Secondary Zone of Aggregation}

There has been mounting evidence for aggregated-assisted sedimentation proximally to the eruptive volcanic vent. (Taddeucci et al. 2011) obtained visual confirmation of this phenomenon. There have also been documented cases of alternating grain-sized distribution of ash fallout several hundred kilometers from the vent (SarnaWojcicki et al. 1981) suggesting that a secondary zone of aggregation occurs in the migrating volcanic cloud. The remote sensing results presented in this report provide support for this process.

The eruption of Kelut began at 1629 UTC on February 13, 2014; whereas, the first image of eruption was obtained by MTSAT-2 at 1700 UTC. After 31 minutes, the plume had already reached an altitude of $15.3 \mathrm{~km}$, calculated using the CTT method. According to the near-by atmospheric sounding station at Surabaya, Indonesia, this altitude corresponded to an atmospheric temperature of about $-73^{\circ} \mathrm{C}$. Homogeneous freezing of liquid water droplets can occur at temperatures as low as $-40^{\circ} \mathrm{C}$ (The University of Manchester 2014); whereas, heterogeneous freezing of liquid water occurs at temperatures much warmer (i.e. about $-11^{\circ} \mathrm{C}$ for volcanic ash nuclei) (Fornea et al. 2009). Therefore, even with the heat caused by the turbulent friction between colliding particles, 
it can be confidently assumed that most of the water in the eruption cloud is solid ice at $15.3 \mathrm{~km}$. Also, due to the work done by Taddeucci et al. 2011, it can be stated that most of these ice is present is in the form of an ice-ash aggregate. According to Rose and Durant 2011, most coarse-grained (i.e. $\sim 2-10 \mathrm{~mm}$ and larger) deposits fallout within the first $30 \mathrm{~km}$ of the vent. The remaining constituents are mostly ice-ash aggregates that cause overseeding in the volcanic cloud. This overseeding of the volcanic cloud forces larger ice-ash concentrations with smaller particle sized-distributions (Durant et al. 2008). According to the height profile generated for the Kelut volcanic cloud, the entire cloud steadily descends in altitude constantly after 2000 UTC. The mass accumulation of the small-sized ice-ash aggregates would cause the terminal settling velocity of the entire cloud (i.e. $\sim 6.5 \mathrm{~ms}^{-1}$ (Scollo et al. 2005)) to be several orders of magnitude quicker than that of an individual particle (i.e. $\sim 10^{-1}-10^{-3} \mathrm{~ms}^{-1}$ (Rose and Durant 2011)).

The area of ash and water coupled with the concentration (i.e. BTD $/ \mathrm{km}^{2}$ ) of ash and water in the volcanic cloud provide evidence for the secondary zone of aggregation. The highest concentration of ash coincides with the largest areal extent of water and the ash at 0300 UTC on February $14^{\text {th }}$. Since the concentration of ash $\left(B T D / \mathrm{km}^{2}\right)$ is analogous to the Mie Domain $\left(\mathrm{BTD} \alpha \mathrm{ND}^{\mathrm{n}}\right)$, the peak in concentration corresponds to the largest sizedistribution experienced by the ash constituents. This increase in the size parameter of the ash indicates an aggregation process, because there was no source for new ash to enter the cloud. Subsequently, the concentration of ash, the concentration of water, and the areal extent of water all declined in the following hours after 0300 UTC. This data suggests the aggregation forced mass sedimentation to occur in a distal region from the vent.

Further supporting evidence is provided by the reflectivity of the volcanic cloud measured by the $4 \mu \mathrm{m}$ wavelength band of the MTSAT-2. A zone of very high reflectivity occurred at precisely $0300 \mathrm{UTC}$; the same time corresponding to the proposed secondary zone of aggregation. According to the height profile, the volcanic cloud descended below a thermal boundary (i.e. $\sim 10-12 \mathrm{~km}$ altitude, $>-40^{\circ} \mathrm{C}$ ) where super cooled pure liquid water was persistent. The relative humidity at this altitude was about $80 \%$, according to the Surabaya atmospheric sounding. Lathem et al. 2011 predicted that a monolayer of water coverage begins at $71 \%$ humidity. It was observed that at a relative humidity 
exceeding $71 \%$ and residence times longer than 50 minutes, the hydrodynamic forces are activated. The zone of high reflectivity was produced due to the differing dielectric properties of liquid and solid water (Marzano et al. 2006). The high reflectivity was only present for one hour and subsequently dissipated to normal background levels suggesting rapid mass sedimentation.

The evidence provided by the remote sensing data enabled the production of a conceptual model adapted from (Durant et al. 2009).

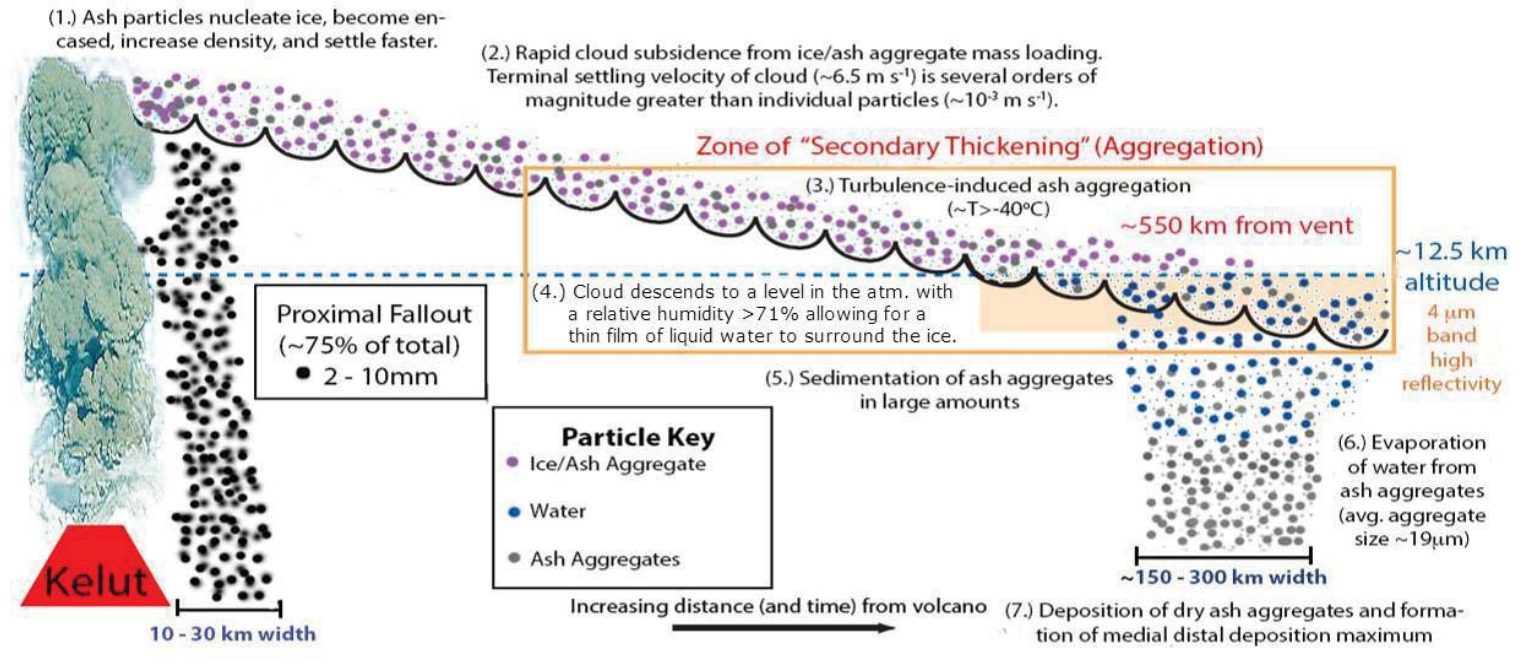

Figure 54. Conceptual model depicting the processes involved for the secondary zone of aggregation proposed for the Kelut eruption cloud on February 14, 2014. Several remote sensing techniques were used to provide the conclusion. Model adapted from (Durant et al. 2009).

The processes occurring are as follows:

1. Kelut eruption occurs spewing hot ash and water that quickly cools at is rise to an altitude of $15.3 \mathrm{~km}$. The water availability in the plume is generated from the abundant volatile component in the magma as well as entrainment of atmospheric water vapor as the plume rises. The volcanic ash acts as an extremely suitable nucleate for the liquid water. As the plume advances past the $-40^{\circ} \mathrm{C}$ (probably sooner) isotherm, the liquid water freezes to produce ice-ash aggregates. Most ( $\sim 75 \%$ total mass volume erupted) coarse-grained deposits fall out relatively quickly close to the vent.

2. The overseeding of the ice-ash aggregates cause increased concentrations and 
decreased particle size. The overabundance of tiny particles forces the entire cloud to descend faster $\left(\sim 6.5 \mathrm{~ms}^{-1}\right)$ than individual particles $\left(\sim 10^{-1}-10^{-3} \mathrm{~ms}^{-1}\right)$.

3. The descending cloud encounters super cooled liquid water vapor at a relative humidity of $\sim 80 \%$, which forms a layer of liquid water around the ice particle. Due to differing dielectric properties between solid and liquid water, a zone of high reflectivity is observed at 0300 UTC corresponding to maximum ash concentration and water areal extent evidenced by MTSAT-2 data.

4. The presence of liquid water enhances the sticking capability (The University of Manchester 2014) of the particles forcing aggregation in a turbulent flow regime.

5. The increased diameters resulting from the aggregation increasing the settling velocities of individual particles and causes mass sedimentation to occur.

6. Increasing tropical temperatures force the water to evaporate as the particles descend leaving only ash aggregate deposits.

\subsubsection{Discussion of Kelut $\mathrm{SO}_{2}$ Cloud}

\subsubsection{1 $\mathrm{SO}_{2}$ Mass Discussion}

An excellent complementary analysis to reinforce the timing proposed for the secondary zone of aggregation in the Kelut eruption plume would be the calculation of the $\mathrm{SO}_{2}$ masses before and after the process. Sulfur speciation dictates the microphysical properties of the molecule. Sulfur speciation ranges from $2^{-}$in the reduced state to $6^{+}$in the oxidized state. The sulfur state that is more oxidized would be more soluble and less reactive (Seinfeld and Pandis 2006). $\mathrm{SO}_{2}$ (oxidation state of $4^{+}$) is highly soluble in liquid water. Therefore, it can be assumed that a large amount of the sulfur dioxide would be sequestered in the ice-ash aggregates and hence blind to the OMI sensor. The secondary zone of aggregation would force mass sedimentation and the eventual evaporation of the water component subsequently releasing the trapped sulfur dioxide and creating a larger mass. Unfortunately, the first overpass by the OMI instrument was several hours after the proposed time for the secondary zone of aggregation. An instrument with greater temporal resolution would be needed to assess this condition, and the data for such an instrument (i.e. GOME-2, IASI, etc.) was not obtained in time for this project. 
Despite the first overpass time ensuing the secondary zone of aggregation, the mass of $\mathrm{SO}_{2}$ during its second day of atmospheric residence (i.e. $116 \mathrm{kt}$ ) still exceeded that of its first day of residence (i.e. $112 \mathrm{kt}$ ). Rose et al. 2000 documented that most eruptions exhibit an increase in sulfur dioxide mass during its second day of atmospheric residence. They attribute this proliferation to the oxidation of $\mathrm{H}_{2} \mathrm{~S}$ (another variably significant magmatic volatile compound). The conversion of $\mathrm{H}_{2} \mathrm{~S}$ to $\mathrm{SO}_{2}$ is highly temperature dependent. At high temperatures (i.e. $>600^{\circ} \mathrm{C}$ ), $\mathrm{H}_{2} \mathrm{~S}$ will readily oxidize to form $\mathrm{SO}_{2}$. Therefore, immediately after the start of the eruption, the hot core of the rising plume can provide enough heat to rapidly convert $\mathrm{H}_{2} \mathrm{~S}$. However, under normal atmospheric conditions (i.e. during the migration of the volcanic cloud), the reaction rate for the oxidation of $\mathrm{H}_{2} \mathrm{~S}$ can slow to $2-5$ days (Hoshyaripour et al. 2012). The increase in $\mathrm{SO}_{2}$ was recorded around 2 days after the eruption, but it was only of the order of $4 \mathrm{kt}$. The ice-ash aggregates can be assumed to have sequestered a more significant amount given the estimated erupted mass index was about 120-140 million $\mathrm{m}^{3}$ of tephra. Therefore, both processes could contribute pivotal contributions to the rise in $\mathrm{SO}_{2}$ mass.

\subsubsection{Discussion of $\mathrm{SO}_{2}$ Plume Area and Concentration}

Given the sensitivity of the UV sensor to detecting sulfur dioxide as well as the longer atmospheric residence time of the gas, $\mathrm{OMI}$ is able to monitor the evolution of the sulfur dioxide cloud for a much longer period than MTSAT-2 can monitor ash. The $\mathrm{SO}_{2}$ plume areal extent and concentration behave as would be expected. As the area of the cloud increases, the concentration (as well as maximum and mean column densities) decrease accordingly, since there is no new source of sulfur dioxide being added to the cloud after the cessation of the eruption. Interestingly, the $\mathrm{SO}_{2}$ plume did not travel as an entity, but rather it elongated in the direction of the wind motion. A lot of the gas persisted around the source evidenced by the following image. 


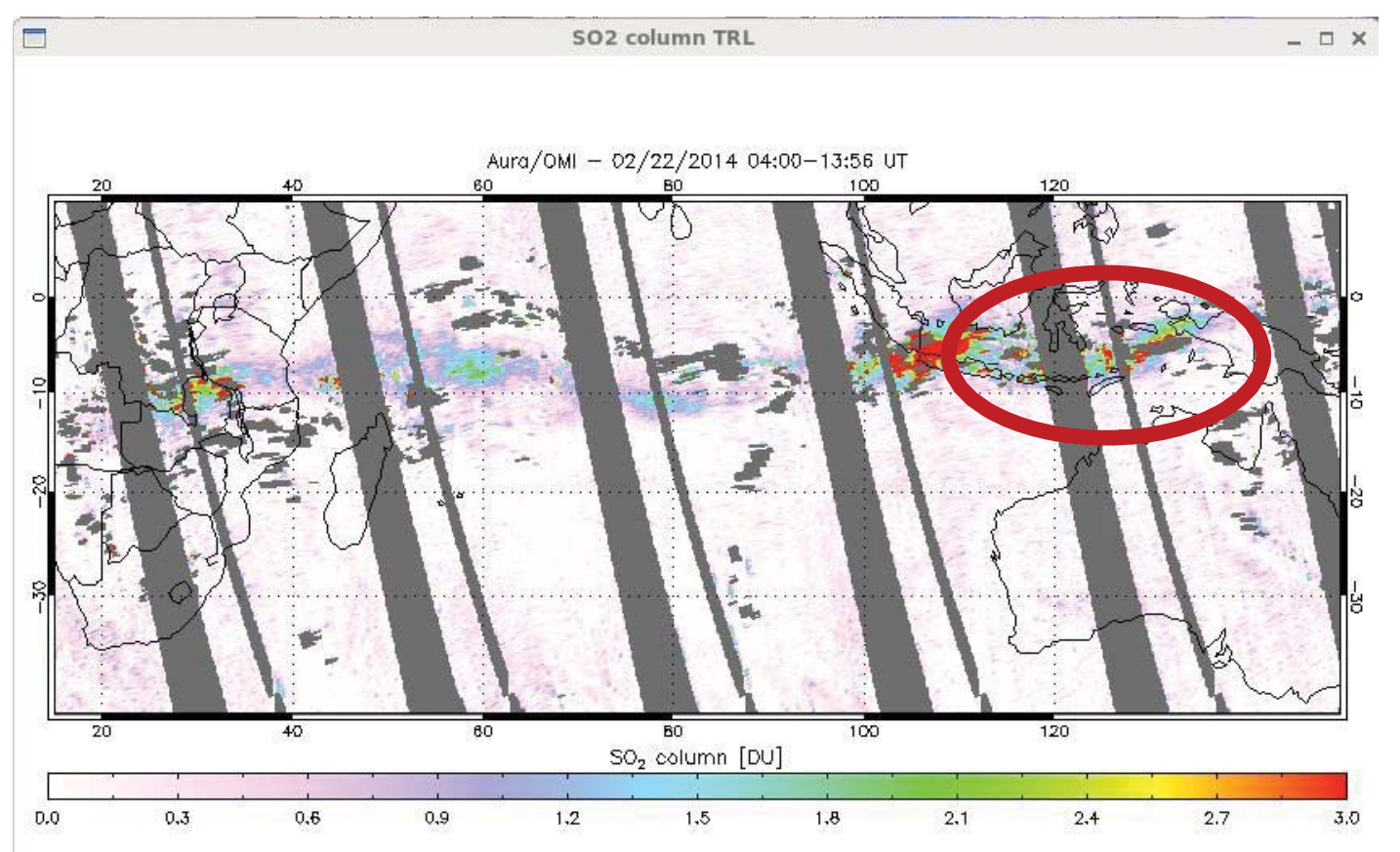

Figure 55. Image displaying the "trail" of $\mathrm{SO}_{2}$ produced by the Kelut eruption and migrating according to wind patterns.

The persistent westward direction of the cloud indicates that the plume did not greatly alternate altitude throughout its lifetime because wind shears are prevalent at higher altitudes.

\subsubsection{Discussion of $\mathrm{SO}_{2}$ Removal Rate}

The $\mathrm{SO}_{2}$ removal rate can be a good indication of the approximate height that the majority of the plume resided and ultimately the fate of climate-altering injections, since the atmospheric lifetime of sulfur dioxide in the stratosphere ( $\sim 36$ days) is much longer than $\mathrm{SO}_{2}$ that barely pierced the stratosphere ( $\sim$ few days). The average removal rate per day for the Kelut sulfur dioxide cloud was about $8 \mathrm{kt} /$ day, which equates to an e-folding time of about 14 days. The short residence time in the atmosphere means that the volcanic cloud was not injected deep into the stratosphere so any conversion to sulfate aerosol would not have any significant climate-altering impact. The removal of sulfur dioxide is restricted to oxidation reactions or wet deposition, given its high solubility. The slightly longer e-folding time than is average for this altitude indicates a dry atmosphere leaving only chemical reaction to remove the $\mathrm{SO}_{2}$. 
In conclusion, this report defined the capabilities of the MTSAT-2 in detection and analysis of eruptive behavior in Indonesia, specifically two key indicators of increased volcanic activity, heat index and the presence of ash. The use of an automated single step algorithm utilizing a fixed threshold to confirm or deny a thermal anomaly is grossly inadequate for daytime monitoring regardless of the proposed method, single-channel thermal (i.e. $46.31 \%$ false alarm) or NTI (i.e. $44.17 \%$ false alarm). The false alarm rate is severely lessened with the implementation of a second step to the automated algorithm involving the spatial comparison of supposed anomalous pixels with their ambient surroundings. This spatial comparison method provides full confidence in the precedent detection limit by minimizing false alarms and maximizing the detection of even very subtle thermal anomalies. The unspectacular difference between the two thermal detection methods analyzed in this study (i.e. single-channel thermal and NTI) creates some speculation as to the best method for implementation into near- real time monitoring. NTI provides no further information about a particular thermal anomaly other than its mere presence due to the fact that algorithm normalizes the radiance values emitted in the 4- and $12-\mu \mathrm{m}$ wavelengths. Therefore, it is our opinion that the single-channel thermal method is best suited to develop a heat index in Indonesia given the additional ability of interpretation of volcanic processes. With the development of an extensive time series regarding different types of heat producing anomalies using single-channel thermal radiance, specific patterns will emerge for particular volcanic processes as shown with the interpretation of the Sinabung data to be related with lava dome activity.

Sulfur dioxide data from the Ozone Monitoring Instrument aided in validating observations provided by the MTSAT-2 thermal data. Not only did the $\mathrm{SO}_{2}$ data reinforce the cogency of the lava dome characteristics, but it also provided more sophisticated analyses of the thermal time-series developed for the Sinabung eruption in January 2014. The combined datasets provided insight into the mechanism for lava dome growth (i.e. endogenous and exogenous), which have direct implications on the specific 
volcanic hazard that is present. These observations strengthen the thoughts that geosynchronous and sun-synchronous satellites can provided unprecedented opportunities for studying dynamic volcanic processes.

The use of the BTD method for volcanic ash detection of MTSAT-2 is fully capable of operational use in Indonesia given its ability to detect even very subtle and fleeting plumes. The use of the MTSAT-2 in tracking ash clouds can be accomplished consistently given the short repeat time of its scans that provide unparalleled data to the aviation community and inhabitants of Indonesia. The CTT method used for defining the plume height has been proven to be very efficient and quick to apply in order to give the necessary parameters for a fully developed plume dispersion model. Not only can the MTSAT-2 be used for monitoring purposes, but the information provided by the BTD method can lead to the understanding of intervolcanic plume behavior such as ice formation, aggregation, and sedimentation processes. Therefore, the use of a high temporal resolution instrument like the MTSAT2 is essential for not only the tracking of a volcanic cloud, but also for the interpretation of the developing processes associated with that ash cloud.

The OMI SO 2 data acquired for the February 13, 2014 Kelut eruption provided complementary information to the MTSAT-2 thermal data, especially regarding dynamic aggregation processes occurring in the migrating volcanic cloud. Unfortunately, some questions regarding $\mathrm{SO}_{2}$ release during the secondary zone of aggregation remain unanswered because of the low temporal resolution awarded by OMI. However, OMI is a very capable instrument for cloud tracking and determining the fate of $\mathrm{SO}_{2}$ on the local and global climate. The combined use of geostationary and polar-orbiting satellite was very successful in this study and should be utilized in future research. 


\section{References}

Armienti, P., G. Macedonio, and M.T. Pareschi. 1988. "A Numerical Model for Simulation of Tephra Transport and Deposition: Applications to May 18, 1980, Mount St. Helens Eruption." Journal of Geophysical Research 6463-6476.

Bhartia, Pawan K. 2002. OMI Algorithm Theoretical Basis Document. Satellite Instrument Documentation, Greenbelt: NASA Goddard Space Flight Center.

Bluth, G.S., J.S. Scott, I.E. Sprod, C.C. Schnetzler, A.J. Krueger, and L.S. Walter. 1995. "Explosive emissions of sulfur dioxide from the 1992 Crater Peak eruptions, Mount Spurr Volcano, Alaska." US Geological Survey Bulletin 37-46.

Bonadonna, C., C.B. Connor, B.F. Houghton, L. Connor, M. Byrne, A. Laing, and T.K. Hincks. 2005. "Probabilstic modeling of tephra dispersal: Hazard assessment of a multi-phase rhyoltic eruption at Tarawera, New Zealand." Journal of Geophysical Research doi:10.1029/2003JB002896.

Breeding, R. J., Lodge Jr, J. P., Pate, Sheesley J. B., Klonis D. C., Fogle H. B., Anderson B., et al. 1973. "Background Trace Gas Concentrations in." Journal of Geophysical Research doi:10.1029/JC078i030p07057.

Brown, R.J., C. Bonadonna, and A.J. Durant. 2011. "A review of volcanic ash aggregation." Physics and Chemistry of the Earth 65-78.

Carn, Simon A. 2008. OMI data processing at MTU. OMI Data Processing, Houghton : Michigan Technological University .

Costa, Antonio, Arnau Folch, and Giovanni Macedonio. 2010. "A Model for Wet Aggregation of Ash Particles in Volcanic Plumes and Clouds: 1. Theoretical Formulation." Journal of Geophysical Research 115.

Draxler, R.R., and G.D. Rolph. 2015. "HYSPLIT (HYbrid Single-Particle Lagrangian Integrated Trajectory) Model." HYSPLIT (HYbrid Single-Particle Lagrangian Integrated Trajectory) Model. Silver Springs: NOAA ARL READY Website (http://ready.arl.noaa.gov/HYSPLIT.php), NOAA Air Resources Laboratory.

Durant, A.J., R.A. Shaw, W.I. Rose, Y. Mi, and G.J. Ernst. 2008. "Ice nucleation and overseeding of ice in volcanic clouds." Journal of Geophysical Research doi:10.1029/2007JD009064.

Durant, A.J., W.I. Rose, A.M. Sarna-Wojcicki, S. Carey, and A.M. Volentik. 2009. "Hydrometeor-enhanced tephra sedimentation: Constraints from the 18 May 1980 eruption of Mount St. Helens." Journal of Geophysical Research doi:10.1029/2008JB005756.

EPA. 2004. Fact Sheet for Trace Level SO2 Monitoring Method. Fact Sheet, Washington D.C.: EPA.

Fink, J.H., and R.W. Griffiths. 1998. "Morphology, eruption rate, and rheology of lava domes: insight from laboratory models ." Journal of Geophysical Research 527545.

Fink, J.H., M. Malin, S.W. Anderson, and et al. 1990. "Intrusive and extrusive growth of the Mount St. Helens lava dome." Nature 435-437.

Flasse, S.P., and P. Ceccato. 1996. "A Contextual Algorithm for AVHRR Fire Detection." International Journal of Remote Sensing 419-424.

Flynn, Luke P., Peter J. Mouginis-Mark, Keith A. Horton, and et al. 1994. "Distribution of Thermal Areas on an Active Lava Flow Field: Landsat Observations of 
Kilauea, Hawaii, July 1991." Bulletin of Volcanology 284-296.

Fornea, Adam, Sarah Brooks, Jeffrey Dooley, and Auromeet Saha. 2009. "Heterogeneous freezing of ice on atmospheric aerosols containing ash, soot, and soil." Journal of Geophysical Research doi:10.1029/2009JD011958.

Francis, P. 1993. Volcanoes: a planetary perspective. Oxford: Clarendon Press.

Free, Melissa. 2002. "Effect of Volcanoes on the Vertical Temperature Profile in Radiosonde Data." Journal of Geophysical Research 107.DOI.

Gawarecki, S.J., R.J.P. Lyon, W. Nordberg, and et al. 1965. "Infrared spectral returns and imagery of the Earth from space and their application to geological problems." American Astronautical Society Science and Technology Series 13-133.

Gouhier, Matheiu, Andrew Harris, Sonia Calvari, Philippe Labazuy, Yannick Guehenneux, Franck Donnadieu, and Sebastien Valade. 2012. "Lava Discharge during Etna's January 2011 Fire Fountain Tracked Using MSG-SEVIRI." Bulletin of Volcanology 787-793.

Gouhier, Mathieu. 2014. "Volcanic Ash: From Magma to Aviation Impact." Laboratoire Magmas et Volcans. Clermont Ferrand : Universite Blaise Pascal.

Guo, S., W.I. Rose, G.J.S. Bluth, and I.M. Watson. 2004. "Particles in the great Pinatubo volcanic cloud of June 1991: The role of ice." Geochemistry, Geophysics, Geosystems doi:10.1029/2003GC000655.

Hamada, Atsushi, and Noriyuki Nishi. 2010. "Development of a Cloud-Top Height Estimation Method by Geostationary Satellite Split-Window Measurements Trained With Data." Journal of Applied Meteorology and Climatology 20352049.

Harris, A., and D. Stevenson. 1997. "Thermal Observations of Degassing Open Conduits and Fumaroles at Stromboli and Vulcano Using Remotely Sensed Data." Journal of Volcanology and Geothermal Research 175-198.

Harris, A.J.L., L.P. Flynn, D.A. Rothery, C. Oppenheimer, and S.B. Sherman. 1999. "Mass Flux Measurements at Active Lava Lakes: Implications for Magma Recycling." Journal of Geophysical Research 2035-2049.

Harris, A.J.L., L.P. Flynn, K. Dean, and et al. 2000a. "Real-time monitoring of volcanic hot spots with satellites." American Geophysical Union Monograph Series 139159.

Harris, Andrew J. L., Anna L. Butterworth, Richard W. Carlton, Ian Downey, Peter Miller, Pedro Navarro, and David A. Rothery. 1997a. "Low-Cost Volcano Surveillance from Space: Case Studies from Etna, Krafla, Cerro Negro, Fogo, Lascar and Erebus." Bulletin of Volcanology 49-64.

Harris, Andrew. 2013. Thermla Remote Sensing of Active Volcanoes . New York: Cambridge .

Hecht, Eugene. 2002. Optics (4th Edition). Addison: Wesley.

Hoshyaripour, G., M. Hort, and B. Langmann. 2012. "How does the hot core of a volcanic plume control the sulfur speciation in volanic emission?" $A G U$ and the Geochemical Society doi:10.1029/2011GC004020.

Kaneko, Takayuki, Martin J. Wooster, Setsuya Nakada, and et al. 2002. "Exogenous and endogenous growth of the Unzen lava dome examined by satellite infrared image analysis." Journal of Volcanology and Geothermal Research 151-160. 
Kidwell, Katherine B. 1995. "Advanced Very High Resolution Radiometer (AVHRR)." AVHRR Sensor Overview.

KNMI. 2012. Background information about the Row Anomaly in OMI. October 26. Accessed March 2, 2015. http://www.knmi.nl/omi/research/product/rowanomalybackground.php.

Krotkov, N. A., S. A. Carn , A. J. Krueger, P. K. Bhartia, and K. Yang. 2006. "Band residual difference algorithm for retrieval of SO2 from the Aura Ozone Monitoring Instrument (OMI)." IEEE Trans. Geosci. Remote Sens. doi:10.1109/TGRS.2005.861932.

Krueger, A. J., L. S. Walter, P. K. Bhartia, C. C. Schnetzler, N. A. Krotkov, I. Sprod, and G. J. S. Bluth. 1995. "Volcanic sulfur dioxide measurements." Journal of Geophysical Research 14,057-14,076.

Labazuy, P., M. Gouhier, A. Harris, Y. Guéhenneux, M. Hervo, J-C. Bergès, P. Cacault, and S. Rivet. 2012. "Near real-real time monitoring of the April-May 2010 Eyjafjallajokull ash cloud: an example of a web-based, satellite data-driven, reporting system ." International Journal of Environment and Pollution 262-272.

Lathem, T.L., P. Kumar, A. Nenes, J. Dufek, I. Sokolik, M. Trail, A. Russell, and S. Clarke. 2011. "The hygroscopic properties of volcanic ash." Journal of Geophysical Research doi:10.1029/2011GL047298.

Marzano, Frank, Gianfranco Vulpiani, and William Rose. 2006. "Microphysical Characterization of Microwave Radar Reflectivity Due to Volcanic Ash Clouds." IEEE Transactions of Geoscience and Remote Sensing doi:10.1109/TGRS.2005.861010.

McPeters, R.D., and Heath D.F. 1984. "Satellite Observation fo SO2 from El Chichon: Identification and Measurement." Geophysical Research Letters 1203-1206.

Nakada, S. 1996. "Characteristics of lava dome eruption and dome growth model at Unzen Volcano ." Mem. Geological Society of Japan 139-148.

NASA. 2014. LIDAR LEVEL 1 BROWSE IMAGES - 2014-02-13 17:44:47Z - SECTION 3. Pasadena.

NOAA. 2015. National Climatic Data Center. Washington D.C.: USA.gov, March 6.

Oppenheimer, C., and P.W. Francis. 1997. "Remote Sensing of Heat, Lava and Fumerole Emissions from Erta 'Ale Volcano, Ethiopia." International Journal of Remote Sensing 1661-1692.

Oppenheimer, C., P. W. Francis, D. A. Rothery, R.W.T. Carlton, and L. S. Glaze. 1993. "Infrared Image Analysis of Volcanic Thermal Features: Lascar Volcano, Chile, 1984-1992." Journal of Geophysical Research 4269-4286.

Oppenheimer, Clive. 1991. "Lava Flow Cooling Estimated from Landsat Thematic Mapper Infrared Data: The Lonquimay Eruption (Chile, 1989)." Journal of Geophysical Research 21865-21878.

Prata, A.J. 1989. "Infrared Radiative Transfer Calculations for Volcanic Ash Clouds." Geophysical Research Letters 1293.

Prata, A.J. 2009. "Satellite Detection of Hazardous Volcanic Clouds and the Risk to Global Air Traffic." Natural Hazards 303-324.

Prata, A.J., and I.F. Grant. 2001. "Retrieval of Microphysical and Morphological Properties of Volcanic Ash Plumes from Satellite Data: Application to Mt 
Ruapehu, New Zealand." Quarterly Journal of the Royal Meteorological Society 2153-2179.

Prata, Fred, Gregg Bluth, William Rose, Dave Schneider, and Andrew Tupper. 2001.

"Comments on "Failures in Detecting Volcanic Ash from a Satellite-based

Technique"." Remote Sensing of the Environment 341-346.

Prins, E.M., and W.P. Menzel. 1992. "Geostationary Satellite Detection of Bio Mass

Burning in South America." International Journal of Remote Sensing 2783-2799.

Pyle, David M., Tamsin A. Mather, Juliet Biggs, and et al. 2013. "Remote Sesning of

Volcanoes and Volcanic Processes: Integrating Observation and Modelling."

London Geological Society.

Richter, A., F. Wittrock, and J. P. Burrows. 2006. "SO2 measurements with SCIAMACHY." Atmospheric Science Conference. Frascati: European Space Agency Center for Earth Observation.

Rolph, G.D. 2015. "Real-time Environmental Applications and Display sYstem (READY) Website (http://ready.arl.noaa.gov)." Real-time Environmental Applications and Display sYstem (READY) Website (http://ready.arl.noaa.gov). Silver Spring: NOAA Air Resources Laboratory.

Rose, W.I., and A.J. Durant. 2009. "Fine Ash Content of Explosive Eruptions." Journal of Volcanology and Geothermal Research 32-39.

Rose, W.I., and G.C. Mayberry. 2000. "Use of GOES Thermal Infrared Imagery for Eruption Scale Measurements, Soufrière Hills, Montserrat." Geophysical Research Letters 3097.

Rose, W.I., D.J. Delene, D.J. Schneider, G.S. Bluth, A.J. Krueger, I.E. Sprod, C. McKee, H.L. Davies, and G.J. Ernst. 1995. "Ice in the 1994 Rabaul eruption cloud: implications for volcano hazard and atmospheric effects." Nature 477-479.

Rose, W.I., G.S. Bluth, G.J. Ernst, and et al. 2000. "Integrating retrievals of volcanic cloud characteristics from satellite remote sensors: a summary." The Royal Society 1585-1606.

Rose, William, and Adam Durant. 2011. "Fate of volcanic ash: aggregation and fallout." Geological Society of America 895-896.

Rose, William, I. 2003. "Advancing Remote Sensing of Volcanic Clouds." EOS, Transactions American Geophysical Union 351.

Sarna-Wojcicki, A.M., C.E. Meyer, M.J. Woodward, and P.J. LaMothe. 1981. "Composition of air-fall ash erupted on May 18, May 25, June 12, July 22, and August 7." US Geological Survey Professional Paper 667-682.

Scollo, Simona, Mauro Cotelli, Franco Prodi, Marco Folegani, and Stefano Natali. 2005. "Terminal settling velocities of volcanic ash during the 2002-2003 Etna eruption by an X-band microwave rain gauge disdrometer." Journal of Geophysical Research doi:10.1029/2004GL022100.

Seinfeld, John H., and Spyros N. Pandis. 2006. Atmospheric Chemistry and Physics. Hoboken: John Wiley \& Sons, Inc.

Shu-Guang, Li, Huo Lan-Tian, Guo Hong-Lian, Zhang Dao-Zhong, Li Zhao-Lin, and Liu Xiao-Dong. 2003. "Effects of Matrices on Mie Scattering in the Mid-infrared Region." Chinese Physics B 1143-1148.

Simkin, T., and L. Siebert. 1997. "Volcanoes of the World, 2nd Edition." Geological 
Magazine 121-142.

Song, Feihu, Chuanlong Xu, and Shimin Wang. 2012. "UV differential optical absorption method for measuring sulfur content in coal." IOP Science doi:10.1088/09570233/23/2/025501.

Taddeucci, J., P. Scarlato, C. Montanaro, C. Cimarelli, E. Del Bello, C. Freda, D. Andronico, M. T. Gudmundsson, and D. B. Dingwell. 2011. "Aggregationdominated ash settling from the Eyjafjallajökull volcanic cloud illuminated by field and laboratory high-speed imaging." Geological Society of America.

The University of Manchester. 2014. Ice and Mixed Phase Clouds. December 2. Accessed March 19, 2015.

http://www.cas.manchester.ac.uk/resactivities/cloudphysics/background/ice/.

Topinka, USGS. 1997. "Map of Indonesian Volcanoes." USGS.

University of Washington. 2012. "Sulfur Dioxide (SO2)." vpl.astro.washington.edu. Accessed March 2, 2015. http://vpl.astro.washington.edu/spectra/so2.htm.

Wen, Shiming, and William I. Rose. 1994. "Retrieval of Sizes and Total Masses of Particles in Volcanic Clouds Using AVHRR Bands 4 and 5." Journal of Geophysical Research 5421-5431.

World Meteorological Organization (OSCAR). 2011-2015. Satellite: Himawari-7 (MTSAT-2). Accessed June 7, 2014. http://www.wmosat.info/oscar/satellites/view/166.

Wright, Robert, Luke Flynn, Harold Garbeil, Andrew Harris, and Eric Pilger. 2002. "Automated Volcanic Eruption Detection Using MODIS." Remote Sensing of the Environment 135-155.

Wright, Robert, Luke P. Flynn, Harold Garbeil, Andrew J.L. Harris, and Eric Pilger. 2004. "MODVOLC: Near-real-time Thermla Monitoring of Global Volcanism ." Journal of Volcanology and Geothermal Research 29-49.

Wright, Robert, Stephen Blake, Andrew J.l. Harris, and David A. Rothery. 2001. "A Simple Explanation for the Space-based Calculation of Lava Eruption Rates ." Earth and Planetary Science Letters 223-233.

Yang, Kai, Nickolay A. Krotkov, Arlin J. Krueger, Simon A. Carn, Pawan K. Bhartia, and Pieternel F. Levelt. 2007. "Retrieval of large volcanic SO2 columns from the Aura Ozone Monitoring Instrument: Comparison and limitations." Journal of Geophysical Research doi:10.1029/2007JD008825.

Yang, Kai, Xiong Liu, Pawan Bhartia, Nickolay Krotkov, Simon Carn, Eric Hughes, Arlin Krueger, Robert Spurr, and Samuel Trahan. 2010. "Direct retrieval of sulfur dioxide amount and altitude from spaceborne hyperspectral UV measurements." Journal of Geophysical Research doi:10.1029/2010JD013982. 


\section{Appendix}

This appendix is intended to provide written documentation of any material obtained from another source, whether it is available in the public domain (http://en.wikipedia.org/wiki/Public_domain) or protected under copyright law (http://www.copyright.gov/).

Here are a list of the corresponding figures that require further documentation for their official use in this thesis, because they are not the original work of the author.

\section{1.) Chapter 1}

\section{a. Figure 1}

This image is in the public domain because it only contains material that originally came from an employee of the United States Geological Survey, and agency of the United States Department of the Interior (Reference Michigan Technological University's "Guide for Dissertations, Theses, and Reports" Section 5.3.1). Therefore, permission is not needed to reproduce this image in this thesis. For more information, see the official USGS copyright policy (http://www.usgs.gov/visual-id/credit usgs.html\#copyright). Also, here is a link to the proper use of this image in Wikipedia with the same disclaimer about using material from the USGS (http://commons.wikimedia.org/wiki/File:Map_indonesia_volcanoes.gif).

\section{2.) Chapter 2}

\section{a. Figure 2}

This image has been granted permission to be used in this thesis by the lead operator of the HOTVOLC website and advisor at the University of Blaise Pascal, Dr. Mathieu Gouhier, through email correspondence.

\section{Mathieu Gouhier <M.Gouhier@opgc.univ- bpclermont.fr>} 3:24 PM (39 minutes ago)

to me

Hi Nick,

From this email I give you the permission for use of HOTVOLC webpage preview.

@++

Mathieu

\section{b. Figure 3}

This image is in the public domain (under GNU Free Documentation License) because it only contains material that originally came from Wikipedia user, Darth Kule. He freely uploaded his work to Wikimedia. Here is a link to the webpage describing free use of this material (http://commons.wikimedia.org/wiki/File:Black body.svg), See Section 
"Licensing".

\section{c. Figure 4}

This document is freely available in the public domain under the GNU Free Documentation License. The copyright allows permission to reuse, copy, etc. without direct permission. It was obtained through Wikimedia. Here is a link to the free use licensing agreement for this figure (http://commons.wikimedia.org/wiki/File:Mie_scattering.svg).

\section{d. Figure 5 \\ JOHN WILEY AND SONS LICENSE TERMS AND CONDITIONS}

Apr 22, 2015

This Agreement between Nicholas Stewart ("You") and John Wiley and Sons ("John Wiley and Sons") consists of your license details and the terms and conditions provided by John Wiley and Sons and Copyright Clearance Center.

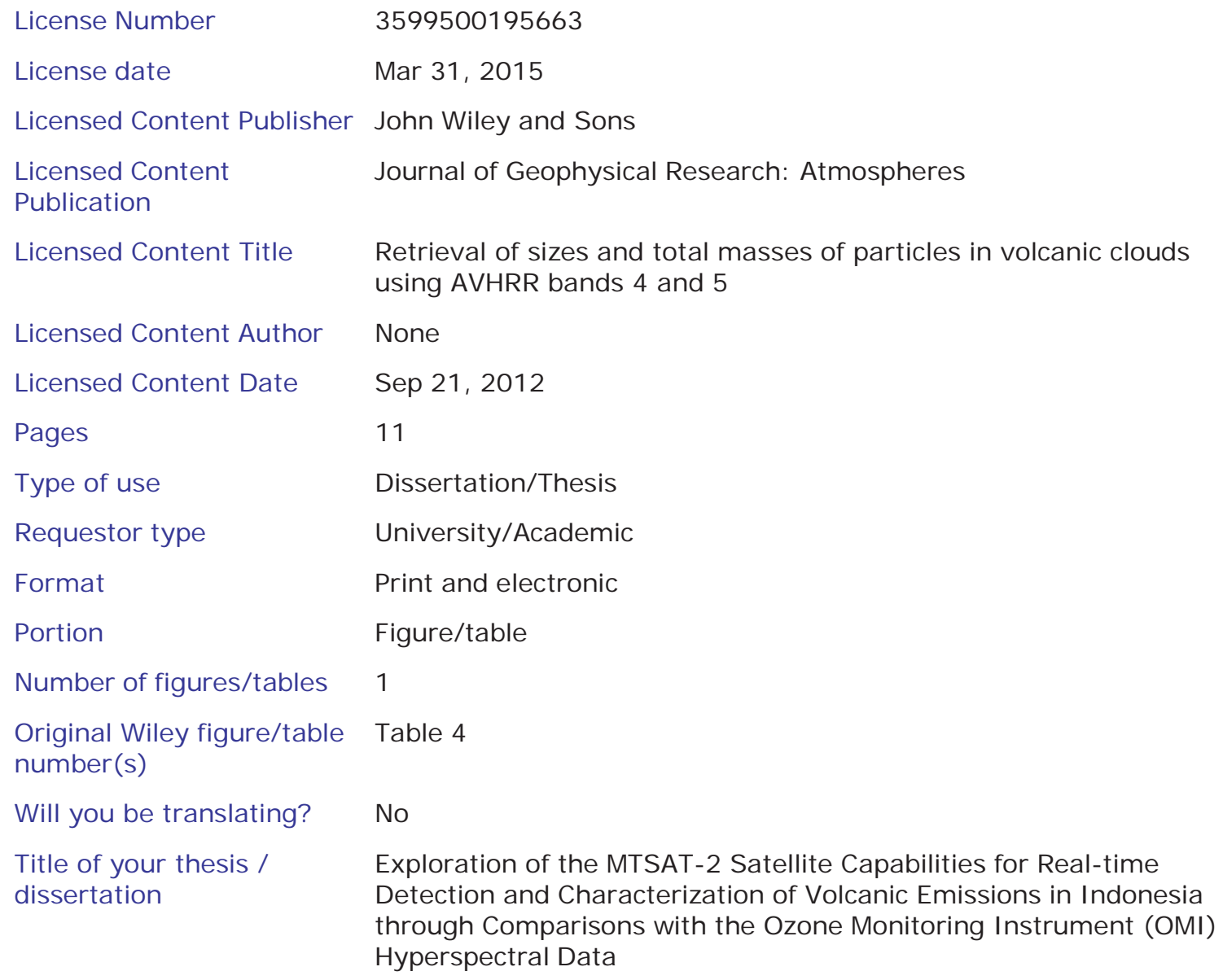




$\begin{array}{ll}\begin{array}{l}\text { Expected completion date } \\ \text { Expected size (number of } \\ \text { pages) }\end{array} & \text { Apr } 2015 \\ \begin{array}{l}\text { Requestor Location } \\ \text { Nicholas Stewart }\end{array} & \\ & \\ & \text { WARRI NGTON, PA } 18976 \\ & \text { United States } \\ & \text { Attn: Nicholas Stewart } \\ \text { Invoice } & \text { Nicholas Stewart } \\ \text { Billing Type } & 2130 \text { Green Ridge Drive } \\ \text { Billing Address } & \\ & \text { WARRINGTON, PA } 18976 \\ & \text { United States } \\ & \text { Attn: Nicholas Stewart } \\ & 0.00 \text { USD }\end{array}$

Terms and Conditions

\section{e. Figure 6 \\ JOHN WILEY AND SONS LICENSE TERMS AND CONDITIONS}

Apr 22, 2015

This Agreement between Nicholas Stewart ("You") and John Wiley and Sons ("John Wiley and Sons") consists of your license details and the terms and conditions provided by John Wiley and Sons and Copyright Clearance Center.

\begin{tabular}{|c|c|}
\hline License Number & 3599500395462 \\
\hline License date & Mar 31, 2015 \\
\hline Licensed Content Publisher & John Wiley and Sons \\
\hline $\begin{array}{l}\text { Licensed Content } \\
\text { Publication }\end{array}$ & Wiley oBooks \\
\hline Licensed Content Title & $\begin{array}{l}\text { The February-March } 2000 \text { Eruption of Hekla, Iceland from a } \\
\text { Satellite Perspective }\end{array}$ \\
\hline Licensed Content Author & $\begin{array}{l}\text { W.I. Rose,Y. Gu,I.M. Watson, T. Yu,G.J.S. Blut,A.J. Prata,A.J. } \\
\text { Krueger,N. Krotkov,S. Carn, M.D. Fromm, D.E. Hunton,G.G.J. } \\
\text { Ernst,A.A. Viggiano, T.M. Miller,J .O. Ballenthin,J .M. Reeves,J .C. } \\
\text { Wilson,B.E. Anderson,D.E. Flittner }\end{array}$ \\
\hline Licensed Content Date & Mar 25, 2013 \\
\hline
\end{tabular}




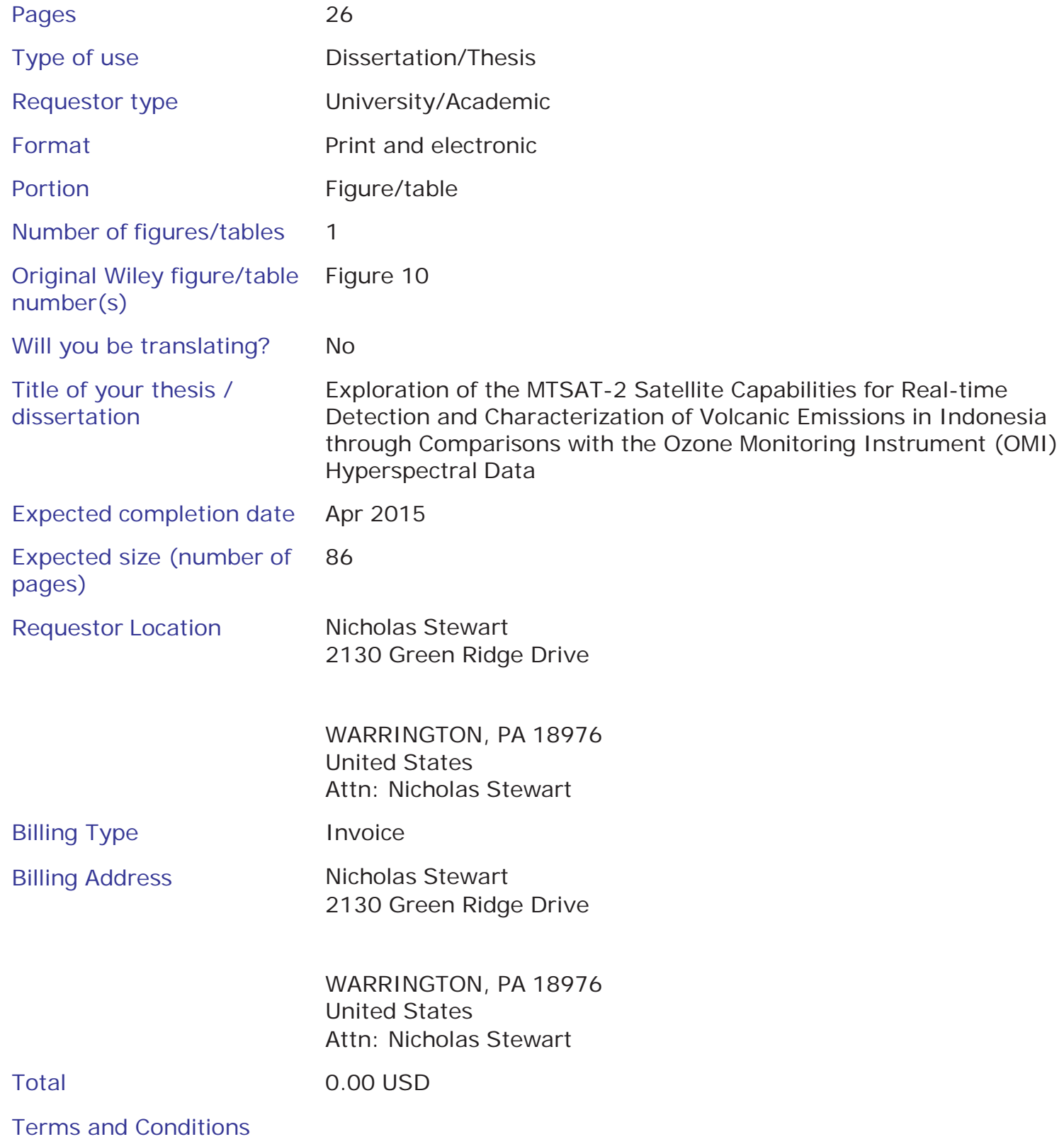

Terms and Conditions

\section{f. $\quad$ Figure 7}

Dear Nicholas Stewart,

Thank you for your request to reproduce IOP Publishing material in your thesis.

Regarding figure 2 (Meas. Sci. Technol. 23 (2012) 025501), we are happy to grant permission for the use you request on the terms set out below.

\section{Conditions}


Non-exclusive, non-transferrable, revocable, worldwide, permission to use the material in print and electronic form will be granted subject to the following conditions:

- $\quad$ Permission will be cancelled without notice if you fail to fulfil any of the conditions of this letter.

- You will make reasonable efforts to contact the author(s) to seek consent for your intended use. Contacting one author acting expressly as authorised agent for their coauthors is acceptable.

- $\quad$ You will reproduce the following prominently alongside the material:

- the source of the material, including author, article title, title of journal, volume number, issue number (if relevant), page range (or first page if this is the only information available) and date of first publication. This information can be contained in a footnote or reference note; or

a link back to the article (via DOI); and

- if practical and IN ALL CASES for works published under any of the Creative Commons licences the words "C IOP Publishing. Reproduced with permission. All rights reserved"'"

- $\quad$ The material will not, without the express permission of the author(s), be used in any way which, in the opinion of IOP Publishing, could distort or alter the author(s)' original intention(s) and meaning, be prejudicial to the honour or reputation of the author(s) and/or imply endorsement by the author(s) and/or IOP Publishing.

- $\quad$ Payment of $£ 0$ is received in full by IOP Publishing prior to use.

\section{Special Conditions - For STM Siqnatories ONLY (as aqreed as part of the STM Guidelines)}

Any permissions granted for a particular edition will apply also to subsequent editions and for editions in other languages, provided such editions are for the work as a whole in situ and does not involve the separate exploitation of the permitted illustrations or excerpts.

If you have any questions, please feel free to contact our Permissions team atpermissions@iop.org.

I should be grateful if you would acknowledge receipt of this email.

Kind regards,

Zora Catterick

Publishing Assistant

IOP Publishing 
Please note: We do not usually provide signed permission forms as a separate attachment. Please print this email and provide it to your publisher as proof of permission.

\section{g. Figure 8 \\ JOHN WILEY AND SONS LICENSE TERMS AND CONDITIONS}

Apr 22, 2015

This Agreement between Nicholas Stewart ("You") and John Wiley and Sons ("John Wiley and Sons") consists of your license details and the terms and conditions provided by John Wiley and Sons and Copyright Clearance Center.

\begin{tabular}{|c|c|}
\hline License Number & 3599500573134 \\
\hline License date & Mar 31, 2015 \\
\hline Licensed Content Publisher & John Wiley and Sons \\
\hline $\begin{array}{l}\text { Licensed Content } \\
\text { Publication }\end{array}$ & J ournal of Geophysical Research: Atmospheres \\
\hline Licensed Content Title & $\begin{array}{l}\text { Direct retrieval of sulfur dioxide amount and altitude from } \\
\text { spaceborne hyperspectral UV measurements: Theory and } \\
\text { application }\end{array}$ \\
\hline Licensed Content Author & $\begin{array}{l}\text { Kai Yang,Xiong Liu, Pawan K. Bhartia, Nickolay A. Krotkov, Simon } \\
\text { A. Carn, Eric J. Hughes, Arlin J. Krueger, Robert J. D. } \\
\text { Spurr, Samuel G. Trahan }\end{array}$ \\
\hline Licensed Content Date & Sep 21, 2010 \\
\hline Pages & 1 \\
\hline Type of use & Dissertation/Thesis \\
\hline Requestor type & University/Academic \\
\hline Format & Print and electronic \\
\hline Portion & Figure/table \\
\hline Number of figures/tables & 1 \\
\hline $\begin{array}{l}\text { Original Wiley figure/table } \\
\text { number(s) }\end{array}$ & Figure 1 \\
\hline Will you be translating? & No \\
\hline $\begin{array}{l}\text { Title of your thesis / } \\
\text { dissertation }\end{array}$ & $\begin{array}{l}\text { Exploration of the MTSAT- } 2 \text { Satellite Capabilities for Real-time } \\
\text { Detection and Characterization of Volcanic Emissions in Indonesia } \\
\text { through Comparisons with the Ozone Monitoring Instrument (OMI) } \\
\text { Hyperspectral Data }\end{array}$ \\
\hline Expected completion date & Apr 2015 \\
\hline
\end{tabular}


Expected size (number of 86 pages)

Requestor Location

Billing Type

Billing Address

Terms and Conditions
Nicholas Stewart

2130 Green Ridge Drive

WARRINGTON, PA 18976

United States

Attn: Nicholas Stewart

Invoice

Nicholas Stewart

2130 Green Ridge Drive

WARRINGTON, PA 18976

United States

Attn: Nicholas Stewart

0.00 USD

\section{h. Figure 9 \\ JOHN WILEY AND SONS LICENSE TERMS AND CONDITIONS}

Apr 22, 2015

This Agreement between Nicholas Stewart ("You") and John Wiley and Sons ("John Wiley and Sons") consists of your license details and the terms and conditions provided by John Wiley and Sons and Copyright Clearance Center.

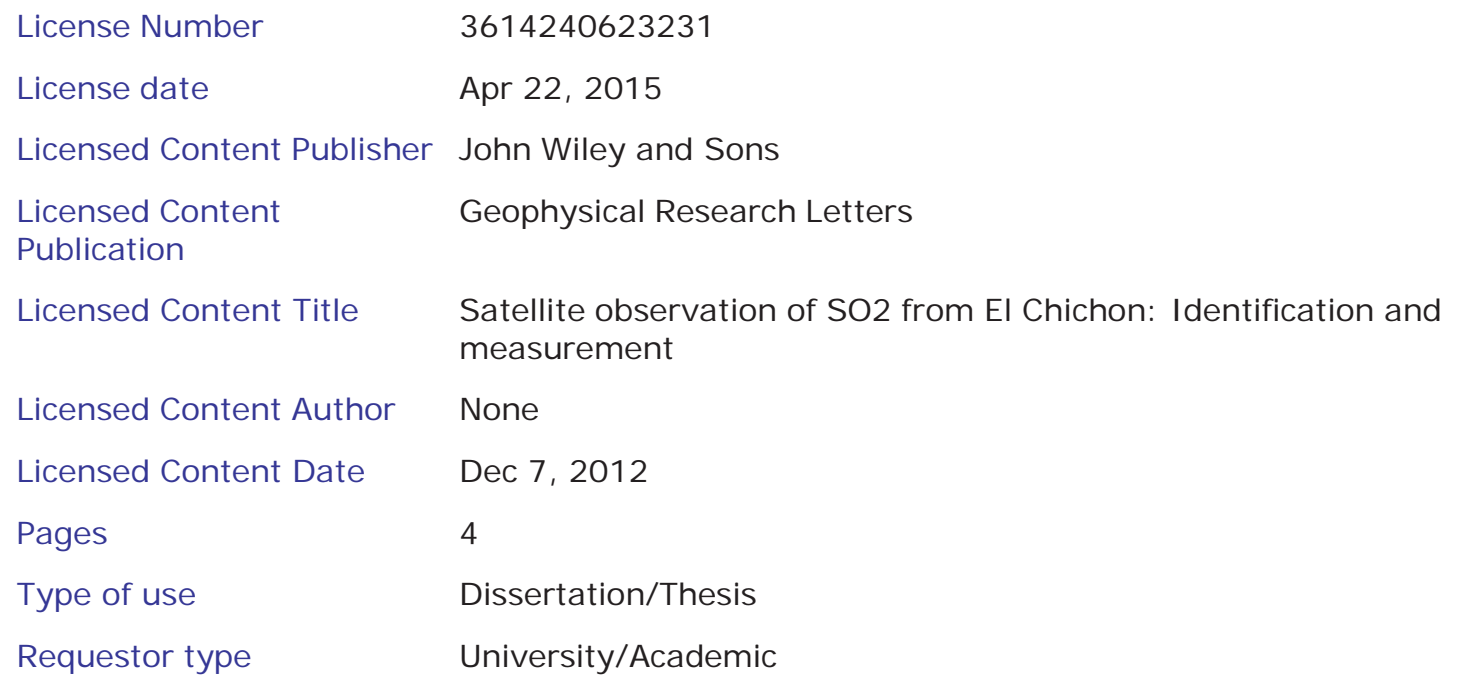




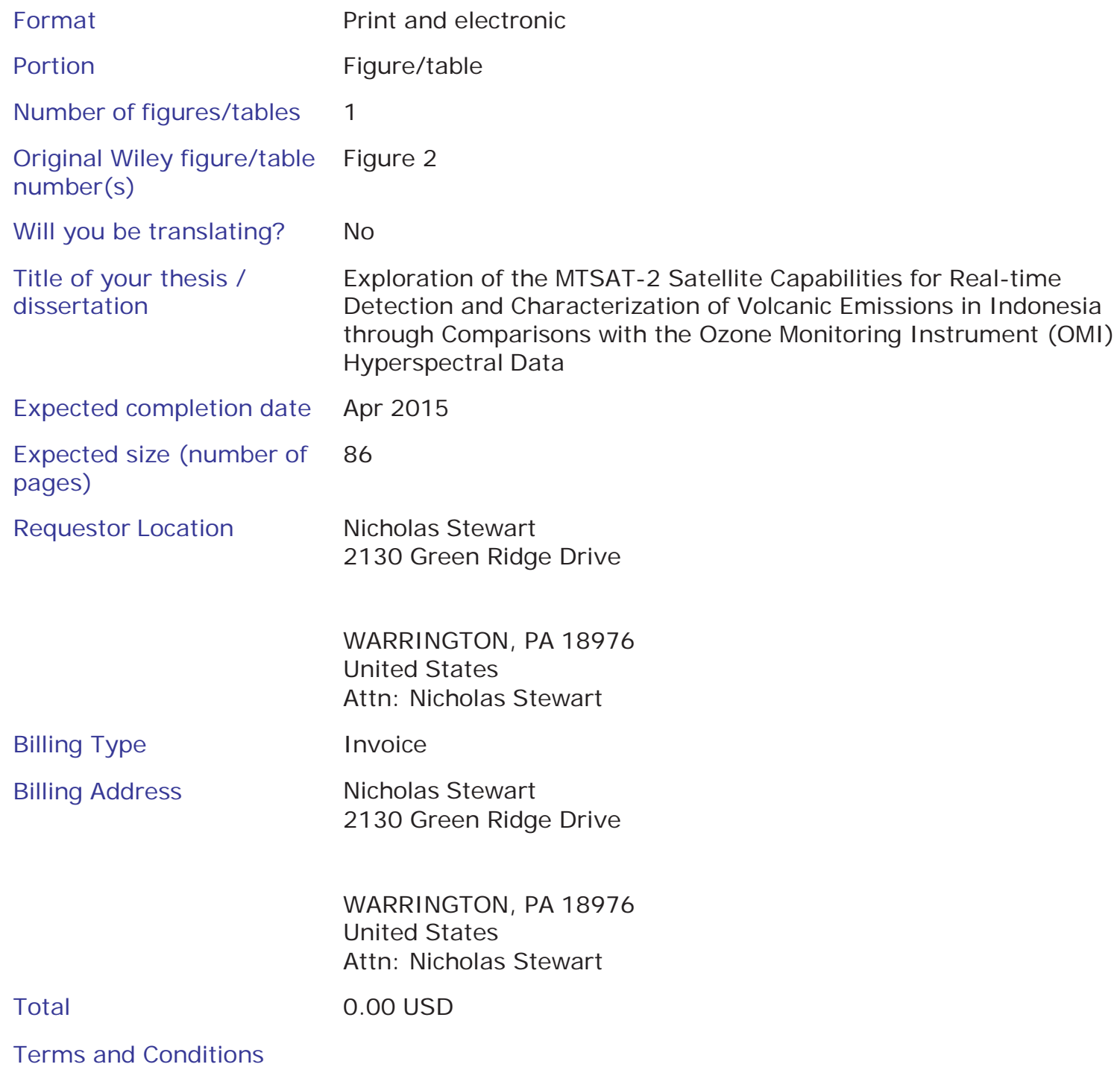

\section{3.) Chapter 4}

\section{a. Figure 49}

This image is data resulting from the use of an online trajectory model. The model, HYSPLIT, is owned and operated by the Air Resources Laboratory (ARL) of the National Oceanic and Atmospheric Administration (NOAA), which is a government entity. The use of data obtained from using this model are granted from ARL and NOAA if there it includes proper citations of (Draxler and Rolph 2015) and (Rolph 2015), which is included in the references section of this thesis. Here is a link to the ARL/NOAA webpage explaining the stipulations of use of HYSPLIT data (http://www.arl.noaa.gov/HYSPLIT pubs.php) (See "If the paper used results from the on-line web version of HYSPLIT, please include the following references:" Section)

\section{b. Figure 50}

This image does not require permission to be used in this thesis because it is data collected 
from a NASA satellite. All images and data from NASA are not copyrighted, unless otherwise noted. Here is a link to the NASA disclaimer stating that the use of this image is allowed because it is not copyrighted (https://eosweb.larc.nasa.gov/copyrightinformation). Here is another link explaining the same republication policy (http://www.nasa.gov/multimedia/imagegallery/reproduction guidelines.html). 